MIN TILE ANIMAL WA Y TOND PATI: 



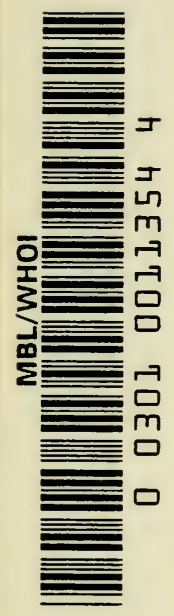



MAN THE ANIMAL 



\title{
MAN THE ANIMAL
}

\author{
BY \\ RAYMOND PEARL \\ Late Professor of Biology \\ School of Hygiene \\ Johns Hopkins University
}

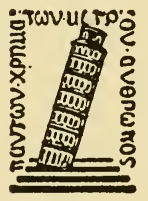

PRINCIPIA PRESS, INC.

BLoomington Indiana

1946 
Copyright 1946, By Indiana University

All rights reserved, including the reproduction of any part. 


\section{F O R EW O R D}

Dr. Raymond Pearl, Professor of Biology, School of Hygiene and Public Health, Johns Hopkins University, delivered the Patten Foundation Lectures at Indiana University in October, 1938. It was his intention to expand these five lectures before final publication. Other duties interfered and the work was left incomplete at the time of his death, November 17, 1940. Mrs. Pearl, with the help of some of Dr. Pearl's friends, reedited the manuscript and gave it to the University in its present form. In presenting the manuscript, Mrs. Pearl recognized its incompleteness and even its imperfections, for no one could do the task as Dr. Pearl, himself, would have done it.

F. PAYNE 



\section{A C K N O W L E D G M EN T}

WE ARE indebted to the following publishers for permission to use in this book some of the material which has previously appeared either in books or magazine articles written by the late Raymond Pearl: W. B. Saunders Company, "Medical Biometry and Statistics," 1923, 1930 and 1940 editions; Williams and Wilkins Company, "Studies in Human Biology," 1924; Alfred A. Knopf, "Alcohol and Longevity," 1926; Paul B. Hoeber, Inc., "Some Aspects of the Biology of Human Populations," in "Human Biology and Racial Welfare," edited by E. V. Cowdry, 1930; Harper and Brothers, "Patterns for Living Together," in Harper's Magazine, May, 1938; Science Press, "The Search for Longevity," in Scientific Monthly, May, 1939; Science Press, "Tobacco Smoking and Longevity," in Science, March 4, 1939; Oxford University Press, "The Natural History of Population," 1939; and D. Appleton-Century Company, a reprint of "The Search for Longevity" in "Landmarks in Medicine" (Laity Lectures of the New York Academy of Medicine), 1939.

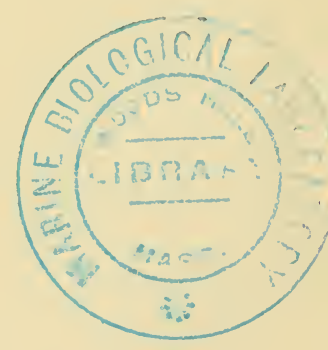



Indiana University

\section{THE PATTEN FOUNDATION}

Mr. Will Patten of Indianapolis (A.B., Indiana University, 1893) made in 1931 a gift for the establishment of the Patten Foundation at his Alma Mater. Under the terms of his gift, which became available upon the death of Mr. Patten (May 3, 1936), there is to be chosen each year a Visiting Professor who is to be in residence several weeks during the year. The purpose of this prescription is to provide an opportunity for members and friends of the University to enjoy the privilege and advantage of personal acquaintance with the Visiting Professor. The Visiting Professor for the Patten Foundation in 1938-1939 was

\section{PROFESSOR RAYMOND PEARL}

The present book consists of the Patten Foundation Lectures for 1938-1939. 



\section{CONTENTS}

Foreword

Acknowledgment

vii

The Patten Foundation . . . . . . . ix

I. The Unique Mammal . . . . . . . . 1

II. The Unique Mammal (continued) . . . . 22

III. Human Longevity . . . . . . . . . . 47

IV. The Numbers of Men . . . . . . . . 81

V. Patterns for Living Together . . . . . 108 

Lecture $I$ -

\section{THE UNIQUE MAMMAL}

I

There ARE living today on the earth well over 5000 different recognizable kinds of animals that have the habit in common of getting their young started on their individual life journeys in a strange way. The mothers elaborate in their own bodies a fluid that is one of the most perfect all round foods known to bio-chemistry and physiology. Furthermore these mothers have their bodies so built as to provide a simple but extremely neat, handy, and beautiful piece of machinery from which their offspring from the moment they begin their free life in the world can get this almost perfect food with a minimum of effort; and without the necessity for the exercise on their part of either intelligence or cunning. It is in fact as easy for them to get this nourishment as it is for them to beat their hearts or to breathe; and, alas, sometimes much easier than it is for them to digest the food after they have got their little paunches full of it.

Because the mothers treat their young in this generous fashion all these thousands of kinds of animals are called mammals. Nearly all of them are distinguished from all other animals in two further ways-one really important biologically and the other merely odd. The first and important distinction is where the mother again shines. She provides for the embryonic development of her young within the superb physiological protection of her own body during the long period from the fertilization of her eggs up to the time the offspring are ready to be born. The machinery of this most perfectly regulated of incubators is highly complicated-too much so to be gone into 
here-but in essence it amounts to the formation of a new and important organ every time a baby gets under way. This organ, the placenta, has for its physiological purpose to make an elaborate ultra-modern plumbing connection between mother and baby, of such a sort that after its function of transferring back and forth the stuffs that life must have and the wastes that living entails it can be sloughed off by both parties to the protracted transaction, without any residual harm to the bodily integrity of either.

The other odd peculiarity of mammals is that, with a few exceptions, they have hair. In nearly all of them it pretty well covers the whole body. That this is an oddity rather than a deep biological necessity is indicated by the fact that it is difficult to think of any useful purpose that is served by hair that is not equally or better accomplished by feathers. And if we may judge by the birds it appears certain that mammals would seem more beautiful if the evolution of skin appendages had been let rest with the achievement of plumage.

\section{II}

Among the thousands of species of mammals man constitutes one kind, flatteringly called Homo sapiens. Clarence Darrow maneuvered William Jennings Bryan into denying this plain fact some years ago, but the denial was an error that Bryan shortly regretted. For man definitely is a mammal; and, as will presently appear, a great part of what he is, and of what he does, is ineluctably consequent upon that fact.

When Linnaeus laid down the classification of animals that in its broad essentials has not required alteration since, he put the mammals at the top of the long ladder that life had climbed in its evolutionary progression; and at the top of the mammals and the very topmost tip of the ladder, man. It is a pleasant thought that this gave him a sort of transcendental allegorical background for his much later acquired and quaint habit of flagpole sitting. No man in his more rational moments has ever seriously questioned the rightness of placing Homo sapiens 
where Linnaeus did in his classification. Nor has anyone doubted that his closest biological affinities were with the other infrahuman Primates. Nor, considering the important part that vanity plays in human nature, is it likely that man's pinnacled position ever will be questioned by himself, even if it were not the fact that the scientific reasons for classifying him as Linnaeus did are inherently sound and convincing.

While everyone agrees that man's closest living relatives are found in the four men-like apes, gorilla, chimpanzee, orang, and gibbon, there is no such agreement about the precise structure of his ancestral pedigree. The evidence that he had a perfectly natural and normal one, and was not specially created to meet a felt need for university professors and bartenders, is overwhelming in magnitude and cogency. But exactly what the individual steps were, or how they came about, is still to be learned. There are nearly as many theories on the point as there are serious students of the problem. All of them at present, however, lack that kind of clear and simple proof which brings the sort of universal acceptance that is accorded the Law of Gravitation, for example. Only on one point, and that one a little vague, can there be said to be general agreement. It is that, on the weight of the evidence, it is probable that at some remote period in the past for which no clear paleontological record has yet been uncovered, man and the other Primates branched off from what had theretofore been a common ancestral stem. The doubt is about when, where, and how this branching took place. Personally I am of the opinion that the conclusions reached by Dr. Adolph $\mathrm{H}$. Schultz, one of the most distinguished and widely experienced students of the problem, are on the whole most closely in accord with all the known evidence. These conclusions, in brief, are that the earliest branch to come off from the common anthropoid stem was the one represented by the existing Hylobatidae (gibbons and siamangs); that shortly after this branch had separated another independent branch came off the common stem and ultimately developed man as we now know him; that at a considerable time after this 
human branch had started on its independent way what was left of the main stem split in two, one limb eventually producing the orang-utan as we know it, and the other limb being the combined gorilla-chimpanzee branch, which not long after split in two, to lead finally to the gorillas and the chimpanzee as they now exist.

Linnaeus recognized that man was the unique mammal, and listed six respects in which he could be so regarded. These were respectively theological, moral, natural, physiological, dietetic, and pathologic. For the most part these differentials alleged by Linnaeus to separate man from other mammals are not regarded now as seriously as they were in a more naively credulous age. To put forward as generic diagnostic attributes that man is created in the image of God and has an immortal soul, or that he has a rational mind so that he may praise his Creator, strikes us today as verging upon the metempirical. And to say that man is physiologically a most perfect and stupendous mechanism is perhaps all right if one feels moved to that kind of language, but after all much the same thing might be said of a gorilla, or a tiger, or an elephant, and hence does not mean a great deal as a differential characteristic. But if Linnaeus's grandiloquently pious characterizations of man are now a bit outmoded, his ringing nosce te ipsum is the perfect slogan for a growing science of Human Biology. For it states as completely as it does concisely the objective of that science.

Nowadays the disposition is to focus attention upon less grandiose points in respect of which man is different from other mammals. There are a good many of these, but four are of very great significance, especially in their implications and consequences. These are:

1. Man's habitually upright posture.

2. His big brain, which is larger both in absolute dimensions and relative to his body weight than that of any other animal.

3. His capacity for articulate speech.

4. His longer life span. 
It will pay us to spend a little time over the first three of these points. The fourth will be left for special treatment in a later lecture to be devoted to that topic alone.

While a number of other mammals for a part of the time either sit, or stand, or even walk upright for short distances, man alone habitually carries on the business of living in that posture. All other higher mammals make locomotion the primary demand upon their fore-limbs. Even the gibbon, which comes nearest to man in the proportion of the whole life span spent in the upright position, still depends heavily upon his fore-limbs as locomotor organs. And the degree or extent of his assumption of the upright posture but fractionally approaches man's, though it comes nearer to it than any other mammal's. The effect of adopting habitually the upright posture and depending solely upon hind legs for getting about was obviously to free the arms for other activities and uses. With this freedom came the development of the human hand; in which "we have the consummation of all perfection as an instrument. This, we perceive, consists in its power, which is a combination of strength with variety and extent of motion; we see it in the forms, relations, and sensibility of the fingers and thumb; in the provisions for holding, pulling, spinning, weaving, and constructing; properties which may be found in other animals, but which are combined to form this more perfect instrument." (Sir Charles Bell's Fourth Bridgewater Treatise, 3d edit. p. 231, 1834.)

Anaxagoras, the intimate friend of Pericles, inspirer of Euripides, and perhaps teacher of Socrates, was of the opinion that the intellectual superiority of man over other animals rested fundamentally on his possession of hands. This view had a certain recrudescence in Benjamin Franklin's designation of man as "the toolmaking animal", and finds today a certain degree of real and substantial support in the underlying philosophy of the behaviorist school of psychology. It was categorically opposed by Aristotle, who almost uniformly spoke disparagingly of Anaxagoras, perhaps because he did not understand him too well. Aristotle turned the case end for end, saying that man had 
hands given to him because he was the wisest creature; thus substituting a bit of teleological natural theology for a perfectly good, if unproven, biological working hypothesis capable of being tested. In this matter Galen trailed along with Aristotle, as was his wont.

Whatever may turn out to be the ultimate views on this somewhat recondite philosophical point, there can be no doubt that the development of the hand enormously aided man in his struggle for survival and progress. A remote, but extremely important, consequence usually overlooked is that the possession of developed hands, as we know them with all their manifold capabilities, opened out to man a much greater range of new and enormously useful methods and techniques of getting a living than those available to other animals. This is a matter about which more will be said later.

Physiologically the habitually upright posture is not yet an unmixed blessing. It is so relatively recent an acquisition in the evolutionary time scale that all of the necessary structural and functional adaptations of the basic mammalian type of body have not yet been completed. An obvious example of this is the frequency of visceroptosis ("sagging innards" in a homely way of speaking) and the distressing complications that often follow in its train. Furthermore the upright posture increases greatly the demands made upon the circulatory system, as compared with the situation under the quadrupedal mode of life. Stout as the circulatory system is there is evidence that the adoption of the upright posture was followed by an associated increase in the proportion of the total mortality assignable to that organ system. But there would seem to be no doubt that the large credit balance in the general biological bank accruing from the freeing of the fore-limbs from locomotory duties, and thus making possible the development of highly specialized hands, a great deal more than offset the general physiological and pathological debits.

The greater size and complexity of the human brain in comparison with that of any other animal has attracted the atten- 
tion of all students of evolution. It has generally been regarded as the most important feature, in a practical point of view, differentiating man from the other mammals. This is, of course, because of the association of greater mental capacities and abilities with the larger and more highly organized brain. The distinguished Dutch anatomist and anthropologist Eugene Dubois, who was the discoverer and principal student of that extraordinary "missing link" between man and his humbler forebears called Pithecanthropus erectus, has for many years laid stress upon the value of brain size in proportion to body size as a quantitative index of evolutionary progress. In 1897 he put forward a formula for what he called the "coefficient of cephalization." This formula stated that for any species of mammal the coefficient of cephalization $K$ was equal to the brain weight in grams divided by the body weight in grams raised to the $5 / 9^{\text {th }}$ power. Numerically evaluating this coefficient on the basis of actual weighings, he first found that the cephalizations of the gorilla, the chimpanzee, the orang, and the gibbons are all approximately equivalent and equal to about one-fourth of the value of the cephalization coefficient for man. The cephalization coefficients for the tiger, the cat, the buffalo, and the goat proved again, according to Dubois, to be approximately the same in each of these forms, and equal to about one-eighth of the value for man. For rodents like the rat and the mouse the cephalization coefficient was much smaller, amounting to only about onequarter of that for the carnivores and herbivores just mentioned. The well-known French student of the brain-weight problem, Louis Lapicque, and his collaborators came forward in 1905 with evidence from birds confirmatory of the same rule, and in 1913 Dubois claimed to have established it for reptiles and fishes. So that now he regards it as a law of evolution for vertebrates in general.

Dubois made an interesting generalization from his numerical results, to the effect that as one goes up the evolutionary series it appears that the coefficient of cephalization tends approximately to increase in a geometrical progression of the term 2; 
by doubling or repeated redoubling, in short. He then concluded that the reason for this progression by doubling of the brain volume was to be found in "the natural property of (most) living beings or tissues to grow by bipartition of cells. It is thus that the number of nerve cells increases and brings about the progression of brain organization." The most interesting thing about this progression is its discontinuity-its doubling jumpsif the results and deductions of Dubois be accepted at their face value. Brain volume, and inferentially mental capacity, have not progressed evolutionally to their present pinnacle in man by gradual travel up a smooth ramp, but rather by climbing a flight of stairs in which each riser is twice as high as the one next below it. When we come near to the top of the stairs Dubois finds, as already mentioned, that there are two degrees of difference instead of one between the existing anthropomorphous great apes and man in respect of encephalization. One step in the old staircase is left out. That missing step Dubois triumphantly assigns to Pithecanthropus, whose coefficient of encephalization he figures out to be "exactly double that of the anthropomorphous apes, and exactly half the human coefficient." Insofar then, but only insofar, the Trinil ape-man may be regarded as the "missing link."

All this makes a fascinatingly interesting story, and whether or not it be fully accepted at the valuation attached to it by Dubois, it is based upon long, patient, and, in the best scientific sense of the word, imaginative research. It almost compels speculation about a theoretically possible, even though long distant future. Suppose it to be the case that the evolutionary process has not yet ended for all eternity with man. And suppose further that man is able to survive as a species for a sufficiently long further period so that a gene mutation or alteration occurs of such sort as to lead the nerve cells of the brain each to make one more division than is now the case before ceasing to divide at all. Then, provided this hypothetical mutation did not alter the dividing behavior of any other cells of the body except those of the brain, the world would find itself possessed of a 
species of veritable super-men, with six-pint brains instead of the present three-pinters that would then seem by comparison so pitifully small and inadequate.

But we must not pursue this speculation, though nothing now known of genetics or brain embryology and anatomy can definitively rule it out as impossible. There is, however, one solid fact about which there can be no disagreement. It is that the greater size of brain, with its associated enhanced mental capacity, has been of enormous practical advantage to man in his struggle for survival, and in bringing him forward from the level on which he emerged as a new genus of mammals, in respect of all those arts, crafts, and techniques of living generally that are peculiarly and indeed uniquely human. Just as in the case of upright posture, however, a biological debit was incurred by this encephalic specialization. The more highly organized human brain breaks down under the stresses of living more easily, and leads more often to the death of the whole organism than is the case with the simpler central nervous system of the lower vertebrates. While comprehensive and precisely accurate statistics on the point are not available a rough approximation suggests that if we take as unity the proportionate mortality in the reptiles and the birds that can be assigned to breakdown of the central nervous system from whatever cause, the corresponding figure for infra-human mammals is about 2.5. That is to say proportionately two and a half times more mammals than birds and reptiles die from causes affecting the nervous system. The corresponding figure for more primitive human groups is about 18.0. That for the most highly civilized and culturally most advanced human groups is about 27.5 . In other words it appears that in the evolutionary progress from reptiles and birds to the most advanced sorts of men the relative mortality assignable to breakdown of the central nervous system has been multiplied more than twenty-seven fold. These figures are not to be regarded as absolutely precise appraisals, but roughly they do indicate something of the biological price that man has to pay for his high-toned brain. Also of interest in this 
same connection is the finding of the recent National Health Survey carried out by the U. S. Public Health Service. This survey indicated that of all chronic diseases afflicting the population of the United States the category "Nervous and mental diseases" took first rank in respect of both number of invalids and number of working days lost because of chronic illness. These diseases of the central nervous system were found to be responsible for nearly twice (1.9 times) as many chronic invalids as heart diseases; three and a half times as many as all forms of tuberculosis together; 4.4 times as many as hardening of the arteries and high blood pressure; 7.8 times as many as diabetes; and almost ten (9.6) times as many as cancer. It would be hard to find a better illustration of the biological rule that a price is always exacted for the benefits that go with evolutionary specialization. In this same connection it is also worth noting that Malzberg, a careful and critical statistical student of the insane, has recently come to the conclusion that in New York State at the present time there is occurring a relative increase in the incidence of mental disease, not very great in amount nor in his opinion warranting at present too serious eugenic concern, but still real.

The capacity for articulate speech, which is unique to man, has plainly been valuable to him biologically. It seems a fair appraisal to say that it may well have been more responsible than any other single factor in the development of his particular type of social organization. Indeed the eminent Sanskrit scholar William Dwight Whitney was quite positive on this point, saying in the first series of his Oriental and Linguistic Studies (1873, p. 296) that: "The specific moving power to the working out of speech was not the monkeyish tendency to imitation, but the human tendency to sociality." The available evidence seems to indicate that in the early stages of his evolution as a distinct species man was probably not naturally much, if any, more gregarious and cooperative than are the great cats like the lion and the tiger at the present time, where such stable sociality as exists is pretty well confined to the biological family group. The 
ability to talk things over and by so doing to bring the then very rugged individualists into a frame of mind for group effort must have greatly aided in the beginning steps of the emergence of human social behavior. In the early stages of man's racial acquisition of the faculty of articulate speech social approval was probably an important element in speeding up improvement in the new art. Pillsbury and Meader, in their very useful Psychology of Language, regard as an important element in the transfer of a baby's "gurgles and poppings of the lips" to words, "the incentive that comes from social approval as the early words are spoken, the smiles they draw from the admiring members of the family, and the pleasing way in which they are taken up and repeated."

It is impossible here, as well as unnecessary for present purposes, to go into further detail regarding the part played by articulate speech in human evolution. It will suffice to let the case be summarized in the words of Edward Sapir, a master in the field: "The truth of the matter is that language is an essentially perfect means of expression and communication between every known people. Of all aspects of culture it is a fair guess that language was the first to receive a highly developed form and that its essential perfection is a prerequisite to the development of culture as a whole." And, as the same author says in another place, society, in the more intimate sense, is "a highly intricate network of partial or complete understandings between the members of organizational units of every degree of size and complexity, ranging from a pair of lovers or a family to a league of nations or that ever increasing portion of humanity which can be reached by the press through all its transnational ramifications."

There have now been discussed in some detail three of the most important respects in which man may justly be called the "unique mammal," namely his habitually upright posture, his out-size brain, and his faculty of articulate speech. Before leaving this phase of the development of our subject, it should be emphasized that in all three of these respects the difference 
between man and the other mammals is at bottom quantitative in character rather than qualitative. In each respect man is different from his other milk-giving congeners by virtue of being only "more so," rather than by being completely alien in kind. Thus most mammals other than man stand up on their hind legs occasionally and for short periods for one reason or another. And, conversely, as one of America's most distinguished anthropologists Dr. Aleš Hrdlička has shown in great detail and wealth of example, human infants not infrequently show a strong predilection for walking on all fours, indicating that it was only a little while ago and not yet protoplasmically forgotten that this was the regular way of locomotion. All that man has done evolutionally in this regard is to acquire the habit of spending more and more of his time upright, with the important consequences already discussed. Again all mammals have a brain similar in kind to man's, only just not so big or so rich in nerve cells. Finally all mammals, as well as many animals lower in the evolutionary scale, have ways of communicating with one another and with the group to which they belong. Our cat Minnie is capable of telling us, in a regrettably raucous and unmusical voice, that she is hungry and that we must do something about it at once; and of vocally making it known to her kittens that they are ranging dangerously far from base and must rush to cover at once. Man's powers of communication have merely been perfected beyond those of his closest zoological relatives to the stage of articulate speech.

So, in sum, it is seen that even in the highest of his biological achievements man still remains a mammal au fond. However snobbish about the matter he may, and in fact does, tend to be there is no escaping from the insistent reality of his family connections. His vain efforts to do so, more particularly under the subtle stimulation of religion and theology, have resulted only in inspiring the great and true humanists like Lucian, Rabelais, Swift, and Voltaire to their highest flights of wit and humor. It lies beyond the range of my biological competence to say whether man is formed "in the image of God," but there is 
no smallest doubt about his being a mammal. And so far from this being a handicap or detriment, the exact opposite is much more nearly true. Man's firm biological anchorage to his solid mammalian mooring is the greatest source of his strength in the cosmic scheme of things.

\section{III}

The three peculiarities of man discussed in the preceding section, though they represent only quantitative differentiations from the mammalian stem, have had four far-reaching consequences in human behavior, that in turn have led to the separating of man very far indeed from all other animals. These we shall now discuss. They are, stated as propositions:

1. Man is a time-binder.

2. Man is an organ-adder.

3. Man is the foremost environment-maker and controller.

4. Man is most diversely adept at getting a living.

Time-binding, to borrow the happy phraseology of Count Korzybski, is biologically one of man's most important achievements, if for no other reason because of the large and always increasing amount of time that it saves him. For time-binding is the permanent accumulation of experience and knowledge by means of the printed record. With the development of written language, and later the correlative art of printing, man started the accumulation in perpetuity of his past racial experience. Furthermore these techniques of preserving and accumulating experience are in the highest degree precise and exact. Euclid's exposition of the basic propositions of plane geometry needs no improvement and has not been bettered. The printed record preserves it for our use forever. The inherent perfection of the time-binding techniques leads to the broad biological result that there is a steady progression, with no backward steps, in man's power to control and adapt to his needs and uses the forces and resources of the world in which he lives. Each generation does not have to discover all over again the ways to do this. 
All other animals except man are able to accumulate only the experience of their own individual life times, so far as concerns everything except the basic physiological processes that have become embedded in their protoplasm as instincts and habits, so-called. This embedding has probably been implemented by a process that may be called "protoplasmic memory," as, on the whole, the best choice from the various terms that have been used to designate it. This process has been particularly discussed by three important persons, the physiologist Hering, who was the first professional biologist to develop the concept in modern times, in a short but valuable essay; the zoologist Semon who wrote a somewhat too verbose book about it (Die Mneme als erhaltendes Prinzip im Wechsel des organischen Geschehens. Leipzig, 1904); and Samuel Butler, the author of Erewhon and of various biological treatises that still probably deserve more attention from professional biologists than they have ever received, except from a few. The concept of protoplasmic memory is basic in Butler's philosophy of biology. He brings pretty much everything under its wide explicatory embrace, with great skill and imagination. Butler's book Life and Habit develops the matter in extenso, but in 1876 he summarized his views in a letter that may be quoted here, both because of its piquant Butlerian charm and because it offers as inherently probable an explanation for certain biological phenomena as any that has ever been proposed by anybody. The extract is quoted from Festing Jones's Samuel Butler, Vol. II, pp. 445-5 (1919):

"1. Actions which we have acquired with difficulty we now perform almost unconsciously, e.g., playing the piano, reading, writing, walking. As soon as we know how to do a thing exceedingly well, consciousness in respect of it vanishes. As long as we know that we know a thing we do not know it; we only know it when we do not know of our knowledge.

"2. Whatever we do in this way is all one in kind, the difference is in degree. We play the piano almost unconsciously, we write more unconsciously, we read very unconsciously, we 
walk and talk still more unconsciously; our breathing is, to a certain extent, under our control, our heart's beating is perceivable but not under control, our digestion is unperceivable and beyond control.

"3. A baby cannot grow itself in the womb unless it knows how to do it, and to know how to do it, it must have done it before or it will be contradicting all human experience. Its unconsciousness is the result of over-knowledge.

"4. It learnt to do it when it did it before; that is, on the previous occasion when it was an impregnate ovum.

" 5 . It has attained to unconscious knowledge of how to do it by doing it a very great number of times in the persons of its ancestors.

"6. But how about identity? There is no identity of matter between me as I am now and me as I was when I was an impregnate ovum, but there may be continuity of existence. And there may be a modified identity between me as an impregnate ovum and my father and mother as impregnate ova. Let us consider my ovum as the means adopted by my parents' ova not for reproducing themselves but for continuing themselves, and let us see the intermediate lives as a long potato shoot from one eye to the place where it will grow its next tuber.

"7. Given a single creature capable of reproducing itself and it must reproduce a creature capable of reproducing itself and so on ad infinitum.

"Then comes Descent with Modification. Similarity tempered with dissimilarity and dissimilarity tempered with similarity - a contradiction in terms like almost everything else that is true or useful or indeed intelligible at all. $A$ begets $A^{\prime}$ which is $A$ with the additional experience of the prime. $A^{\prime}$ begets $A^{\prime \prime}$, which is $A$ with the additional experience of $A^{\prime}$ and $A^{\prime \prime}$ and so on to $A^{n}$, but you can never eliminate the $A$.

"8. Let $A^{n}$ stand for a man. He begins as the primordial cell splitting himself up for ever, and for ever gaining experience, always doing as he did before when last he was in the same position but always with the additional experience gained by 
his having done it once oftener than when he did it last. First he will do his tadpoles by rote, so to speak, on his head, from long practice; then he does his fish trick; then he grows arms and legs, all unconsciously from the inveteracy of habit till he comes to doing his man, and this lesson he has not yet learnt so thoroughly. Some part of it, as the breathing and oxidization business he is well up to, inasmuch as they form part of previous rôles, but the teeth and hair, the upright position, the power of speech, though all tolerably familiar, give him trouble-for he is very stupid, a regular dunce in fact. Then comes his newer and more complex environment and this puzzles him-arrests his attention-whereas consciousness springs into existence, as a spark from a horse's hoof.

"Thus we are all one animal, and reproduction and death are phases of the ordinary waste and repair which go on in our bodies daily."

Considered as a theory of inheritance, which was Butler's main interest in the whole business, all this is not only out of date, but in fact never was in date. This is not merely because it got no serious consideration from competent biologists, except in a few instances. More generally it is because all theories of heredity that have ever gained general acceptance, aside from local national loyalty as in the case of Lamarck's, have been atomistic doctrines, in which "little balls" or tiny "chemical packets," in the germ cells are held to be the essential mechanism by which inheritance is caused and controlled. But if we confine attention to the biology of accumulating racial experience about physiological matters, such as heart beating and breathing, the modern gene theory is inherently even funnier as a rationalized explanation than old Butler's protoplasmic memory based on unbroken protoplasmic continuity.

But even supposing that Butler's theory of accumulating racial experience were to be accepted at full face value it is evident that it would be enormously inferior in precision and comprehensiveness to written language and the printing press as devices to achieve the same end. However one views the 
matter, man's talents as a time-binder not only make him unique among all other animals, but in itself alone assures that his culture-his techniques of living-must in the nature of the case always move forward if they move at all. Only a universal cataclysm that destroyed all his written records could set him back on the road he has travelled.

We turn next to the consideration of man as an organ-adder. It has been the accepted teaching of evolution that man gained his ascendancy in the organic world because of the superior development of his brain. Weaker than many other animals, less swift of foot, a comparatively poor swimmer, and limited by his meager physical endowments practically to life on the surface of the earth alone, man is generally thought to have become the dominant species among living things solely because of his superior cunning and wisdom. However adequate this picture may have been in the very earliest stages of his emergence as a new and distinct form of life, the case is different now. Man is not merely smarter than other forms of life. Today he is physically the strongest of all known animals, by a vast amount. He can move from place to place at speeds enormously greater than those of any other known animal, and do this either on the surface of the earth, in the air, or in or on the water. He can see through opaque objects and for great distances, and can hear a fly's gentle footfall. He can talk to a friend on the other side of the world without raising his voice. He can project lethal agents vastly farther than any other known animal, and kill distant prey, or a predator seeking to annihilate him.

In short, man has taken an evolutionary step during a relatively short period wholly unparalleled in his prior history. $\mathrm{He}$ has added to the power and strength of his muscles and bones, and to the delicacy and range of his sense perceptions in a degree beyond anything that even the wildest imaginations were ever able to conceive before the event. It is customary to regard the methods by which all these results are accomplished as purely mechanical, having nothing to do with biology or life. 
But consider the matter more carefully. If a man wields an axe for eight hours a day, week in and week out, he presently adds certain definite, new, useful structures to the physical equipment with which he started. These are the calluses which develop at the main bearing points on his hands. When they are well developed these calluses are as dead as the axe handle itself. But they are highly useful to the man. They are useless and meaningless in any other relation. Biologically they are adaptive structures added to man's previous manual equipment. But so precisely is a steam shovel. A modern steam shovel is an adaptive structure which can be attached to a man's hands. With his hands strengthened by the addition of this equipment his power is so increased as to make the Behemoth a "wee, sleekit, cowrin, tim'rous beastie" by comparison. The man and the steam shovel together constitute one single organism, partly made of flesh, partly made of steel, but operating, if it operates at all, as one single integrated unit.

All useful machines are additions to the adaptive biological equipment of man as an animal. Some are additions to his motor powers; others to his sensory. But their fundamental meaning is always biological. Except as a part of man's biological equipment they have no significance.

To what does this lead us? The thought has been advanced by not a few persons that the development of machinery is per se a menace to mankind; that machines will dominate men. But why? Machines are only parts of men. They are merely extensions of, or additions to, his arms, or his legs, or his eyes, or his ears, or to some other organ system. They are added organs. And man is the only animal that is an organ-adder, in any significant degree. This attribute or capacity has been of great, indeed incalculable, value to him in his struggle for survival and in his evolutionary progress.

In order that the significance of man's achievements as an environment-maker may be adequately appreciated it will be necessary to digress for a moment to speak briefly of the rela- 
tionship between organism and environment generally. For the sake of brevity this discussion may start with the bald and condensed proposition that the relationship between any organism and its environment is particular, continuous, indissoluble, and reciprocal. It is particular because each individual organism has its own environment peculiar to itself and not fully shared with any other organism. Adam Short, six feet three inches tall, has a definitely different environment at all times and places than does Hiram Long, who is five feet tall and nearly as broad. All conceivable differences between individual organisms, and there is an indefinitely large number of such differences, necessarily entail associated differences in the environment that is particular to the individual. The relationship is continuous because at no time while life exists can organism and environment be separated. It is indissoluble because organisms are dependent for their very existence upon energy and matter derived from the environment. Finally the reciprocal characteristic of the organism-environment relationship arises because each individual organism is continually altering its environment in some degree even if only very slightly, and in turn is itself being altered by the environment. For example in running across a snow-covered field a rabbit alters the field at least to the extent of the tracks it leaves; and, conversely, after this simple event the rabbit itself is a different rabbit from what it was before or would have been if the field had been, let us say, grassinstead of snow-covered. This is designedly a very simple, and in that sense "far-fetched" example of an extremely complex and important part of biology. What it leads to is the broad principle that, in varying degrees from species to species, all animals both choose and make their environments. In other words the organism-environment relationship is never a completely haphazard or random connection, such as that between pennies and their environment when say 50 perfect and physically identical pennies are tossed together. In the latter case the behavior of the pennies is wholly determined by the action of the environ- 
ment (gravity, air pressure, etc.) upon them. In the case of the living organism the environment only partly determines what it will be under any particular set of circumstances.

Man has carried these characteristics of environment-choosing and environment-making to vastly greater extents and degrees than any other animal. So much is this so that although the difference is in principle only quantitative, as we have seen, it nevertheless by its magnitude alone puts man in a class by himself. His prowess in environment-making is primarily the result of his superior intelligence, which in turn has led to the development of his arts and sciences. It is sometimes alleged, and a good deal of evidence is advanced from such sources as geographical distribution, survival of extreme hardships in exploration, and the like, that man exhibits the highest degree of biological adaptability of all animals. In a superficial view this seems probably true. But in reality the point has never been adequately tested. For what happens when people habitually live in the dreadfully harsh environment of the polar regions, for example, is that by the arrangement of their housing and clothing and in other ways they make for themselves an effective environment that in the most essential respects approximates the environments of temperate or even torrid zones. The distinguished Arctic explorer Vilhjalmur Stefansson has given much information on this point from his long experience with the Eskimos. During the long winter night these people spend nearly all their time virtually naked in igloos at temperatures of the order of $80^{\circ} \mathrm{F}$. and above. Furthermore their clothing is so constructed as to be most effectively protective when they are out of doors. Stefansson has even suggested that the relatively early age at menarche observed among Eskimo girls is probably connected with the high temperature of their effective environment. Again the environmental hardships of explorers are now generally recognized to be expressions only of failure to push out around them as they advance an adequate quasi-pseudopodial cloak of mellow temperate environment. How can the comparative grade of man's organic 
adaptability be justly appraised when he persists in making himself an environment demanding only a minimum of true biological adaptation?

In the case of "civilized" man achievements in environmentmaking need no emphasis. Manifold examples are everywhere. He modifies the earth, air, and water of his world to his use. He alters to his wishes and needs, in greater or less degree, the plants, animals, and men with whom he makes contact immediately or remotely. The activities comprised within the term "public health" furnish perhaps the most impressive example. By his alterations of the environment to this end man has added something of the order of a quarter to a third of a century to his average duration of life in a relatively short period of his history as a species.

I shall stop at this point and continue the discussion of man as the unique mammal in the next lecture.

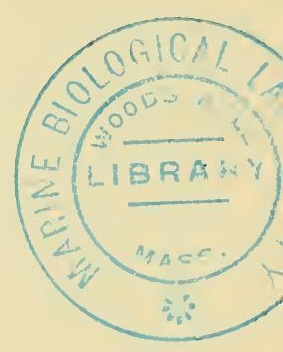




\section{THE UNIQUE MAMMAL (Continued)}

THE THREE unique characteristics of man discussed in the preceding lecture-upright posture, big brain, and articulate speech -and their three derivatives-time-binding, organ-adding, and environment-making - have all combined to make available to man vastly more diverse ways of getting a living than are enjoyed by any other organism. In essence any living organism is a pattern through which must pass continually a stream of matter and energy if it is to continue to live. If and when this flow of matter and energy stops for more than a very short time, life stops too and the pattern that was the individual organism ceases to exist. So long as this flow continues the pattern has all the importance that we are accustomed to attach to individuality. It has also the added importance that derives from its being the sole repository and guardian of whatever there is of personal identity. When an individual is born he is given a name as a symbol of personal identity. As long as he lives he is thought of as the same identical individual, even though for some reason or other his name may get changed. But the matter of which he is composed, his physical and chemical substance, is constantly changing throughout his life. It is only the pattern that remains permanently his.

Samuel Butler discusses this matter entertainingly and penetratingly in Life and Habit, though in his zeal to bolster his theory of heredity he gets off in places into a very miry bog of 
quite unsound biology. But up to a point he paints a true picture of the difficulties that inhere in the concept of personal identity of a living organism. As he says (pp. 84-5): "Surely all reasonable people will feel that an infant an hour before birth, when in the eye of the law he has no existence, and could not be called a peer for another sixty minutes, though his father were a peer, and already dead,- - surely such an embryo is more personally identical with the baby into which he develops within an hour's time than the born baby is so with itself (if the expression may be pardoned), one, twenty, or it may be eighty years after birth. There is more sameness of matter; there are fewer differences of any kind perceptible by a third person; there is more sense of continuity on the part of the person himself, and far more of all that goes to make up our sense of sameness of personality between an embryo an hour before birth and the child on being born, than there is between the child just born and the man of twenty. Yet there is no hesitation about admitting sameness of personality between these two last.

"On the other hand, if that hazy contradiction in terms, "personal identity,' be once allowed to retreat behind the threshold of the womb, it has eluded us once for all. What is true of one hour before birth is true of two, and so on till we get back to the impregnate ovum, which may fairly claim to have been personally identical with the man of eighty into which it ultimately developed, in spite of the fact that there is no particle of same matter nor sense of continuity between them, nor recognised community of instinct, nor indeed of anything which goes to the making up of that which we call identity."

Now keeping up the flow of matter and energy through the organism means getting a living, in the literal and complete sense of the words. Nearly all living things other than man get their livings in one or the other of two ways, or by some combination of them. These two methods are:

A. By preying upon other organisms, plant or animal in nature as the case may be. In general this is the animal way of getting a living. 
B. By directly transforming inorganic material into their own living substance, with or without the aid of energy derived from sunlight, or from complex chemical processes. This is, in general the plant way of getting a living. Most animals, including man, have no natural talents or facilities for getting a living this second way.

Now man has added to these two basic methods a great variety of other ways of getting a living, which however may all be brought together under a single broad category:

C. By doing things, or making things, that can be traded with other men for things necessary for living.

It was a momentous day in evolutionary history when this mode of getting a living was hit upon. Commerce and industry were then and there engendered. The "economic man" was born, and also the slave; not to speak of policemen and politicians.

Biologically the two most important consequences of so widely expanding the effective ways of getting a living were: first, that great numbers of persons were individually able to survive who would not have been capable of doing so by the old method A; and, second, that a much greater total population could support itself on the earth than had before been the case. To see how these results came about it will be necessary to look a little more in detail into the specific techniques by which mankind has gone about getting its living. The primary and dominant business of life is getting a living and its modes have determined the type patterns of culture back through the whole history of human kind. There have been four such broad culture types or stages: the hunting type, the pastoral type, the agricultural type, and the industrial-commercial-service type.

In the pure hunting type of culture mankind lives by direct and never-ending predacity upon other animals and to a lesser and more seasonally limited extent upon plants. This mode of life achieves only a very low degree of what we call economic security in present day language, and that little at the expense of a maximum of physical labor. It requires large areas of terri- 
tory per unit of population. Or conversely expressed this type of culture will support only very low densities of human popution. Further it demands a high degree of nomadism, or in other words a small amount of domesticity in the sense of fixed permanent abode. When the supply of game animals of a region has been depleted by persistent hunting the hunter and his family are compelled by necessity to move on to new regions. Finally hunting is a mode of life not conducive to the development of social organization beyond the level of the biological family. In essence it is a system of individual exploitation of natural biological resources, with little or no element of conservation or economic safeguarding of the future through the exercise of thrift and the consequent building up of capital reserves against a potentially difficult future time.

The pastoral type of culture represents in nearly all respects an advance beyond the hunting stage. Its philosophy rests fundamentally on the idea of domesticating in some degree particular sorts of animals on which it is the intention to prey, so that the supply may to that extent be controlled and conserved. Furthermore it separates the plant predation one step away from man himself by having the domesticated, or partly domesticated, animals that the humans in this culture stage propose to live off gather in the plant resources and process them for human use. The pastoral mode of life achieves a definitely higher degree of economic security than the hunting, and demands in doing this a distinctly smaller output of human energy in the form of physical labor. Like the hunting way of living it requires large territorial areas and can support only low densities of human population, though in this respect it again operates, on the average, at a somewhat higher level than the hunting type. It requires a considerable degree of nomadism, but not to the same extent as the hunting stage. Under the pastoral culture plan the migrations tend to be seasonal and within rather definite and fixed geographical limits-back and forth between good grazing territories in short. But there can be nothing like real permanence of abode. As Gibbon said: "The camp and not the 
soil is the native country of the genuine Tartar." Little in the way of sociality is developed, though it goes somewhat farther in this way than the hunting type. Beginning elements of thrift and deliberate conservation of resources are a definite and important part of its plan.

The agricultural way of living represents in all respects an enormous advance over the two preceding types. Its philosophy is much more profound. In the first place it fundamentally exploits directly the chemical resources of the earth as well as the strictly biological resources. The soil is the farmer's "country." The underlying reasoning is as though the primitive farmer said to himself something like this: "Why not always have plenty of plant food, and other desirable things that come from plants, for myself and my animals, by the simple device of saving seed each year and planting it the next. Then I shall not have to work so hard to get a living. I can fix myself up a nice comfortable place to live in and not have to be always packing up and moving." In putting the case in this way it is not intended to imply that any great number of actual farmers ever consciously thought thus cogently and consecutively, either in the dim evolutionary past or now. But however vaguely sensed this is the philosophy of agriculture. It still remains at bottom, like its cultural predecessors, biologically a predaceous way of living, but the predacity is now ordered and controlled. The only haphazard element theoretically left in it is what rests on vagaries of climate and weather-what man has long been accustomed, in one form of language or another, to call "acts of God," though now to some extent improperly so. As the great legal authority Wharton once (Law of Negligence 557, p. 435, 1878) said: "Why is a hurricane an act of God, when by our weather-signals we are able to anticipate hurricanes?"

The advantages of the agricultural way of life over its predecessors are manifold. It achieves much greater economic security with less physical labor. The total expenditure of human labor is reduced partly because of the nature of the agricultural process itself, and partly because fixation to a definite territorial 
location makes it possible to use extrahuman sources of power much more effectively to do necessary work. Its areal requirements are smaller, and consequently population and population density per unit area can increase. It encourages domesticity and takes away the necessity for nomadism, and in so doing satisfies the human trait of "stay-at-homeness" that is deeply rooted in man's mammalian ancestry. The very vast majority of all human beings live and die near to the spot where they were born. The 1931 census of India showed that of more than 350 million people enumerated by birth place fewer than one million were living elsewhere (Wattal, The Population Problem of India, p. 123, 1935). The same thing in principle is undoubtedly also true of mammals generally. Among them there appears to be a strong sense of home territory. Fraser Darling (A Herd of Red Deer, 1937) while emphasizing the meagerness of present knowledge of the subject, and the crying need for intensive research, ventures the following interesting and pertinent generalizations from his field studies of the red deer in Scotland (pp. 30, 31): "Range, then, is determined physiologically more than psychologically; territory psychologically as much as, or more than, physiologically. There are two great classes of territorial animals - hunters and grazers-and this division is of greater significance to the observer of animal behaviour than in zoological classification. The hunting pack is comparable with a capitalist organization having a fair measure of state control. Territory is guarded jealously and fighting follows intrusion. Size of territory is governed largely by the density of numbers of the animals hunted. The limited degree of gregariousness and co-operation is for the purpose of hunting rather than being familial in origin. In fact, many hunting animals show no sociality beyond the single family. The hunting animal which invades another's territory goes in fear of his own kind and is ready to run or fight. The grazing herd, on the other hand, shows a state comparable with the City of the Laros of Plato: Communality and disciplined orderliness which need but little discipline. Environmental conditions being equal, territories are 
bounded by choice and not by jealousy. If circumstances call for it, another group's territory may be occupied; but this occupation is tolerated, and the groups may combine in face of the common need. The herd is in itself a bulwark against the hunter and predator."

Finally it is to be noted that agriculture promotes the development of sociality to a far greater extent than the more primitive culture types. Its territorial fixation in itself tends to hold together by community of interest larger groups than the immediate biological family, first through progressively more and more remote collateral relatives. At a later stage exogamy brings the necessity for social relations with similar "foreign" groups.

As has already been pointed out the most momentous cultural epoch in man's history began when he became aware that he was able to get a living by a wide variety of techniques different in kind from the three that have been discussed, and embarked in a big way upon the industrial-commercial-service mode of life. It automatically and at once appeared to, and in a comparative sense in fact did, achieve a degree of economic security never before dreamed of. If a living could be got by making or doing things for people, a job was plainly going to be at hand so long as there were people about. The physical labor necessary to get this security was again plainly on the whole a mere fraction of that required under the old techniques. Organ-adding helped to guarantee this. Territorial requirements became minimal. In fact the nature of the technique itself demanded higher and ever higher densities of population per unit of area, leading rapidly to the development of ever larger and larger cities until the average density of population over the whole land surface of the globe, including all the bad and uninhabitable land in the computation, has now come to be about 41 persons per square mile. The necessity for nomadism disappeared, to be replaced by almost obligatory domesticity and fixed habitation. Not merely was it conducive to social organization but it absolutely required and led to a most extraordinarily 
complicated and intricate form of sociality; such, in fact, that no individual or group could possibly avoid social relations. Predacity gave way to service; and altruism, not much heard of before, burgeoned to replace the protoplasmically grounded selfishness of the biological struggle for existence. At least these were the plain theoretical implications of this way of living. It needs no pedantic elaboration of the matter to convey the suggestion that in some respects the actual course of events has not always closely followed the theoretical path. But these divergences may best be left at this point for more ample discussion later. The main point now is that the industrial-commercialservice way of life has been, up to the present time, the culmination of the long process of setting man apart from all other animals as the unique mammal that we have so cursorily reviewed.

It is hoped that in this review one leading fact has been made plain. It is that in the evolution of ways of getting a living the trend of the progression has all along the route been from harder to easier methods, insofar as concerns the expenditure of physical (muscular) energy. Reflection suggests that it would perhaps not be an unfair statement to say that biologically the development of easier ways to get a living is on the whole the greatest achievement of the human intellect. Looked at from an evolutionary point of view the result appears to be congruent with the general rule of organic nature that all living things tend to get their livings with the minimum of effort possible under their circumstances of life. Remembering that plants are just as much and as truly living organisms as animals, it is an obvious and somewhat overwhelming statistical fact that the vast majority of living individuals on the earth are sessile-rooted to one particular geographical spot and spending none of their energies on getting about. Incidentally it is worthy of note that it is among these fixed and rooted plants that by far the longest individual life spans are found. Various species of trees outlive many times over any known multicellular animal. Evaluated by the impersonal biological yardstick of survival the unbustling fixed way of life would seem to be a good one. Later on in these 
lectures occasion will be taken to follow further the implications of this point.

\section{IV}

So far the discussion has been of those characteristics that set man apart as unique among the mammals. The treatment of the case has been positive and affirmative in character. Now it will be well to emphasize the conclusions reached by looking briefly at the negative side-that is by showing in outline that a great many of man's characteristics and behavior are essentially identical with the characteristics and behavior of the other mammals-the lower classes of animals from which he stemmed. It will then be completely clear that while man is the unique mammal, he is so in only a comparatively few respects, but those extremely important ones.

In the first place the general plan and pattern of man's anatomical structure is mammalian. The correspondence is uncannily close and manifold, as every budding biologist learns the first time he dissects a cat and compares his findings with the pictures in Gray's Human Anatomy. As J. S. Prichard, one of the founders of modern anthropology, said in his Natural History of Man (1843) more than a quarter of a century before Charles Darwin's Descent of Man appeared: "In all the principles of his internal structure, in the composition and function of its parts, man is but an animal. ... The points of resemblance are innumerable; they extend to the most recondite arrangements of that mechanism which maintains instrumentally the physical life of the body, which brings forward its early development and admits, after a given period, its decay, and by means of which is prepared a succession of similar beings destined to perpetuate the race."

What is true of man's anatomy in this respect is also true of his physiology. His heart, his lungs, his kidneys, and his endocrine organs function in the same way as the corresponding organs in his mammalian relatives. In a broad view and that is the only one that limitations of time allow to be taken here, the 
convincing evidence that this is so is found in the history of the science of physiology itself. For what that history shows is that the overwhelmingly greatest part of our knowledge of human physiology has been initiated from experiments made on infrahuman mammals. In every medical school today the fundamentals of physiology are demonstrated to the students from the bodies of dogs. And the information so gained is found to be completely reliable and trustworthy in the practice of the art and science of medicine when applied in the relief of human suffering.

If the essentials of man's physiology are identical with those of mammalian physiology in general, it is reasonably to be expected that much of his behavior will be found upon analysis to be like that of other mammals in similar or equivalent situations. This is in fact so. A host of examples might be given in proof. Books could be, and have been, written to this end. But again taking a broad view, the prime significance of the fact that a large part of human behavior is just animal behavior is perhaps best seen in the way this fact has come to be the very foundation stone of the most advanced modern psychiatric thinking and action in the treatment and prevention of mental disease, under the influence of Freud and with the rise of psychobiology. The adequate recognition of the community between man and the lower animals over great ranges of their psychology and behavior, and the practical implementation of this recognition to therapeutic uses, are relatively recent developments. But the idea itself is at least as old as Aristotle. For it is implicit in the central thesis of his Psychology, which was that life and mentality were to be regarded as identical terms.

G. Stanley Hall in 1920 (Preface to Freud's General Introduction to Psychanalysis) drew an interesting comparison between Wundt and Freud. Until the appearance of the latter upon the scientific scene Wundt had been for a long time the dominant world figure in psychology. There is perhaps no better way to get a realization, that strikes home with almost shocking force, of the profound change that has come over all thinking 
about psychology and behavior, than to examine the contrast between Wundt's outlooks and attitudes towards his subject and those that prevail generally now. To be sure this change is not wholly attributable to Freud's influence, but a large part of it directly or indirectly is. As Hall said, Wundt had "little use for the unconscious or the abnormal, and for the most part he ... lived and wrought in a pre-evolutionary age and always and everywhere underestimated the genetic standpoint. . . . It is rather precisely just the topics that Wundt neglected that Freud makes his chief corner stones, viz., the unconscious, the abnormal, sex, and affectivity generally, with many genetic, especially ontogenetic, but also phylogenetic factors. The Wundtian influence has been great in the past, while Freud has a great present and a yet greater future." As events turned out this last statement was an extraordinarily good brand of professional prophecy.

Modern psychobiology rests firmly upon an evolutionary, phylogenetic base. Indeed it would become largely devoid of philosophical meaning or sense if that base were shorn away from under it. This is apparent from the formulation of the attitudes and objectives of psychobiology in relation to psychiatry set forth by the distinguished leader in the field, Dr. Adolf Meyer (Contributions Dedicated to Dr. Adolf Meyer, etc., edited by S. Katzenelbogen, 1938): "We [have] come to find ourselves in harmony with the concept of the individual as obtained by individuation and organization, as a biological entity with vegetative osmotic functions; next also with motor functions and, further, with segregation of motor and sensory functions, which, however, were found to have culminated in the total-action of the individual presenting symbolization processes and thereby 'more or less consciousness'; that is to say, performance studied as a unitary problem first (such as the fertilized egg-cell), and then secondary subdivisions and differentiations in the process of growth and assimilation and metabolism; these secondary subdivisions might not be only the subdivisions of what we cultivate in anatomy and physiology, but subdivisions that have their own working principles, those de- 
rived from the new and specific unit, the living person. These working principles in the personality function must no doubt be brought into harmony with what we know of the principles of the sciences of physics and chemistry but also with the sciences of growth and the sciences of organisms. We have to realize that the study of the organismal total-function, the function that hangs together by means of symbolization and consciousness, will have to follow its specific path, according to the relations and facts found, and that is the path which we found in the biography, which we found in the study of the various directions of functions, the activities, the intellectual functions, the motor functions proper, the action functions and the affective functions, and altogether the 'sense,' that which we find only and always as organismal functions. There we find ourselves with what human wisdom and sagacity has long worked with, as we say, by intuition, i.e., by using the immediately available facts and emergents, which ultimately we have to bring into harmony also with facts and relations arrived at through other channels and directions and relations."

Human "organismal total-function" spoken of in this quotation just read is an evolutionary emergent, genetically directly. descended from, and in large part still identical with, infrahuman animal "organismal total-function." Unless this fact is constantly in mind human behavior cannot be sensibly interpreted. A great part of what you and I do every day we do in the way we do because it is a part of the entail of the mammalian pattern and substance of which we are made.

It would be difficult to find a more unpedantic (and insofar praiseworthy) way of making clear something of the range and nature of the deeply embedded mammalian bases of human behavior than is afforded by Alice Crowell Hoffman's little disquisition which may now be quoted, by permission, from the September 1938 issue of Your Life.

\section{What You Can Learn From Your Dog}

To keep clean.

To love children. 
To keep your place.

To chase away flies.

To size up an enemy.

To drink plenty of water.

To be faithful unto death.

To be a dependable friend.

To take plenty of exercise.

To express pleasure when favored.

To speak up when you want anything.

To stay where it's warm in winter and cool in summer.

To guard faithfully the interests of those who care for you.

This list could obviously be almost indefinitely extended to include not only items common to human and animal behavior in relation to alimentary and excretory functions, sex and reproduction, but also a great deal of what is often naively regarded as "higher" sorts of behavior. Every young man and woman is pleased to think that they have made novel discoveries peculiar and perhaps even "sacred" to themselves in the technique of the art of making love. This is, alas, only a delusion, albeit a nearly universal one. If a sort of super-television-dictaphone apparatus were available for an objective statistical investigation of the matter it would be found that in their amatory behavior the Whitechapel costermonger and his lady say and do pretty much about the same things as the dainty denizens of Mayfair. This is because human courtship behavior stems from deep mammalian roots. The proof of this cannot be undertaken in a public lecture, but must be left for the seminar and laboratory. But no one of an observant and philosophic trend of mind, who was brought up on a farm, will require pedantic documentation on the point.

Dogs, like humans, do "express pleasure when favored," as every dog lover knows. Dogs, however, have very feeble powers for the discrimination of motives behind the "favors" vouchsafed them; or for understanding clearly the consequences foreseen 
by the grantor of the "favors" as likely to follow. It is interesting to note that men are sometimes not very different from dogs in their behavior in these respects. This was made evident to the observant human biologist when five billion dollars of the public money was quite legally distributed where it would do the most good in a recent election campaign. Neither unctuous asseverations of nobility of motive, nor indignant denials by the persons responsible that they were buying votes, nor the serene unawareness of the recipients of the favors that their votes were being bought, made any smallest alteration of the realistic fact that the distribution of the funds was so managed that it did do a stupendous amount of political "good."

In his vanity man prides himself on being a rational animal. But really only a small fraction of his behavior is rational. The rest is just mammalian, or of still lower evolutionary order.

\section{V}

As everyone knows there are a great many kinds or varieties of men. There are white, black, yellow, and red kinds, to consider only the very superficial matter of skin pigmentation. There are also many other readily distinguishable kinds where the features that make it easy to tell them apart have to do with more fundamental matters. Yet strangely enough the genus homo includes but one species, though it has many varieties. Among other forms of life than man it is the rule, to which there are but relatively few exceptions, that if two individuals really belong to different species they are infertile inter se. That is, if they mate together no offspring will result, though in all other respects they may be extremely, even minutely, alike. The decisive evidence that man, even with his wide and striking varietal differences in structure, is properly placed in a single species is found in the fact that all known kinds of human beings are not only fertile inter se but produce fertile offspring, when they breed together. The political philosophy temporarily in vogue in Germany takes the view that Jews are different in kind from Aryans (a blessed word of very dubious biological mean- 
ing, if any). That philosophy also contends that the Jews really, on a just view, ought properly to be classified with infra-human primates rather than as men. Not a few professional Southerners of the ancien regime have held similar views about Negroes. But the indubitable if sometimes uncomfortable fact remains that Aryans and Jews, or whites and Negroes, he or she as the case may be, are exuberantly capable of producing racially mixed babies by the quite normal and usual technique appropriate to such matters.

This universal fertility amongst mankind is a phenomenon of extreme importance in human biology. In the beginning of man's evolutionary emergence as a new form of life it was presumably of some help in the struggle for survival. But with the very limited powers of getting about that he then had the statistical and social consequences could not have been very great. By the time man had subdued the horse and the camel to his uses, however, and had learned that rafts and boats made it possible for him to "walk on the water," what must have considerably astonished him was the discovery that pretty much wherever he went desirable girls were to be found, and that nature could be depended on to take its course there just as at home.

One of the greatest consequences of the process of organadding that came with the development of the arts and sciences, and the consequent control and use of natural forces, was an enormously increased facility and speed of transportation and communication, a trend that we have not seen the end of yet. As the shrewdest writer on politics since Machiavelli says: "During the lifetime of many of us the world has shrivelled and puckered like a child's balloon slowly deflating, so that now we find ourselves cheek-by-jowl with peoples and regions that fifty years ago were regarded as half mythical. And not only do we see strange faces at close quarters, but we are beginning to have confidence that some day we may be able to read the hearts that belong to them."

In a world "shrivelled" by the ease and rapidity of transportation there inevitably and automatically are created more op- 
portunities for people to mate together who under earlier conditions never had any such chance. Such opportunities are always taken advantage of. No degree of strangeness of people to each other, dissimilarity or supposed ugliness of form or features, or habit or custom represses completely, or even significantly, the gratification of the sex appetite. Contact of races or peoples whenever and wherever it happens means sexual congress across whatever varietal differences there may be between them. With charming naivete an unsophisticated young lad who kept a diary of his experiences when on the gold rush to the Klondike in 1898 (W. R. Curtin, Yukon Voyage, 1938, p. 154) made a profound biological observation when he wrote: "I see and hear of so many men who will marry any kind of woman when women are scarce; not bums either. So-called refined, educated gentlemen, even college professors, the best we have will do the same. If a man can live with a smelly Indian squaw, any kind of white woman is too good for him." Presumably only inexperience led this young man to fail to recognize that something other than mere statistics of "scarcity" was involved in the picture that so shocked him.

If all races and varieties of mankind are fertile among themselves, as is the fact, it follows that increased facility of transport and travel will result, and is resulting, in the steady breeding out of the differences that have hitherto marked the varieties of men. This process is going on at the present time at an ever accelerating rate. The "swamping effects of inter-crossing," in the phrase of the old Darwinists, is being exemplified by man on a world-wide scale. Men get about easily and freely nowadays. Because they do, humanity is being slowly but surely bred to a dead level of mediocrity, using this term in a strictly technical statistical sense rather than one of disparagement. In genetic terminology there is being brought about, at an ever accelerating pace, a more and more uniform, horizontal, or random distribution among mankind of the genes that hitherto have maintained racial or varietal differentiations, because of their original segregation in separate groups of people.

For lack of the right kind of data it is impossible to measure 
precisely the rate at which this process is occurring. But an interesting local indication about the matter is seen in the fact that in 1933, of the 1,763,351 white babies born alive in the United States to parents of known birthplace, 160,665 or over 9 per cent, were produced by mothers who were born in different countries from those in which the fathers had been born. Now difference in country of birth does not necessarily or universally connote difference in race or variety, but in the great majority of cases it does mean that the two parents represented considerable differences in genetic as well as social backgrounds. If in the computation we consider only specifically named parental countries of birth, the percentage rises to 10.1. So that, even in 1933 in this country where immigration has for some years been greatly restricted by law, something of the order of a tenth of the white births each year, as a minimum, are contributions to the levelling process of random redistribution of genes. The figures are for the whole of continental United States and therefore include those parts of the deep South where "foreigners" have even yet penetrated but little as compared with the heavily urbanized and industrialized northern and eastern sections of the country. But, in any case, the precise figure is of no great moment. The important thing is that in one of the larger countries of the world the process of amalgamation of human group differences by breeding goes on steadily year by year to a significant degree.

The social consequences of this process are highly important, and bound to be increasingly so the longer it is continued. Consider war as a single example. As has been elsewhere pointed out (Pearl, Studies in Human Biology, 1924, pp. 542-3): "In general, why men deliberately plan wars is because they are different biologically, in structure, habits, mental outlook, thought, or other ways, and wish to preserve intact their differentiations. The more truly conscious they become of these group differences, the more likely they are to fight as groups. As soon as they attain the first glimmerings of such consciousness they are apt to see, or to think they see, something in the behavior of their 
neighbors which threatens the maintenance of that which begins to mark them as a nationality. It is the business of their national leaders to be on the lookout for such things. They may merely fancy that they detect some danger to the maintenance of even their present status in something that a neighboring nation does. It may be a very intangible thing, and the interpretation of its significance may be entirely wrong, but that does not matter. The explanation of why men fight is very simple. It is, first, because their kind of people is different from other kinds; second, because they want to make sure that their kind shall either maintain or improve its status in the world; and that which is thought to ensure most certainly the maintenance and extension of group differences in the widest sense is relative politico-social domination by the group; and third, because of a general physiological law that certain emotions tend to lead to action."

Quite plainly the more the differences between peoples are bred out by universal intercrossing the more difficult it will be to stir up wars. Biological internationalism supplements and aids political and social internationalism. In the far-off end all mankind will presumably be a rather uniform lot; all looking, thinking, and acting pretty much the same way, like sheep. Just in proportion as biological differences between peoples diminish so will the frequency of wars diminish. But the diminution seems likely to be at a fearfully slow rate; it will be a long time yet before the last war is fought. And a low cynic might suggest that even war, horrid and stupid as it is, would perhaps be preferable to that deadly uniformity among men towards which we are slowly but surely breeding our way.

\section{VI 、}

In considering the consequences of the universal fertility between the varieties of the human species emphasis has been put upon the initial group differences between these varieties, and their gradual diminution and probable eventual complete obliteration as the result of ever more widespread interbreeding. Let us now give some consideration to the differences between 
individual human beings. It is one of the most obvious truisms of biology that no two living individuals are exactly alike in any respect, whether of form, or function, or chemical constitution. We know a great deal about these differences between individual men. An enormous amount of effort in the aggregate has gone into the measuring of them. The whole science of physical anthropology is made up of such efforts and their results. A great part of present-day psychology is turned in the same direction. What broad generalizations have resulted from these efforts?

There are three such generalizations that it seems important to discuss. The first is that many more men differ from each other by small amounts in respect of any characteristic whatsoever than differ by large amounts. This is a universal law of variation in the organic world and an expression of its inherent stability. The distribution of individual differences tends to cluster about a center of variation, which is regarded as the typical condition or norm for that character. Average, run-of-mine individuals are much more frequent than outsize freaks in whatever respect they may be observed. This first generalization about individual variation is really no more than a simple description of how the world of living things is organized. It has inherently no occult meaning, and in fact baffles any inquiry as to why it happens to be so, quite as completely as does the fact that bodies attract each other in proportion to their respective masses. It also illustrates the fact that such concepts about natural phenomena as "normal," "typical" or "truth" itself are merely the expressions of majority opinions so widely concurrent and congruous as to be practically universal. To illustrate: in a world so organized that the differences between men in stature were so distributed as to yield a U-shaped curve instead of in a cocked-hat curve, as they are in fact, "normal" or "typical" men would be either very short men or very tall men. In such a world the freak would be the man of average height. The only reason why in our world men of about average height are "typical" and "normal" is that there are so many more of them that 
they constitute an overwhelming majority of the vote when the "normality" or "type" issue is up for consideration. There is no absolute or transcendental normality or type. This is a point well to remember when we get into the more complicated realms of human biology such as sociality, political behavior, and the like. The second generalization about human variation is that the differences in respect of various separate characteristics of the individual are statistically correlated in greater or smaller degree, so that, for example, if a man has extra long arms he is also likely to have extra long legs. This phenomenon of correlation is an expression of the integration that is so important a feature of the organism in contrast to the inorganic, and that makes the living organism something more than and different from the simple sum of its component parts.

The third generalization is that the total range of variation that exists relative to any characteristic and species stakes out the limits of viability, or survival, relative to that characteristic in the whole frame of reference that constitutes the pattern of that particular form of life. Here we enter upon somewhat new territory, and illustration and example will be required. Everyone knows that while the pulse rate per minute varies from individual to individual, and from time to time in the same individual, it does so within quite narrow limits. Furthermore everyone knows that if the individual's life is to continue the rate of heart beat cannot transcend these limits. In the state of normal health and well-being these limits are roughly from somewhere around 50 beats per minute to 90 odd beats per minute. If under the influence of disease or injury the heart rate goes out much or long beyond these limits, the individual goes out too, for good and all. So then a rule can be stated about variation in human pulse rate that no living human being ever has a pulse rate more than $m$ times greater than the pulse rate of any other human being. When a numerical value has been assigned to $m$ we shall have a limit of viability of the human organism in respect of individual variation in this characteristic, rate of heart beat. By taking into account a sufficient number of obser- 
vations of pulse rates on different people an approximate numerical value can be assigned to $m$ close enough to satisfy all practical purposes. And so similarly for other characters, until in the end one could plot out the whole pattern of the extent of biologically permissible individual variation consistent with viability and continued survival, for a great range of characteristics, structural, physiological, mental, behavioral, and so on. When this has been done we shall have a sort of map of the organization territory within which man does his living, and, by and large, must do it.

Now because of the vast amount of scattered but carefully collected information regarding the variation of man that exists in the literature of anthropology, anatomy, physiology, psychology, etc. it is possible to construct such a map. For a number of years I have been engaged in so doing, as opportunity offered. Though far from finished the results obtained are of some suggestive interest. In order to present briefly here some idea of their nature six broad categories of human characteristics have been chosen, and a relative mean value of $m$ for each category computed. The categories are as follows:

I. Size and shape dimensions. These include linear measurements of bodily characters, such as stature, arm length, etc., and indices measuring shape, such as the cephalic index, and the like. In this first category there are included over 200 separate series of measurements, involving all told many thousands of individual measurements. In general this category shows the narrowest limits of variation of any so far studied. The absolute weighted mean value of $m$ for the whole category is 1.153 . The physical interpretation of this figure is that, as an average of the whole category, the linear and shape dimensions of the largest and queerest formed adult human beings are only about 1.2 times as great as the corresponding dimensions of the smallest observed human beings. It must be again emphasized that this is an average for many different dimensions of the sort named, and for various races and kinds of people.

II. Physiological dimensions. This category includes such 
characteristics as pulse rate, body temperature, various biochemical characteristics of the blood, etc. In a broad way this category corresponds roughly to Claude Bernard's concept of the "internal environment."

III. Weights. This category includes such characteristics as the weight of the body as a whole, of its separate organs, etc. In a general way this category, as compared with the first one discussed, includes the factor of individual variation in alimentation-eating habits and their bodily consequences.

\section{TABLE 1}

Relative Variability of Normal Adult Human Beings

Character Category

I. Size and shape dimensions

II. Physiological dimensions

III. Weights (alimentation factor)

IV. Motor and sensory performance

V. Judgment

VI. Behavior
Relative Weighted Mean Value of $m$

1.00

1.78

3.37

9.27

47.42

135.52

IV. Motor and sensory performance. This category includes such characteristics as speed of running, visual and auditory acuity, marksmanship, etc.

V. Judgment. Psychological performance in relatively simple tests involving primarily the faculty of judgment.

VI. Behavior. This category includes measurements of individual variation in habits and behavior relative to such things as smoking, use of alcoholic beverages, frequency of coitus, etc.

In Table 1 are set down the relative weighted mean values of $m$ for each of the six broad categories of characters that have been described, the value of $m$ for category I being taken as 1.00. It is to be understood that thèse values are at present only tentative, and subject to revision as the investigation here reported for the first time proceeds further.

The figures of this little table are shown graphically in Fig. 1.

The first three categories include only what may be regarded as the lower attributes and faculties of man-just anatomical and physiological things that he has in common with the beasts. 
The last two categories deal only with what are regarded as higher faculties, peculiar to man and not shared with lower forms of life. The fourth category (motor and sensory performance) falls in between the other two sets, in common

\section{RELATIVE EXTENT OF HUMAN VARIATION}

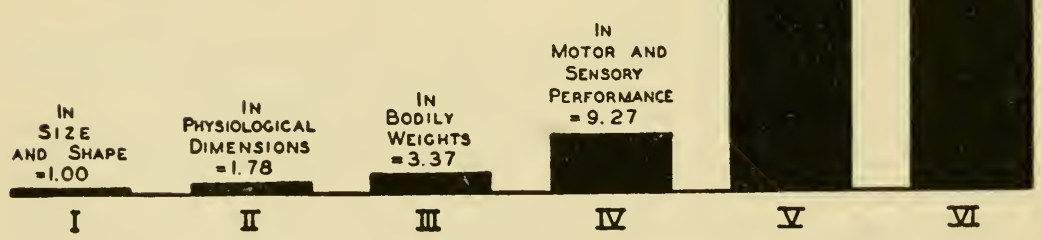

FIG. 1. Relative mean weighted values of $m$ for six broad categories of human characteristics. (For explanation of what $m$ means see text.)

every-day interpretation and in biological fact, but in variability lies much nearer the lower than the higher group.

It is evident that the extent of variation or differences between human beings is much greater in respect of the attributes and faculties of the sort included in categories V and VI, than in respect of those in categories I, II, and III. Insofar as these figures may be trusted as approximations, it appears that men and women differ from each other in their behavior more than a 
hundred times more than they do in their bodily build and general physical make up. In simple judgments they appear to be nearly 50 times more variable from individual to individual than in size and shape.

This wide variation among men in behavior, judgment and such-like things furnishes the primary reason why human living in this world today is so interesting, so exciting and at one and the same time both so pleasant and so irritating. If we were all as alike in our behavior as we are in our bodily build this would be a dull world indeed. Boredom would not only be justified but inescapable. As things are now the differences between individuals stimulate them all to fuller and richer living, day by day. Just because differences are irritating they are also stimulating. Right now Mr. John L. Lewis and his C.I.O. irritate profoundly a great many people. But can any sensible person doubt that out of his activities is coming a searching reconsideration of the whole question of the relations of labor and capital? Or that the very ones who hate him most heartily are being driven to give their best thought to this matter?

The wide-ranging variation among human beings in their behavior and mental faculties is not, however, universally acclaimed as a benison. On the contrary there is abroad in the world today, and rather rapidly spreading, a viewpoint that has for its primary objective to reduce this variability as much as possible. It aims to accomplish this result speedily, without waiting for the slow results of interbreeding. It proposes so to regulate and regiment human beings that they will all come to think and act as nearly alike as possible. We are told by those of this view that discipline is inherently a good thing-good for soul and body. We are further told that if all men only will act and think alike, and as ordered to think and act by somebody who alleges, like papa, that "he knows best what is good for little boys and girls," they will collectively be able to accomplish much more for the common welfare than if each goes his own way, guided only by his own entirely inadequate capacities. We are further told that all who do not subscribe heartily to this 
doctrine are merely dumb fools, who confuse abstractions, myths, and symbols with reality, and are therefore incapable of managing their own affairs, but really should, for purposes of government and the common welfare, be regarded as inmates of a great insane asylum and treated accordingly by "wise" and "humane" persons who know what is best for them. Oddly enough this kind of doctrine is separately rationalized by different groups of folk by the application of one or another of utterly and fundamentally opposite political theories, such as communism, fascism, and New Deal humanitarianism, so-called. Each protagonist argues that only by sternly reducing the range of human variation in behavior and thought can the ultimate blessings of his curative eye-wash be achieved.

In a later lecture in this series we shall try to see whether a better way of life cannot be found than any such scheme of turning man, the unique mammal, into man, the contented cow! 
Lecture $I I I$ -

\section{HUMAN LONGEVITY}

\section{I}

IN THE first of these lectures it was pointed out that one of the important characteristics that set man apart as the unique mammal was his great individual longevity-greater than that of any other mammal. It was promised that this characteristic would be given special discussion in due course. The present lecture aims to redeem that promise. To do this we must first justify the categorical statement that man has in fact the longest life span of any mammal. This is quite easy to do, because there is but one contender against him for the position of supremacy in longevity. That is the elephant. There has long prevailed a popular belief that the elephant is fabulously long-lived. This is only a myth, however, quite unsupported by quantitative records. On the contrary all the available evidence agrees on two points: first, that elephants under domestication, about which India furnishes long and extensive experience, live on the average longer than in the wild state; and second, that few individuals tame or wild ever live more than 50 years, and for those few reliable evidence is lacking that any ever achieves more than about eighty years of life as an outside maximum. The case is different with man, as we shall now see.

The available evidence indicates that during the last twentyfour hours something upwards of a sixth of a million fresh new human beings have appeared for the first time upon this earth as a whole. Each of these babies that starts today on the journey through time called the life span will endeavor, with all its might and main, to make that journey last just as long as pos- 
sible. For the will to live is the most deeply rooted and persistent of the biological characteristics of protoplasm organized into individuals. At the beginning of each persons's life this urge to survival is wholly unconscious, just a part of living like digestion or respiration; later on this underlying protoplasmic will to live, the vital momentum, will be supplemented in the individual by a conscious effort for longevity. The great part of today's babies who manage to survive until they are somewhere in the twenties, will then begin to think a little about what they should do to preserve their health so that they may keep on living longer. Virtually all of them who live until they are seventy years of age or upwards, will think about little else from that time on. For it is an odd but profoundly true generalization of human biology that the longer a human being has lived, the more anxious and personally concerned he is, by and large, to keep on living still longer.

\section{II}

The duration of the journey through life that so many young hopefuls have started upon today will vary greatly amongst them. Some of the lot will end it tomorrow, so incomplete is their vital resource and so fragile their design for living. Others, a very few others, of the lot will be living a hundred years from now.

The pattern of these varying life journeys, and the changes in that pattern in quite recent years, are matters of considerable interest and worth looking into on their own account as well as to give us a solider ground for the further discussion of human longevity. The "order of dying" of a cohort of individuals all born at the same time is given with great accuracy by a device known as the life table, that combines mathematics and biology in a happy and useful mating. For purposes of the present discussion a certain function called the "survivorship" for two life tables has been put in a graphic form, on the supposition that the life journey of which we have been speaking consists in climbing a long and huge ladder. The first of the two life tables 
chosen for this treatment is based on the mortality experience of 1929-31 inclusive, and is one of the latest comprehensive American life tables. The second table to be depicted is based upon the mortality experience of the state of Massachusetts in the year 1890. In both cases we shall deal with the order of dying of white males only. What will be shown in Figure 2 is the

NNUS Right about here will be one

'OMINI

2098

2028

2018

2008

1998

1988

1978

1968

1958

1938 grand old gatfer who will have reached thevery $y$ top of theladder 29 centenarians will here look back over 100 wonderful years Only 2,37) will $H$ be left at 90
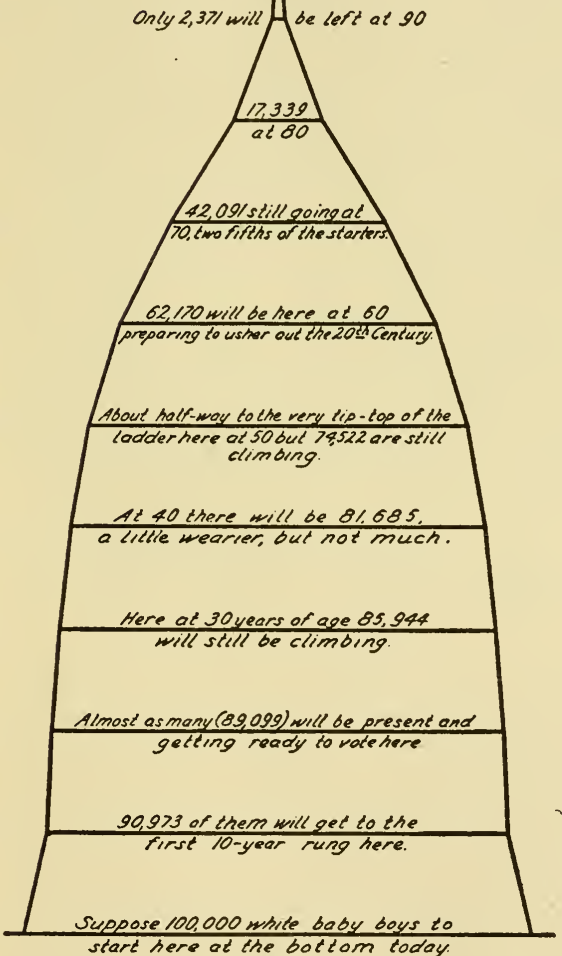
start here at the bottom today.

1929.31

THE LADDER OF LIFE

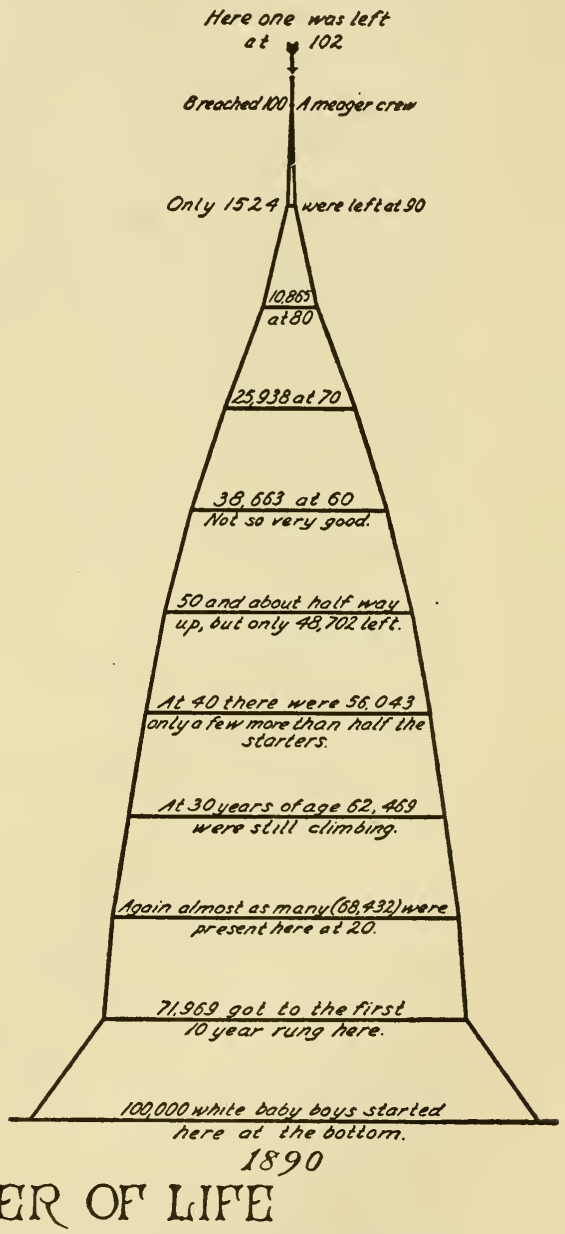

IG. 2. The ladder of life as it is shaped now (on the evidence of 1929-31) and as it was in 1890, forty-eight years ago. (For further explanation see text.) 
shape and dimensions of the Ladders of Life which the respective cohorts of white boy babies-that of 1930 and that of 1890 - may be imagined as climbing.

The construction of the Ladders is as follows: the total length (or height) of each ladder is the total span of life, which is about the same in each case-a little over 100 years. The rungs of the ladder are in each case set ten years of age apart, so that the bottom rung of each is at 10 years of age, the second rung at 20 years, and so on. The length of the rungs-the width or spread of the ladder-is, at each rung, proportional to the numbers of persons in the cohort who live long enough to get a foothold on that rung. Naturally both ladders are drawn to the same scale in the picture. In both cases 100,000 just-born white male babies are supposed to start together climbing the ladder. In the case of the 1929-31 Ladder there has been placed opposite each rung a calendar year date. This is meant to suggest that it will be a Ladder of Life much like the one here depicted that the white American boy babies born today will climb. This is not an entirely wild bit of prophecy, because past experience indicates that the ladder they will ascend will almost certainly actually be as good as or better than this one, because it is not likely that medical and public health progress will abruptly stop tonight. It is progress in these two fields in the recent pastwithin the lives of most of us here tonight- that in large part has wrought the 1929-31 Ladder of Life into the shape we have seen.

It is at once evident that the two Ladders, less than half a century apart in time, are quite different in shape. The one for 1930 has an air of broad substantiality-a solid structure that holds a lot of people. The 1890 one stands on the same base, but after the lowest rung is passed it becomes a rather narrow, gangling thing, with much less of an air of solid stability; resembling strikingly the sort of ladder built for fruit picking, rather than the broad and heavy firemen's ladders on which human lives depend. At the fifty-year rung the 1890 Ladder of Life accommodated fewer than half the persons who started 
the climb, while the 1930 Ladder at the same point will hold almost three-quarters of the starters.

\section{III}

In these pictures we see graphically how the prospects for the duration of the journey of life have been altered in the last fifty years or so, and for the better. The improvement has been great, and much credit is due to the medical and public health professions for the part they have played in bringing it about. But the pictures of the Ladders do not make it entirely clear just how and wherein the improvement has been made. They give rather a broad general impression of the whole effect. In order to apprehend more clearly a very important, and often overlooked, point about this average improvement in the duration of the individual's life resort must be had to some other pictures, shown in Figure 3.

These are pictures of Life Ladders too, but of only their upper parts. Suppose we consider what happened subsequently to 10,000 white males who got to the forty-year rung of the 1890 Ladder in comparison with 10,000 who will get to the same rung of the 1930 Ladder; and then suppose we make the same comparison between 10,000 who got to the 70-year rung of the 1890 Ladder and an equal number at the same position on the 1930 Ladder.

It is at once evident from the figure that the duration of the life journey after age 40 for those who have attained that age is, on the average, only slightly longer now than it was in 1890 . According to the 1929-31 mortality experience 2.9 per cent of all those (males) reaching forty lived to reach ninety years of age. But the 1890 experience shows that 2.7 percent, or almost as many relatively, did the same then. The gain in the half century for the forty-year old boys is wholly insignificant in any practical point of view.

The figure further shows that those who attain the age of 70 now actually do not do so well relatively, on the average, in the way of further survival to still higher ages as did the 
stalwarts of 1890. At that time six hundred out of every 10,000 white males alive at age seventy lived on to ninety or more. Now, on the basis of the 1929-31 experience, only 563 manage this feat.

So it becomes plain that the important achievements in alter-

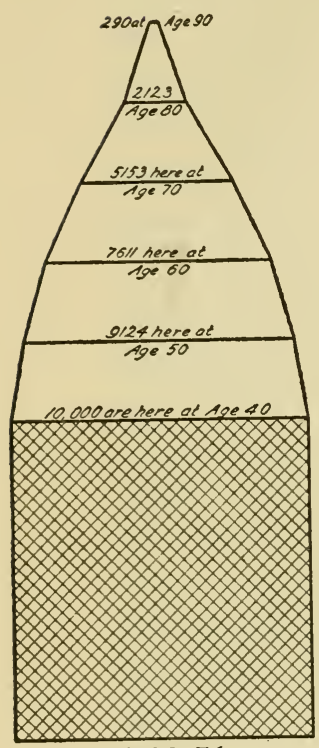

$1929-31$

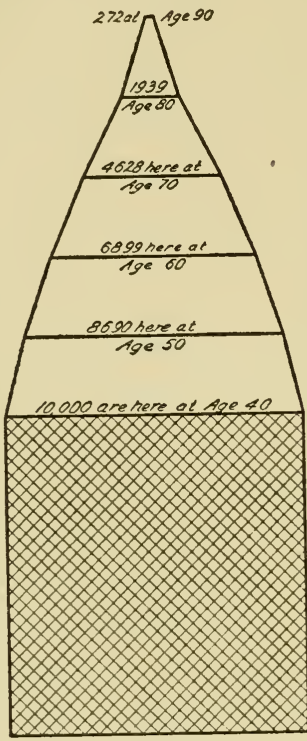

1890

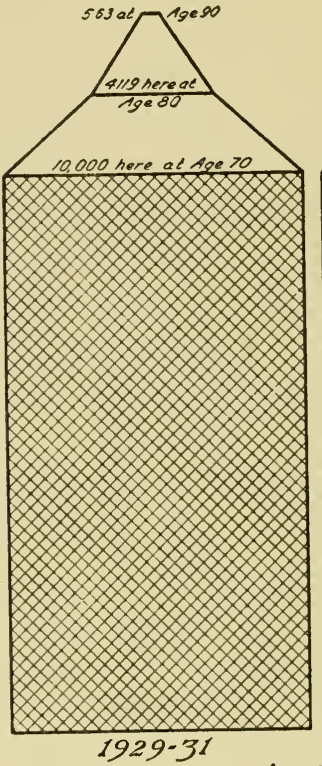

$1929 \cdot 31$

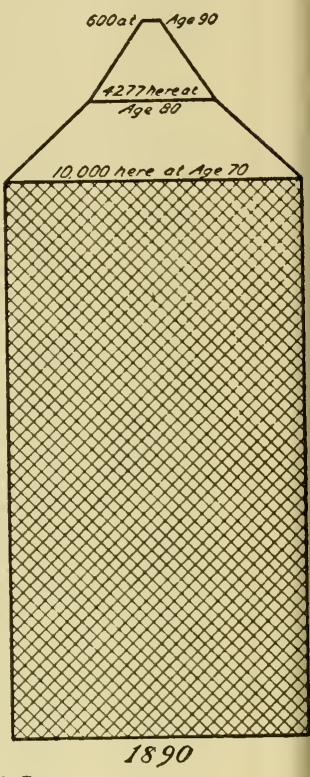

SURVIVAL AT THE HIGHER ADULT AGES

Fig 3. The number of survivors at the later ages from an equal number starting at age 40 and at age 70, as shown by the U. S. Life Table (exclusive of Texas and South Dakota) of 1929-31, and the Massachusetts Life Table of 1890 White males.

ing the shape of the Ladder of Life in the last fifty years, have been mainly in regard to the lower rungs. And it is chiefly the lowest, or ten-year rung that has been improved. In 1890 only 72 per cent of the boy babies starting got a foothold on that 10-year rung; now 91 per cent do. This is splendid and must certainly be warmly approved of by every small boy. But there is extremely little in it to bring cheer to the man at forty who would like to buy an annuity and look forward to gloating over the issuing insurance company as a nonagenarian.

In the common way of thinking longevity really means liv- 
ing past eighty years, and great human longevity means being a nonagenarian or centenarian. Progress in medicine and improvement in the public health have done little or nothing about enabling the individual to achieve such a goal, as the cold statistical facts about the order of human dying make abundantly clear. The span of human life has not been lengthened, and there is no present prospect that it soon will be. The average duration of life is all that has been altered, and that has been accomplished chiefly by giving more babies a fairer start in life's journey than they used to have. Because more of them get by the early and very difficult hurdles, absolutely more of them survive at later ages. But the terms of the bet that any individual man aged seventy today can safely say that he will be alive at ninety appear to be not quite so good as they were fifty years ago.

\section{IV}

Why is it that some individuals alive at any given age will live thereafter longer than others? In principle the duration of life of any individual is the net resultant of the interplay between his own innate biological make-up and the forces acting upon it, favorable or unfavorable, external and internal. This is a complete and sufficiently logical statement of the case, but not so immediately useful as might be wished for the purpose of disappointing eager morticians.

One of the most often quoted things that Oliver Wendell Holmes ever said was that if one is setting out to achieve "three score years and twenty," the first thing to be done, "some years before birth, is to advertise for a couple of parents both belonging to long-lived families." "Especially," said he, "let the mother come of a race in which octogenarians and nonagenarians are very common phenomena." When this statement was made its only foundation was the general impression of a wise physician who had spent his own life in a region where octogenarians and nonagenarians were common phenomena. To what extent or degree has this impression been supported by exact, quantitative investigation?

As the first and simplest approach to the question let us 
consider briefly the analysis of the pedigrees of persons who have actually achieved great longevity. For many years we have been collecting data about persons actually living at ages of ninety years and above. The collection now includes more than

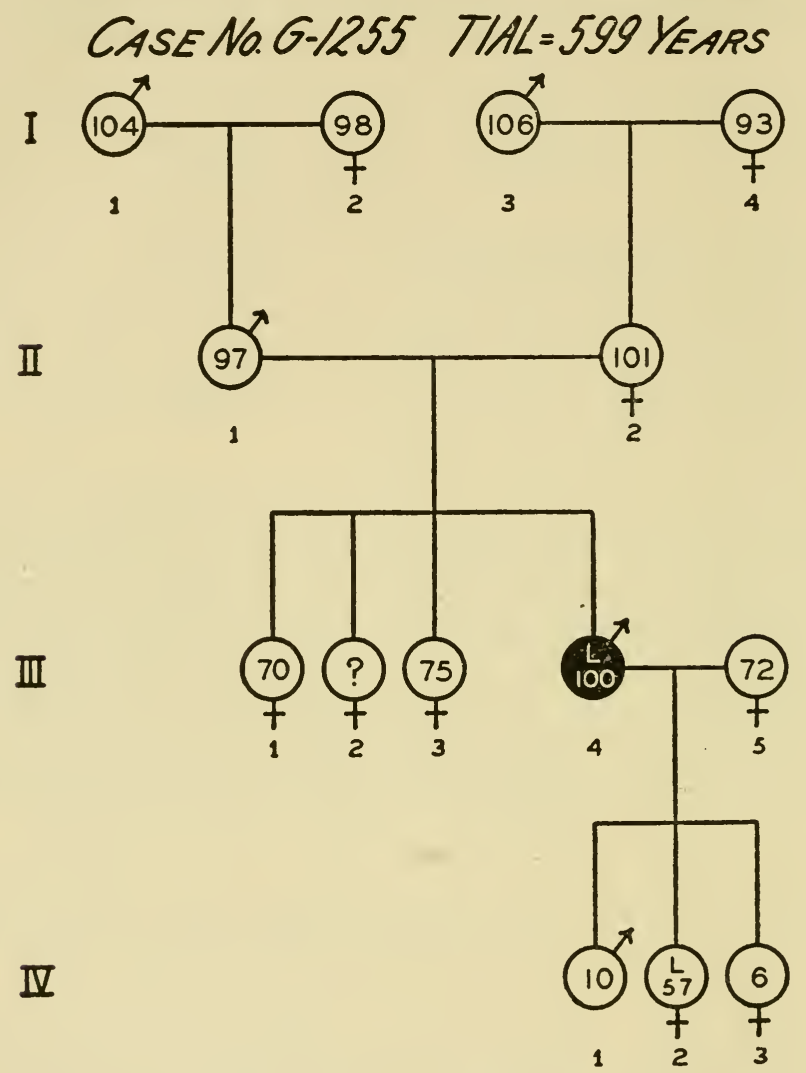

FIG. 4. Pedigree of individual having highest observed TIAL

2000 such persons, for whom the personal and family records may be accepted as reliable and trustworthy, after having been thoroughly and critically checked. Many more cases than this have gone through our hands, but have been rejected for scientific study because they did not meet the standards of proof that were set up. 
In 1934 my daughter and I published a rather extensive and detailed analysis of 365 of these cases of proven extreme longevity. For each of these cases the ages at death of the six immediate ancestors (two parents and four grandparents) were known and recorded, as well as a great many other things about the person and the ancestors. As an example, the pedigree of one of these highly longevous persons is shown in Figure 4.

In this pedigree the person under discussion (the propositus) is indicated by a solid sex sign. Figures within the circles of the sex signs indicate the ages at death in years, except where there is an $\mathrm{L}$ above the age figure, which means that the person was living at the time of record, and at the indicated age in years.

At the top of the chart the mysterious word TIAL is merely an abbreviation for "total immediate ancestral longevity," and is used to designate the sum of the ages at death of the parents and grandparents. Thus in the present case $104+98+$ $106+93+97+101=599$ years. It is safe to say that few human beings have ever had an authentic TIAL number higher than this.

But how much lower are the TIALS of ordinary people, just "run-of-mine" folk who do not themselves live, on the average, longer than the average of the general population? To get an approximate answer to this question, and to have a group to compare with the highly longevous group of nonagenarians and centenarians we assembled, entirely at random so far as concerned their own ages, a group of 136 living persons all six of whose immediate ancestors (parents and grandparents) were dead at the time of observation, and for each of whom the age at death was known and recorded. This seems as fair a group for comparing TIALs with the longevous group as it is humanly possible to get. This comparison group had an average living age of 48.75 years, and contained 29 persons over 60 at the time of observation, 6 over 70, and 1 over 80 . The average age of the group was almost 16 years higher than that of the living white population of the United States in 1930.

How does the ancestral longevity of this group of ordinary 


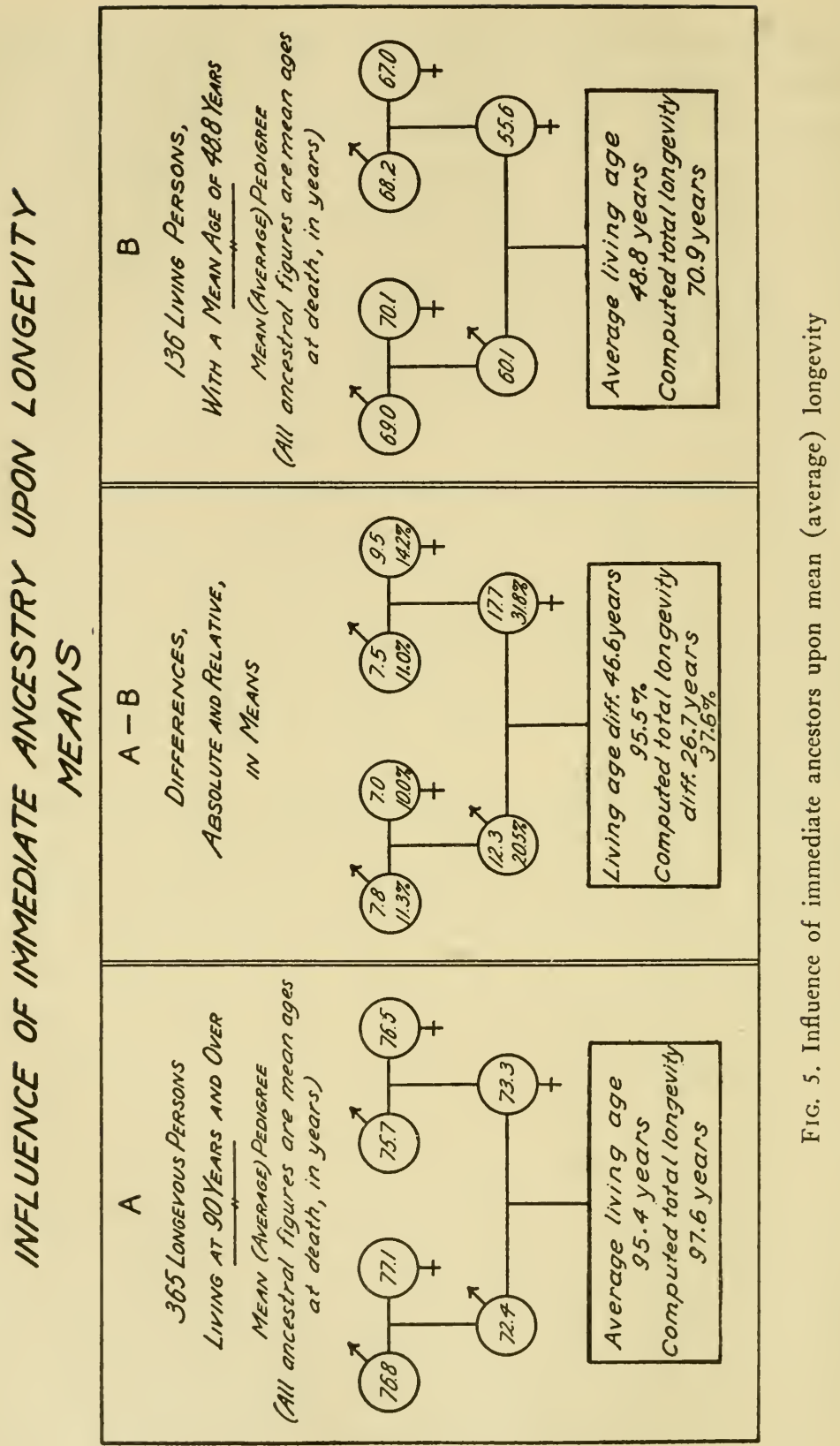


folk compare with that of the elite group of extraordinary long-livers, the nonagenarians and centenarians? Figure 5 gives the answer in graphic form.

From this diagram it is seen that, on the average, each single immediate ancestor, father, mother, grandfather, or grandmother, of the extremely longevous persons of panel $\mathrm{A}$ on the left side was longer-lived than the corresponding ancestor of the ordinary persons of panel $\mathrm{B}$ on the right side. Thus the fathers of the longevous died at an average age of 72.4 years. This was 12.3 years older, or over 20 per cent, than the average age of the fathers of the panel $B$ folk at the right end of the chart. The central panel $A-B$, gives the differences, in absolute numbers of years (upper figures in each sex sign) and as percentages of the panel B means, for each category of the six immediate ancestors.

From this chart two results indubitably emerge regarding the influence of heredity upon longevity, namely:

First: People who achieve extreme longevity have immediate ancestors (parents and grandparents) who are, on the average, definitely longer-lived than the corresponding ancestors of the general run of the population. This is true without exception for each particular category of immediate ancestors.

Second: This hereditary influence promoting longevity is between two and three times as great relatively for parents as it is for grandparents, so far as the results of this investigation indicate.

It appears, then, that old Dr. Holmes was sound in his advice to select long-lived parents, and particularly long-lived mothers.

Let us now go a little deeper into the matter, by proceeding to examine more specifically how each of the parents of the extremely longevous persons was bred relative to longevity, as compared with the parents of the general run of folk. For the purposes of this inquiry let us regard an individual who dies under fifty years of age as short-lived; one who dies between fifty and sixty-nine years as average or mediocre in life dura- 
tion, and one who dies at seventy or over as long lived. These ranges in general agree fairly with common-sense opinion and usage.

Figure 6 shows the percentages of the fathers and mothers respectively that had (a) both of their parents long-lived (shown by the solid black portion of each bar); (b) one parent longlived and the other mediocre or short-lived (shown by the cross-
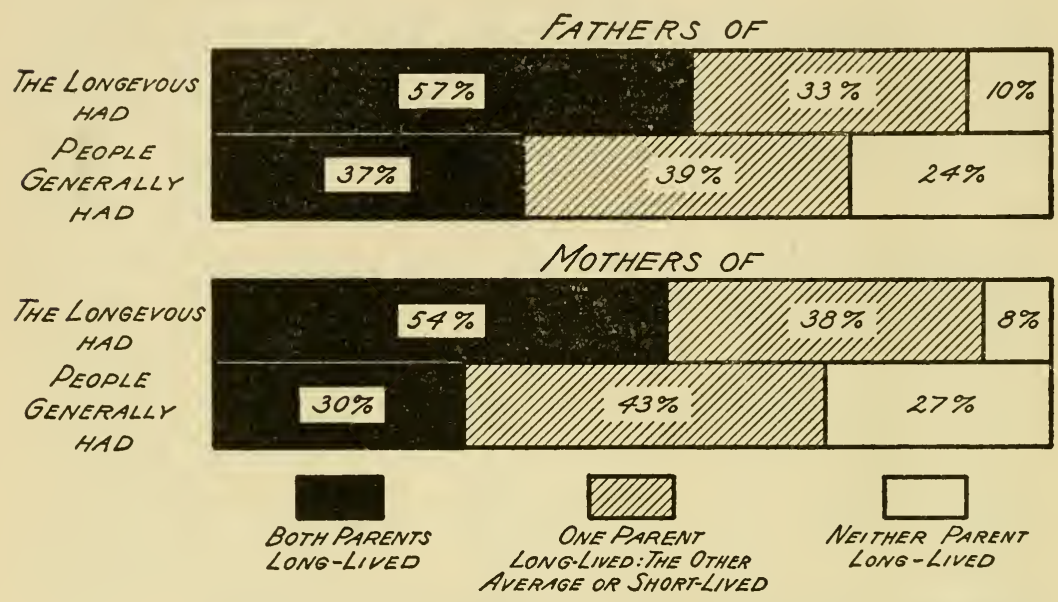

\section{HOW THE PARENTS OF THE LONG-LIVED ARE BRED}

FIG. 6. The percentage distributions, relative to the nature of the parental matings producing them, of the fathers and of the mothers of (a) an extremely longevous group (nonagenarians and centenarians), and (b) a defined sample of people generally

hatched portion of each bar); and (c) neither of their parents long-lived (shown by the white portion of each bar).

The picture presented is precise and striking. The nonagenarians and centenarians were produced by parents who were themselves bred out of wholly longevous parentage in more than half of all the cases observed-a markedly higher proportion than that shown by the parents of the general population sample. At the other end of the genetic scale the opposite is true. Fewer than half as many proportionally of the nonagenarians 
and centenarians as of persons generally were produced by parents who themselves had no longevous parentage whatever. It seems clear beyond question of doubt that breeding counted

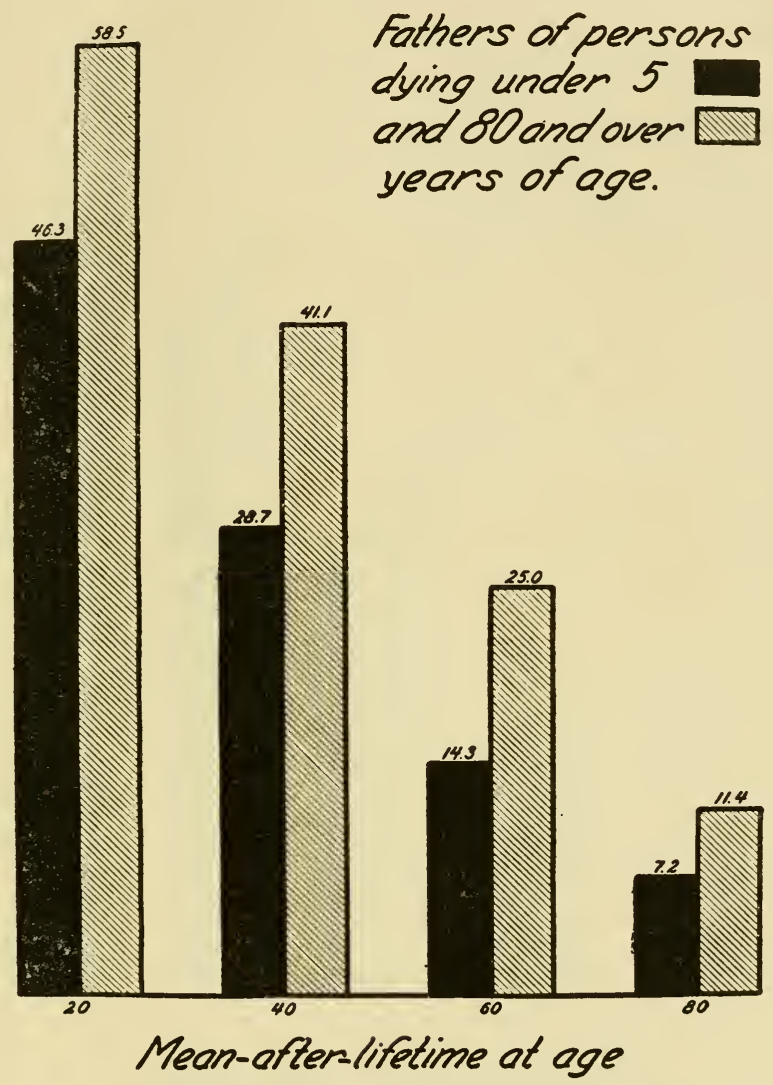

FIG. 7. Expectation of life in years (mean-after-lifetime) at ages $20,40,60$, and 80 , of fathers of children dying (a) under 5 years of age (solid bars) and (b) 80 and over years of age (cross-hatched bars)

mightily in the production of these nonagenarians and centenarians.

Let us now turn to another method of approach, and a wholly different material, to get still another view of the importance of inheritance in the matter of longevity. Suppose one were to 
go out and collect entirely at random every single case possible to find of children dying before they were five years oldextremely short-lived human beings in fact, who were unable to get far in the pleasant business of living either because they were inherently bad biological eggs literally or figuratively, or because they never had a fair chance to live on account of a bad environment associated with parental poverty or ignorance or vice. Now suppose further that we followed the fathers of these poor creatures along through their whole lives and set down in the record their ages at death when they (the fathers) finally died. It would then be possible to construct a life table for the category of Fathers of Persons Dying under 5 Years of Age. Having done all this, suppose we next did precisely the same thing for a group of fathers of persons who did not die until they were eighty years old or more-in other words, a group of old gaffers with demonstrated great powers of living, which powers may conceivably have arisen from their innately superior biological make-up, or from great good luck combined with good sense in their choice of victuals and drink, or from always wearing their rubbers when it rained, and so on through the entire list of precepts and superstitions thought to promote longevity. When the data had been collected and the computations made we should then be in possession of a life table for the category of Fathers of Persons Dying at 80 and Over Years of Age.

How will these two life tables compare with each other? The next figure, Figure 7, shows the answer so far as concerns the expectation of life (or average-after-lifetime) at four selected ages twenty, forty, sixty, and eighty years.

It is at once evident that, so far as concerns the present material involving well over a hundred thousand life years exposure to risk, the long-lived children had fathers who were much longer-lived than the fathers of short-lived children.

Corresponding life tables for mothers tell the same sort of story.

The relative excess in life duration of the parents of long- 
lived as compared with short-lived children is very considerable. Thus the mean-after-lifetime of fathers of children dying (or living) at ages of 80 and over is about 75 per cent greater at age

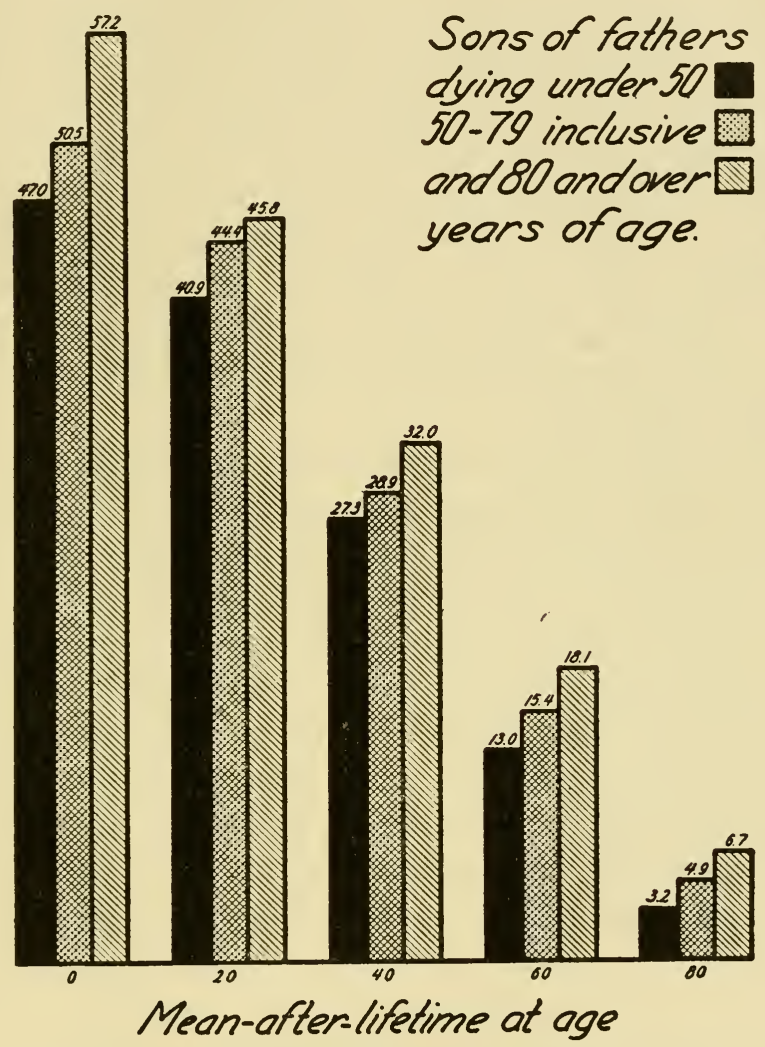

FIG. 8. Expectation of life in years (mean-after-lifetime) at ages 0 (birth), 20, 40,60 , and 80 years, of the sons of fathers dving (a) under 50 years of age (solid bars); (b) between 50 and 79 years of age (double cross-hatched bars); and (c) 80 and over years of age (single cross-hatched bars)

sixty than the mean-after-lifetime at the same age of fathers of children dying under five.

What now of the situation turned the other way about? How will the respective life tables compare if we construct them for 
the children of short-lived, moderately long-lived, and very long-lived parents? This we have done for sons as a class, with the results shown in Figure 8.

Plainly the results of these life tables for sons confirm the conclusions derived from those for fathers that have just been examined. As we pass upwards through the three broad classes of paternal longevity the expectation of life of the sons at all ages steadily rises. The expectation of life of the sons of shortlived fathers is less than that of the sons of moderately longevous fathers, and still less than that of the sons of extremely longlived fathers. Thus at age sixty the sons of very long-lived fathers (eighty and over) have a further average expectation of life nearly 40 per cent greater than that of sons whose fathers died before age fifty.

It seems unnecessary to present further evidence to demonstrate the great significance of genetic factors in determining individual differences in the length of human life. The inherited biological constitution of each individual human being-his or her genetically determined inherent viability-is beyond question one of the major determiners of the probable length of that persons's life. It is not, however, the sole or absolute determiner. Obviously anyone can behave in such a way that his or her genetic birthright in longevity is prevented from coming to its full expression. Prematurely taking one's own life by the suicide route is perhaps the most nearly perfect example. On the other hand the general effect of public health and sanitary measures is to create and promote such conditions of living as will permit the greatest possible number of people to bring as nearly as possible to complete realization and expression the inherent vitality with which they have been genetically endowed. In the changing shapes of the Ladder of Life shown earlier it has been seen how great the progress has been in this respect for the earlier years, and how little for the later years of the life span. This suggests, in the light of the evidence regarding the inheritance factors in longevity, two conclusions that may be of considerable significance. The first is that there exist broad 
classes of human beings differentiated from each other in their innate endowments in respect of inherent viability, one class being short and the other being long of this important quality. The second suggested conclusion is that improving the environmental circumstances of living can do, and has done, a great deal more for the first class than for the second in the way of increased longevity. It appears probable that there is now, and always has been in past ages, a class of human beings by nature so abundantly endowed in the matter of viability that they have always, as a statistical group, so nearly realized their innate potential viability regardless of environmental circumstances as to be not significantly affected in average duration of life by any general improvement of those circumstances.

Detailed study of the life histories of extremely longevous persons, such as has been possible with our collection of such records, strongly suggests that nonagenarians and centenarians are biologically differentiated from the general run of mankind in just the manner postulated for the second biological class just described. As a group nonagenarians and centenarians have definitely not led protected lives in specially favorable environmental circumstances; nor have they had better medical advice or care than the generality of men; nor, finally, have they conducted their lives more hygienically than others, according to the rules and precepts generally regarded as conducive to long life. On the contrary they have just lived, but lived a much longer time than most.

\section{V}

So far the discussion has been almost entirely of the innate, constitutional elements concerned in the determination of individual life duration. It is now time that some attention be devoted to the environmental aspects of the picture. Here is where the quest for personal longevity finds its greatest interest. While in an academic or philosophical point of view it is doubtless desirable to know as much as possible about the hereditary and constitutional factors influencing life duration, still these are 
after all not matters about which much can be done in the way of promoting personal longevity. What Everyman really wants is to be able to do something effective right here and now about a matter of such transcendent personal concern. He would like

\section{H I S T O I R E \\ DES PERSONNES \\ QUI ONT VECU}

PLUSIEURS SIECLES,

ET QUI ONT RAJEUNI:

AVEC LE SECRET

DU RAJEUNISSEMENT.

Tiré d'Amauld de Villenerve.

Et des Régles pour fe conferver en fanté; $\&$ pour parvenir à un grand âge.

Par Mr. DE LQNGEVILLE HARCOUET.

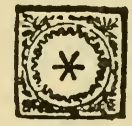

A $P A R$ I $S$,

Cliez la Veuve Cabpentier, \& Lalu. RENT LE COMTE. 1716.

AVEC APHROBATION ET PRIVILECE.

Se vend $A B R U \times E L L E S$,

Chrz J EAN LE ONARD, Libraire \&: Imprimeur rue de da Cour.

FIG. 9. Facsimile of the title page of Harcouet's Histoire 
to be authoritatively told how he should conduct his life so to live long. Still better he would like to be provided with some pleasant pill or potion guaranteed to keep him going until he reaches ninety at least, without any bother about what he eats or

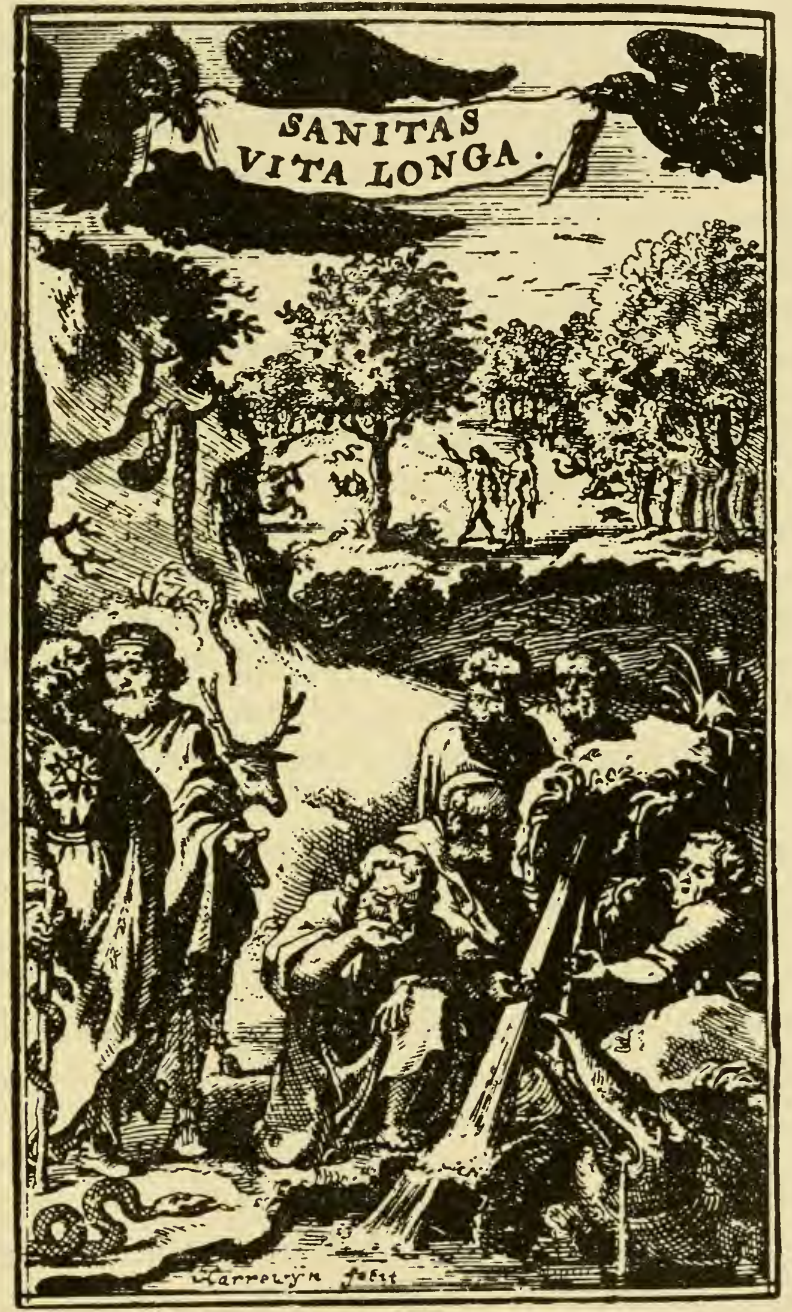

FIG. 10. Facsimile of the frontispiece of Harcouet's Histoire, depicting the Fountain of Youth. Original size of engraved area, $110 \times 66 \mathrm{~mm}$. 
drinks in the meantime, or whether he bundles up well when he goes out in the cold. Best of all he would like to be supplied with some of the authentic juice that flows from the Fountain of Perpetual Youth.

Since mankind started making literary records of his thoughts and aspirations the search for that elusive Spring has been earnestly prosecuted. Many people have figured out just what it would look like when it was found. One of the most charming and delightful of its many portrayals serves as the frontispiece of a rather rare book that is one of the gems of an extensive collection of tracts and treatises dealing with longevity down through the ages. The title page of this book and the frontispiece depicting the Fountain of Perpetual Youth are shown in facsimile in Figs. 9 and 10.

One notes the triumphant and smug satisfaction with which his conductor is telling the weary and sceptical old physician in the lower left foreground, who may be Aesculapius himself: "There, you doubting old fuddy-duddy, I said it was here, and here it is! See for yourself!" In the right foreground is evident the almost obscene eagerness of the old boys just arrived to guzzle the precious fluid gushing from the Fountain, while the bloated saurian leers up at them and gets his share. In the distant background we get a glimpse of the Garden in which so much of humanity as was there remained perpetually youthful, until the lady unfortunately committed a technical error. The fauna of the environs of the Fountain is characteristically reptilian. It will also be noted that an elephant is emerging from the trees in the background. This is to round out the lesson of the picture as a whole; because, of all mammals except man, the elephant is the longest lived. The Reptilia of course have always been noted for longevity. The banner borne by the two Rocs at the top of the picture is an anchronism, plainly put in as a sop to conservative respectability. For if we really had access to the Fountain of Perpetual Youth who would worry about health?

Unfortunately it has proved impossible to get a supply of water from the Fountain of Youth to distribute on this occasion. 
Lacking this the best that can be done is to discuss some of the environmental factors that have been thought to be, or in fact are, importantly concerned in the achievement of longevity. Only those will be chosen for discussion about which there exists definite scientific evidence, pertinent to the point at issue.

Of all such factors the use of alcoholic beverages has probably been most discussed. The problem of the effect of such usage upon longevity has excited violent and unreasoning prejudice on the part of large numbers of people. They contend that alcohol always and everywhere shortens the lives of its users. There is much evidence, experimental, statistical, and actuarial that this is not a universally valid generalization. This evidence does not make the slightest impression upon those who believe, that is to say have faith, that the generalization is valid. So an impasse results. So far as I am aware there has been constructed only once a set of life tables for classes of persons homogenous in respect of their habits relative to alcoholic indulgence, and based upon critically adequate and pertinent data collected at first hand. Those life tables lead to the general conclusion graphically depicted in Figure 11.

That conclusion is that moderate drinking is not significantly associated with any alteration of life duration, either for better or worse, when compared with total abstention from alcohol, while heavy drinking is definitely associated with a serious diminution in the length of life.

These results have been accepted by some, and rejected by other equally sincere, equally honest, and intelligent groups of people, who however differ widely in their emotions and sentiments regarding the use of alcohol by man as a beverage. Nothing further can be done about the case. Presumably each one of the present audience is already a component of one or the other of these two groups.

Let us turn next to the use of tobacco and longevity. This usage is probably, along with that of alcohol, one of the most widespread amongst humanity relative to substances or materials 
that are not, in themselves, necessary to the maintenance of life as is food. Is the smoking of tobacco associated statistically with any impairment of the normal expectation of life, or with an improvement of it, or is there no measurable association one way or the other? This question, too, has excited controversy,

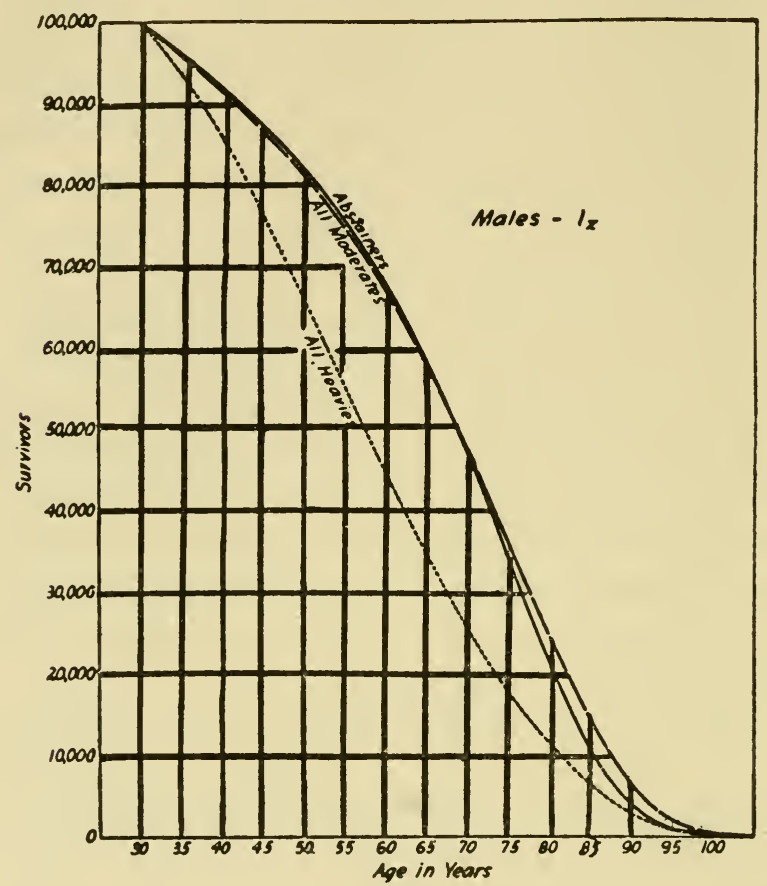

FIG. 11. The number of surviving males out of 100,000 starting together at age 30, in three drinking categories: (a) abstainers (solid line), (b) moderate drinkers (dash line), and (c) heavy drinkers (dot line)

though not so violent as that over alcohol. It is the intention to present now a small part of the results of a statistical investigation of this problem. The data were collected at first hand. Their accuracy as to the relative degree of habitual usage of tobacco, and as to the ages of the living at risk, and of the dead at death can be guaranteed. The figures to be presented deal only with white males, and with the usage of tobacco by smoking. 
The material falls into three categories, as follows: non-users of tobacco, of whom there were 2094; moderate smokers, of whom there were 2814; and heavy smokers, of whom there

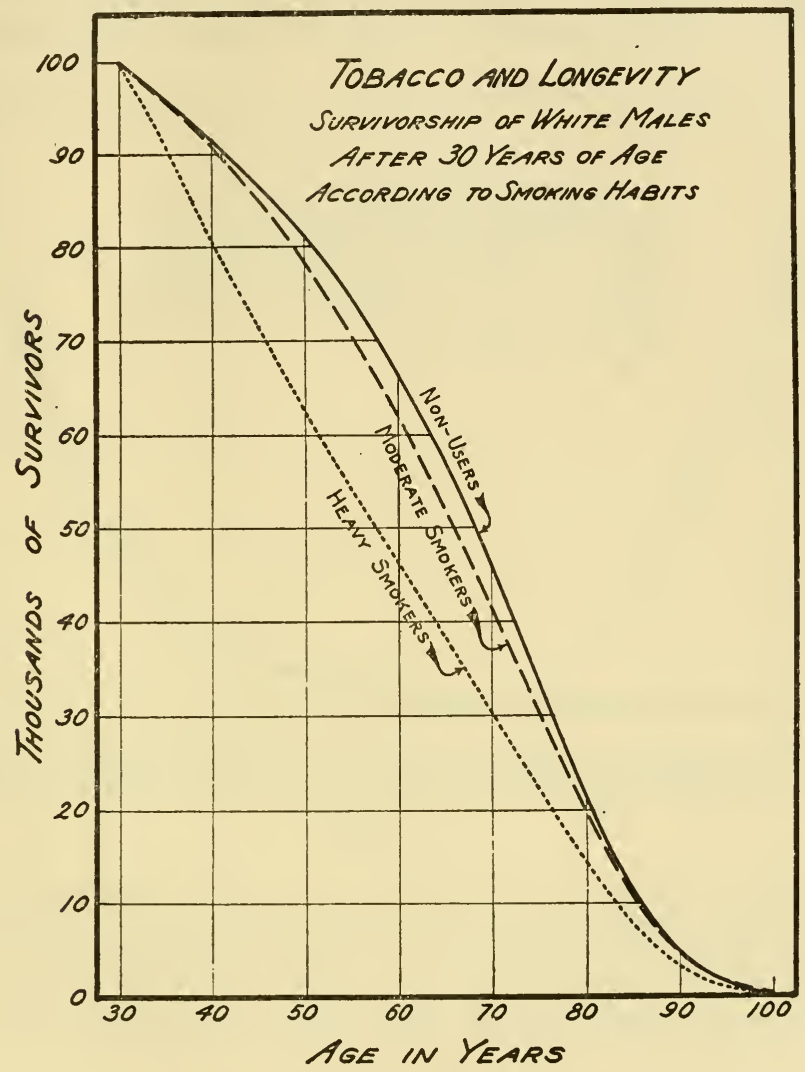

FIG. 12. The survivorship lines of life tables for white males falling into three categories relative to the usage of tobacco. A. Non-users (solid line); B. Moderate smokers (dash line); C. Heaviy smokers (dot line).

were 1905. In other words, the results presented here are based upon the observation of 6813 men in total. Naturally these men were an unselected lot except as to their tobacco habits. That is to say they were taken at random, and then all sorted into categories relative to tobacco usage. For each of the three cate- 
gories of tobacco usage complete life tables from age thirty on to the end of the life span have been constructed. Figure 12 shows the survivorship lines.

The net result is obvious. In this group of nearly 7000 men the smoking of tobacco was associated definitely with an impair-

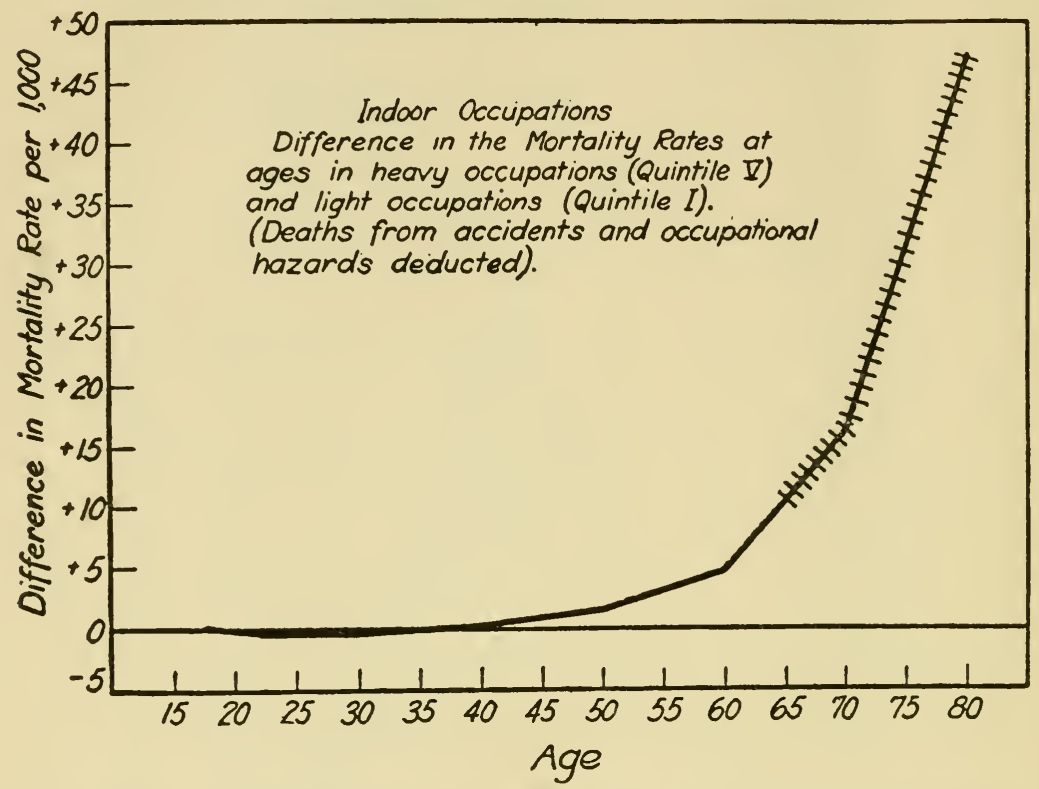

FIG. 13. Difference between (a) indoor occupations involving the greatest amount of physical exertion (quintile V) and (b) indoor occupations involving the least amount of physical exertion (quintile I), in respect of age specific mortality rates. The line is crossed from age 65 on to indicate that its true position is uncertain at advanced ages, because of the meagerness of the data available.

ment of life duration, and the amount or degree of this impairment increased as the habitual amount of smoking increased. The contrast between the life tables relative to the implied effects upon longevity of moderate smoking, on the one hand, and the moderate use of alcoholic beverages, on the other hand, is very striking. The moderate smokers are definitely shorter lived than the total abstainers from tobacco; the moderate drinkers are not significantly worse or better off in respect of lon- 
gevity than the total abstainers from alcohol. Heavy indulgence in either tobacco or alcohol is associated with a very poor life table, but the life table for heavy smokers is definitely worse than that for heavy drinkers up to about age sixty. Thereafter to the end of the life span the heavy smokers do a relatively

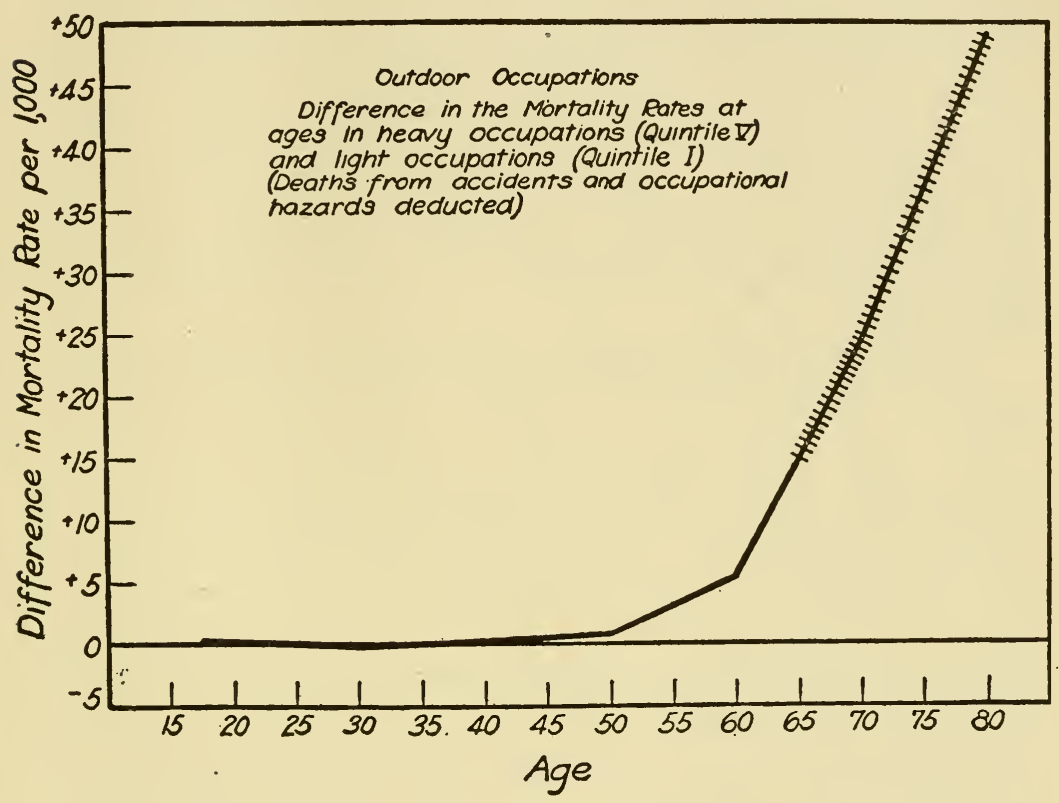

Fig. 14. Same as Fig. 13, except that it deals with outdoor occupations

better job of surviving than the heavy drinkers. But neither group has anything to boast about in the matter of longevity.

The third environmental problem to be discussed may be put in this way: Is hard physical labor associated with a shortened life? The answer to this question for indoor occupations is shown graphically in Figure 13.

The results indicate that there is a direct and definite correlation between the magnitude of the age specific death rates from age forty to forty-five on, and the average expenditure of physical energy in occupation, after accidental deaths and deaths directly resulting from the hazards of each of the several occu- 
pations have been deducted. This relation is of the sort that associates high mortality with hard physical labor. The relationship prevails whether the labor is performed chiefly indoors or chiefly outdoors, Figure 14.

It is not primarily to be attributed to the general environmental factors connoted by social class distinctions, which are themselves correlated with average energy expenditure in occupation. Before age forty is attained, it makes no difference in the rate of mortality whether the occupation involves light or heavy physical labor. After roughly age forty to forty-five it appears that the average duration of human life is shortened, by definite amounts, in proportion as physically heavy labor is performed.

The literature of longevity is full of advice, recipes, and precepts for the attainment of long life. These precepts touch upon nearly every conceivable aspect of personal physiology and hygiene. Yet it is an odd fact that careful study of our collection of life records of nonagenarians and centenarians leads, as one of the broadest generalizations it is possible to make from them, to the conclusion that these 2000 and more persons exhibited substantially the same range and degree of variation relative to these various items of personal hygiene as is found amongst people in general. Some were light eaters, others on the gluttonous side; some used tobacco, others didn't; some drank heavily, others moderately, while still others were teetotalers; some slept a lot, others didn't; some had been in robust health all their lives, others had been ailing a great part of the time; and so on. In only one outstanding respect besides great longevity did the group markedly differ from the generality of mankind, on the whole. That is in the fact that a vast majority of these extremely longevous folk were of a placid temperament, not given to worry. They had taken life at an even, unhurried pace. In this respect this human material agrees with and confirms a generalization that has emerged from experimental studies on life duration. It is that the length of life is generally in inverse proportion to the rate of living. The more 
rapid the pace of living is, the shorter the time that life endures. This relationship has been shown to exist for a variety of forms, including plants, various lower animals, insects, and men. It is a relation that is obviously in some degree within the power of individual, personal control.

The study of longevity is not ended. In the view of the biologist it has only just got well under way. A great deal more will be learned, and just possibly we may find out how to lengthen significantly and at will the span of human life, instead of merely increasing its average duration. But if and when this happens there will immediately become evident some of the difficulties inherent in another set of problems of social biology, different in kind from those of longevity per se. Let us now give some consideration to these other problems.

\section{VI}

Up to this point the discussion has been of the total duration of life of man considered as a whole. But in actual fact the life span of man from birth to death falls into three natural biological divisions. The fact itself that there is such a natural division, and the nature of the parts themselves into which the total span divides itself, are phenomena of great significance, and particularly so in relation to their social consequences, both superficial and fundamental. These three divisions of the life span may be conveniently and justly labelled as (I) the infantile pre-reproductive period, extending from birth up to fifteen years of age, as a round figure; (II) the reproductive period, extending from fifteen years up to about fifty years; and (III) the senescent post-reproductive period, extending from about 50 years to the end of the life span. The first two of these periods are obviously of first-rate importance in the business of human living, philosophically viewed. For if the vital fires are to be kept perpetually alight the young must be nurtured until they are ready to reproduce. Also the reproducers must keep busy about their breeding as long as they retain the capacity, if the continuance of the race is to be safely assured. 
Persistent living during these two periods has not only biological justification but is absolutely imperative in a statistical sense. For the third period there is no evident biological justification. The preservation in life of individuals who have passed the reproductive period is a biological and social luxury that we encourage only because civilized man is the kind of animal that likes this particular form of vital extravagance. Among lower animals and primitive men the existence of a postreproductive period of life is only, and strictly, on a permissive basis rather than one of solicitous promotion as with us. Biologically life after reproduction is ended is only the expression of a sort of vital momentum. The machinery of living having got well going in infancy and maturity it keeps on by sheer momentum for various lengths of time after any valid biological reasons for its continuance have ceased to operate.

The relative or percentage distribution of the life span of present-day civilized man between these three portions is, in round figures, about as follows: roughly 21 per cent of the whole span is spent in the infantile period as here defined, 53 per cent in the reproductive period, and 26 per cent in the postreproductive period. At first glance more than a quarter of the whole of life seems to be an excessively long portion to be spent in the running down of the machinery after the main business of life is finished. It is, however, in no way exceptional or peculiar to the human species. As an example, we have been able to show by life table analysis that a moth, the pecan nut case bearer Acrobasis caryae Grote, spends about 23 per cent of its total adult life span in the post-reproductive period. And this is a form whose total adult life span from emergence to death is only from six to eight days long. But even with so short an absolute sojourn for Acrobasis, it and civilized man both agree in taking about the same proportionate time to make their exits from their respective nutty worlds after they have finished biologically justifying their existences.

But the social implications and consequences of the threefold partition of the life span are very different in Acrobasis and man. What makes them so widely different is because man's 
capabilities and attitudes about the problem of getting a living are different from those of any other animal, as we have seen in the preceding lecture. In man's case the pre-reproductive period of life is one of true infancy, in the important sense that practically no children below the age of fifteen are or can be completely self-supporting by their own unaided efforts. Somebody else has to get their livings for them. It does not matter in its general social import whether the parents do this directly and in each instance, or whether the burden is taken over by government and distributed over the whole social body. In either case it is somebody other than the infants themselves that gets their livings for them. And it is interesting to note that in this country there is a strong and widespread body of opinion that regards itself as enlightened, progressive, and humanitarian in contending that the span of human infancy should be prolonged by law beyond its natural limits. There is a proposed amendment to the Constitution now pending, the consideration of which is still kept alive only by a species of political chicanery. This amendment asserts in principle that children up to the age of eighteen, when in the natural course of events many of them would already be married and breeding, shall be legally forbidden to take any part whatsoever in the provision of their own livings. The difficulties that have been encountered in enacting this philosophy into law indicate clearly enough that many people take a dubious view of it. It will not help, however, to call these people who are doubtful of its wisdom bad names, or to infer that they are not quite as well aware as anyone else of the evils and horrors of sweated child labor. They are. Their first and frankest scepticism is over a quite different point, namely as to whether prohibition is the wisest way to set about solving social problems, or indeed whether it is a wise way at all. They further doubt whether conditioning the child for eighteen years to the notion that it has no responsibilities whatever for getting its own living is likely to be the best preparation for meeting the sad but unescapable fact of life that eventually it must get its own living.

The case is similar in principle for the group that finds itself 
in the third or senescent period of the life span. A large proportion of persons over fifty years of age are also not capable, alone and unaided, of getting their livings by their own efforts at those ages. They either cannot get jobs, or their vital momentum has so decreased as a result of previous illnesses, accidents, or the natural processes of physical and mental decay that they could not hold jobs if they had them. In short their efforts do not achieve the subsistence level. The cynic may jibe as much as he likes at the findings of the recent National Health Survey (Prelim. Repts., Sickness and Medical Care Ser., Bull. 7, 1938), that the unemployed workers showed proportionally twice as much disablement by illness as the employed workers; and that the ratio was still higher as between unemployables and employed; and as between older and younger groups in the respective classes. Any sensible person knows that even partial breakdown and wearing out of the bodily machinery is bound to be a major variable in the determination not alone of employability but also of intrinsic capability to get a living any time or anywhere.

The social and biological fact of overwhelming importance is that the portion of the population falling in the reproductive period, between the ages of fifteen and fifty, has to support a great part of the rest of the population, the infants and the old, as well as themselves. This burden includes both direct expenditure at the time, that is while they are under fifty, and also savings for their own old age, when they can no longer work. And it must not be forgotten that intrinsically it makes no essential difference whether the assumption of this burden is directly and immediately segregated within the biological family of parents, children, and grandparents, or is spread over the whole social organization through the machinery of "social security" so-called, or old age pension systems, or other similar devices. It still remains the workers in the fifteen to fifty age group that have got to carry the load, by and large, because they are the only ones that produce the wealth that must pay the cost of all the livings. This extraordinary overlapping of 
generations characterizes human populations to an extent perhaps not equalled in any other living form. It is a factor of profound importance in population biology. This tremendous burden is borne by mankind for reasons in large part emotional. We (in a statistical sense) care for our parents beyond the time limits of biological necessity in good part only because we want to. But for this emotional satisfaction we pay a high price.

In these facts is to be found unquestionably one of the basic reasons for the practice of contraception or birth control in countries having what we are pleased to regard as a "high" state of civilization. As the burden becomes more and more clearly recognized the natural tendency is to attempt to reduce it by limiting the number of children, since the emotional conflict over the care of unborn babies versus provision for our own old age and that of our parents is the easiest one to resolve out of the whole assortment presented to us. But the optimism thus engendered is in some degree illusory, because what happens is merely that the distribution of the burden is altered, not its total drag. For it turns out that the proportionate number of persons falling in the middle portion of the life span-the workers-is nearly the same in all populations of the world today. The proportion of the infants and of the old vary widely from country to country. But the proportion of the workers stays relatively constant at approximately 50 per cent.

A tabulation demonstrating this point for the populations of fifty countries, as they existed at an average date of about the middle of the year 1929, is too long to be shown in full here, but Table 2 gives a condensation of this table down to workable limits.

While this condensed table is not as impressive as the complete one, it serves to show clearly that no matter how the workers' burden is shifted between the young and the old its total remains about constant, as does the proportionate number of workers who must bear it. Thus whether the numbers in the infantile period of life are high and those in the senescent period are low, as in the populations of Brazil and India, or whether 
TABLE 2

Sex and Age Distributions of Certain Human Populations

\begin{tabular}{|c|c|c|c|c|c|c|c|c|c|}
\hline \multirow{3}{*}{ Country } & \multicolumn{3}{|c|}{$\begin{array}{l}\text { Sex ratio }=\text { Females } \\
\text { per } 100 \text { males }\end{array}$} & \multicolumn{6}{|c|}{$\begin{array}{l}\text { Proportion in total population of } \\
\text { indicated sex (percent) }\end{array}$} \\
\hline & \multirow{2}{*}{$\begin{array}{l}\text { Age } \\
0-14\end{array}$} & \multirow{2}{*}{$\begin{array}{c}\text { Age } \\
15-49\end{array}$} & \multirow{2}{*}{$\begin{array}{l}\text { Age } \\
50 \\
\text { and } \\
\text { over }\end{array}$} & \multicolumn{2}{|c|}{ Age $0-14$} & \multicolumn{2}{|c|}{ Age $15-49$} & \multicolumn{2}{|c|}{$\begin{array}{l}\text { Age } 50 \\
\text { and over }\end{array}$} \\
\hline & & & & Male & $\begin{array}{l}\mathrm{Fe}- \\
\text { male }\end{array}$ & Male & $\begin{array}{l}\mathrm{Fe}- \\
\text { male }\end{array}$ & Male & $\begin{array}{l}\mathrm{Fe}- \\
\text { male }\end{array}$ \\
\hline Belgium & 98.9 & 1 & 102.2 & 25.5 & 24.5 & 55.4 & 54.7 & 19.1 & 20. \\
\hline Samoa & 84.5 & 93.9 & 94.7 & 38.9 & 39.3 & 54.7 & 54.3 & 6.4 & 6.4 \\
\hline Switzerland & 98.6 & 108.1 & 119.7 & 29.1 & 26.7 & 53.3 & 53.7 & 17.6 & 19. \\
\hline Germany ${ }^{2}$. . & 98.4 & 114.7 & 115.3 & 30.1 & 27.0 & 52.7 & 55.0 & 17.2 & 18.0 \\
\hline United State & & & & & & & & & \\
\hline (Cor & 98.0 & 96.6 & 91.0 & 31.6 & 32.1 & 52.6 & 53.0 & 15.8 & 14.9 \\
\hline England and Wales & 98.7 & 113.3 & 116.5 & 29.3 & 26.3 & 52.3 & 54.1 & 18.4 & 19.6 \\
\hline Czechoslovakia... & 98.6 & 109.6 & 116.0 & 30.6 & 28.1 & 52.0 & 53.1 & 17.4 & 18.8 \\
\hline Union of South Af- & & & & & & & & & \\
\hline frica $(\mathrm{Na}$ & 98.6 & 95.2 & 150.9 & 41.5 & 42.0 & 52.0 & 48.0 & 6.5 & 10.0 \\
\hline Finland ........ & 96.9 & 101.7 & 118.1 & 32.6 & 30.8 & 51.7 & 51.2 & 15.7 & 18.0 \\
\hline $\begin{array}{l}\text { Australian Con- } \\
\text { federation }{ }^{3} . . .\end{array}$ & 97.1 & & & 31.6 & & 51.5 & 52.8 & 16.9 & 15. \\
\hline France. & 107.1 & 112.8 & 116.4 & 24.0 & 21.6 & 51.5 & 52.6 & 24.5 & 25.8 \\
\hline Canada ${ }^{4}$. & 119.4 & 92.4 & 90.1 & 33.7 & 35.2 & 51.2 & 50.3 & 15.1 & 14.5 \\
\hline Hung & 99.0 & 111.7 & 103.3 & 31.8 & 29.6 & 50.5 & 53.2 & 17.7 & 17.2 \\
\hline Greenland ${ }^{5}$. & 102.3 & 109.3 & 147.3 & 42.2 & 39.5 & 50.5 & 50.7 & 7.3 & 9.8 \\
\hline Holland & 97.1 & 102.1 & 107.5 & 33.3 & 31.9 & 50.2 & 50.7 & 16.5 & 17.3 \\
\hline Uniono & & & & & & & & & \\
\hline & 97.4 & 95.2 & 82.2 & 36.7 & 37.9 & 50.2 & 50.7 & 13.1 & 11 \\
\hline Denm & 98.5 & 106.4 & 115.2 & 32.2 & 2 & 50.2 & 50.6 & 17.6 & 19.2 \\
\hline Sweden. & 96.0 & 102.1 & 120.0 & 30.5 & 28.3 & 50.1 & 49.3 & 19.4 & 22.4 \\
\hline $\mathrm{Gu}$ & 96.2 & 108.1 & 142.3 & 45.0 & 41.3 & 49.8 & 51.6 & 5.2 & 7.1 \\
\hline British India. & 93.9 & 81.9 & 97.2 & 39.2 & 41.6 & 49.6 & 46.0 & 19.2 & 12.4 \\
\hline Lithuania ${ }^{7}$ & 98.6 & 116.3 & 111.4 & 32.6 & 29.2 & 49.3 & 52.5 & 18.1 & 18.3 \\
\hline Japan & 97.7 & 96.2 & 104.2 & 35.1 & 35.0 & 49.0 & 48.1 & 15.9 & 16.9 \\
\hline Portugal. & 96.7 & 115.8 & 129.0 & 35.2 & 30.6 & 48.6 & 50.6 & 16.2 & 18.8 \\
\hline Spain. & 99.1 & 109.3 & 112.7 & 35.6 & 33.3 & 48.5 & 49.8 & 15.9 & 16.9 \\
\hline Ireland. . & 95.2 & 103.2 & 131.0 & 34.8 & 31.6 & 48.5 & 47.5 & 16.7 & 20.9 \\
\hline Brazil... & 97.2 & 99.9 & 97.0 & 43.0 & 42.5 & 48.2 & 48.8 & 8.8 & 8.7 \\
\hline Colombia. & 99.5 & 113.7 & 119.9 & 41.8 & 39.4 & 47.6 & 49.9 & 10.6 & 10.7 \\
\hline Bulgaria... & 95.4 & 105.5 & 95.8 & 37.2 & 35.4 & 47.1 & 49.6 & 15.7 & 15.0 \\
\hline Russia (in Europe) & 101.3 & 147.0 & 121.2 & 45.2 & 37.4 & 39.6 & 47.6 & 15.2 & 15.0 \\
\hline
\end{tabular}

1 Excluding Eupen and Malmedy.

2 Excluding the Saar region and Eupen and Malmedy, but including Schleswig Holstein.

Excluding the native population.

4 Including Eskimos and Indians.

s Native population only.

${ }^{6}$ Excluding the Faroe Islands.

${ }^{7}$ Excluding Melme. 
the reverse situation obtains as in the populations of France and Sweden, the number of workers still remains constant at about 50 per cent, and so does the total load they have to carry. As we go down the table it is seen that as the first column of figures - the percentage in the population of persons in the prereproductive period-decreases, the figures in the last column increase-the percentages in the post-reproductive period.

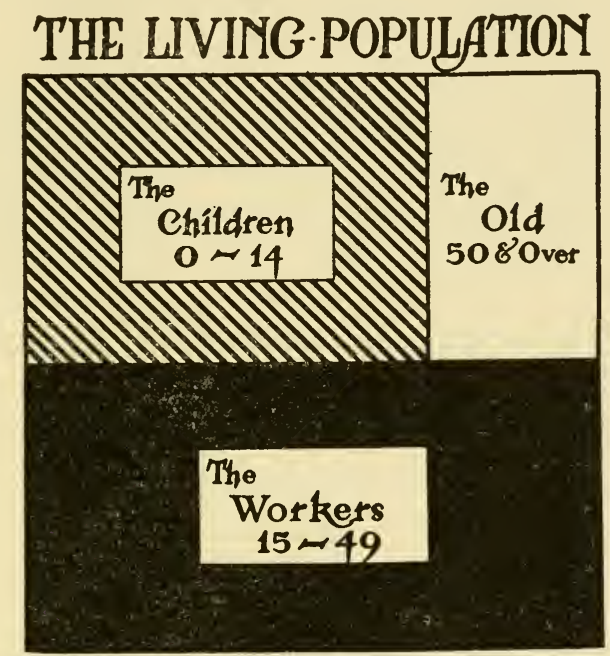

FIG. 15. Approximate average distribution of living human population. Frequencies are depicted as areas.

The situation may be graphically generalized in the manner shown in Figure 15.

The bottom half of the square, representing half the population, supports the upper half, which may be divided variously between the children and the old, but always still remains about a half of the total population.

On the basis of this natural biological classification of the age distribution Sundbärg distinguishes three types of population, the progressive type, the stationary type, and the regressive type. His definitions of these types are that, on a percentage 
basis, in all types 50 per cent of the total falls in our worker group aged 15 to 49 inclusive, while in the progressive type of population the percentages of infants and senescents are respectively 40 and 10 ; in the stationary type 33 and 17 ; and in the regressive type 20 and 30 . These are, of course, arbitrary figures but in a general way do correspond with reality. From the point of view of population growth Brazil, India, and the Argentine are in the progressive state, while England, France and Sweden are in the regressive state.

We must stop at this point, but perhaps enough has been said to make it plain that man's life span, and its prolonged periods of infancy and senescence, are of great potential importance in connection with his sociality, and human biology generally. 


\section{Lecture $I V$ -}

\section{THE NUMBERS OF MEN}

IN THE lectures that have preceded this we have examined some of the more important respects in which man the animal is uniquely different from all other animals. In this survey very little was said about one of the most important of man's biological characteristics that he shares not only with other animals but with all other living things, namely the capacity and urge to reproduce. This urge is a powerful one-nearly the most powerful known in the whole realm of biology. And its consequences to humanity are far-reaching. They lie at the root of our most serious and baffling social problems and troubles today. All over the world a great deal of emotion is being spent and thought exercised over such matters as poverty, unemployment, social unrest, war, and human misery generally. Not only governments but also ways of living generally are almost everywhere being radically altered in the pathetic hope that we shall by this process suddenly emerge into a new and better world. Yet ever since man has existed there surely has been poverty (because men have always had unequal talents and luck in acquiring goods); there has been unemployment (because men have been unequally endowed in respect of laziness and capacity); there has been social unrest (because the zest for trouble-making was never exactly equally distributed among men - if it had been the uniform dose to each individual would have been too small to produce any physiological effect); there have been wars (because man is by nature a fighting animal); and there has always been misery (because talent for being 
miserable is a peculiarly human trait). But the great point is that while all these dreadful things have always existed, serious concern and excitement about them has, on the whole, grown just in proportion as the numbers of men-the sizes of populations-have increased. So then we shall devote this lecture to some consideration of the numbers of men-human populations as they exist today, how they got that way, and the implications they may have for human biology generally.

A recent analysis (Pearl, The Natural History of Population, 1938), has led to certain broad results and principles that seem to throw light on the general biology of population considered dynamically. Perhaps we may start with a brief statement of these results. In the nature of the case the statement will have to be categorical, because there is not time to present the detailed evidence. I regret that this is so. But I think the material painstakingly gathered together may fairly be said to have made the following general relations clear.

1. The major problems of population are primarily and fundamentally biological in nature, because the size and other characteristics of populations rest upon the operation of the basic biological principles of individual survival, reproduction, variability, and their mutual interactions and integrations with the environment.

2. The state of any particular population at any particular moment depends primarily upon and is determined by the manner in which the specific biological elements that influence fertility have been, and are, acting, in the direction either of its promotion or its restriction.

3. There is great variation among individuals and groups in the biological elements that influence fertility, such as frequency of coitus in wedlock, age at menarche and at menopause, and other similar physiological and behavioral matters.

4. The basic biological pattern of human reproductivity is inherently and intrinsically different in a number of important respects from that of other mammals and animals lower in the evolutionary scale, and has been rendered still more widely divergent by artificial alterations that man has consciously and 
deliberately made in his own intrinsic pattern of reproductivity, particularly through such things as the practice of contraception, postponement of marriage until long after puberty, and other factors of a comparable sort.

5. In the population of the United States, at least, differential fertility relative to race (Negro versus white) and to the three most important social class differentiations (economic, educational and religious) are due primarily to differences in the relative prevalence and effectiveness of the efforts made to prevent conception, correlatively aided by relative frequency and postponement of marriage, and the practice of criminal abortion, and to practically nothing else.

6. But in this same United States population it appears in high degree probable that the general level of fertility, and particularly the steady decline of total fertility that is now going on and has been in the recent past, both in the population as a whole and in differentiated classes within it, cannot be justly regarded as due solely, or possibly even primarily, to the operation of the forces that have just been enumerated. Other, and more obscure factors are involved, about which literally almost nothing of a precise and definite character is now known.

While the evidence that has been offered here in support of the six general points that have been enumerated has come largely from one population only, that of the United States, it seems plain that the same principles and forces are operating in all populations, in widely different and varying degrees and extents, to be sure, but always and everywhere in some degree. If this be granted, as seems reasonable, it then follows that in the population of the world as a whole we are presented with the objective record, at any particular time, of the net integrated effect of the operation of all these complexly interrelated factors and forces that have been enumerated. So then let us now turn to an examination of the population of the world.

\section{II}

It should be emphasized that it is as impossible now as it has always been in the past, and will be for a long time in the future, 
to know exactly how many human beings are or were living on the face of the earth at any stated moment. The primary difficulty arises from the fact that the process of census counting has never included all the people or areas of the globe; and a secondary one from the fact that in different countries censuses are taken on different dates and with widely differing degrees of accuracy. But the situation grows steadily more encouraging. At the present time it can be said that something of the order of 75 per cent of the present population of the world is either regularly counted in recurring censuses, or has been counted at some time in the past, or at least an attempt has been made at a count. Of the wholly uncounted residue, for which there have never been many figures except estimates as a base, China constitutes by far the major portion. According to what seems to be the most reliable estimate, China's population at the present time constitutes something of the order of 22 per cent of the world total. When China takes a real census, if she ever does, the study of world population will then rest upon a basis of sufficient statistical security to justify a very substantial degree of confidence in results and inferences.

It is the practice of our laboratory to make from time to time revisions of the figures for world population. The plan used is to assemble separately on work sheets the latest available data regarding population, area, and time (date of count or estimate) for each of the smallest areal and political divisions of the earth for which data are available, and then combine them into larger divisions by summation, checking the figures at each stage in every way possible.

The data of three recent revisions are given in Table 3.

The steady decline in the area figures between the successive revisions appears at first glance completely paradoxical, not to say verging slightly on the idiotic. The earth's surface is plainly not shrinking at any such rate. The land area of the globe apparently shrivelled, according to this table some 717,212 square miles between average dates of 1930.1 and 1934.7. All that this means is that two things have happened. The first is 
that more accurate surveys of outlying parts of the world are being made available each year. These have led in recent years to official revisions of area particularly in French West Africa, Venezuela, Iraq, Nicaragua, Tanganyika, and Southwest Africa. The results of these surveys, as they become available, we incorporate in our revisions. In the second place we are increasingly able to make corrective deductions for the areas included in inland waters (lakes, broad rivers, etc.), which formerly were counted as land area.

TABLE 3

World Population

\begin{tabular}{|c|c|c|c|}
\hline . & $\begin{array}{l}1934 \\
\text { revision }\end{array}$ & $\begin{array}{l}1935 \\
\text { revision }\end{array}$ & $\begin{array}{l}1937 \\
\text { revision }\end{array}$ \\
\hline Area (sq. miles). & $52,139,677$ & $51,742,763$ & $51,422,465$ \\
\hline Total population (in millions). & $2,050.4$ & $2,073.3$ & $2,104.8$ \\
\hline Density (persons per sq. mile). & 39.3 & 40.1 & 40.9 \\
\hline Mean date to which figures apply.. & 1930.1 & 1931.5 & 1934.7 \\
\hline
\end{tabular}

Our figure for total world population of 2,104.8 millions is a little greater than the latest League of Nations figure, which is 2,095.0 millions. But obviously the two world estimates are in substantial agreement, the difference being less than one-half of one per cent of the mean of the two estimates.

The mean density of world population between 1930 and 1935 appears to have been almost exactly identical with that of continental United States at the 1930 census-about 41 persons on the average for each 640 acres of the earth's land surface.

The apparent mean annual growth rate per cent of the world population between the mean dates 1930.1 and 1934.7 is 0.58 per cent; that is six-tenths of a person added in each year net to the living population for each hundred living at the beginning of the year.

It is, however, uncertain as to how much significance should be attached to these apparent growth rates, because of the fact that they include at all stages purely estimated population 
figures, as well as counts and legitimate short intercensal extrapolations from counts. If we deal only with those countries (or other political subdivisions) for each of which there are available data from which a separate individual growth rate can be computed-134 "items" at the 1934 revision, 140 "items" at the 1935 revision, and 158 "items" at the 1937 revision, each

TABLE 4

Recent world population growth-rates for those countries only for which the necessary data are separately available

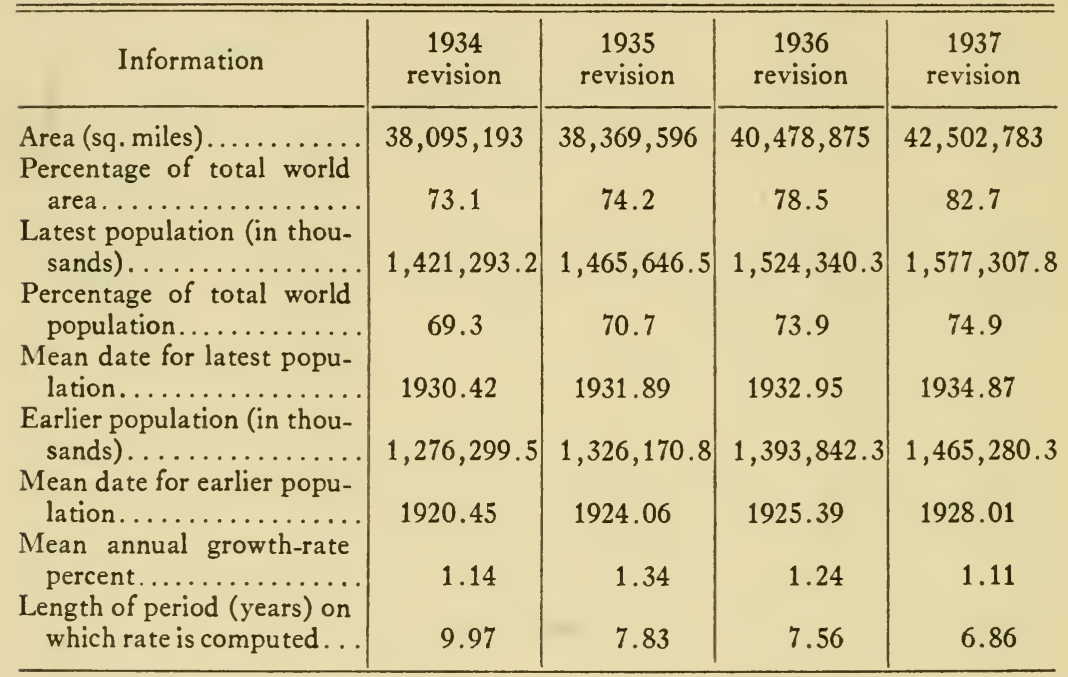

"item" being a country or political subdivision-the results shown in Table 4 are obtained.

It is evident from the second and fourth lines of this table that the areas and populations included here are substantial percentages of the world totals. Furthermore the figures include none of the very doubtful data (particularly those for China) necessarily embodied in the earlier table. On these two grounds of large proportionate size of sample and relatively greater reliability of the data it is reasonably to be expected that the growth rates of the table before you probably represent more 
accurately the general situation than the apparent rates derived from the figures of estimated total world population.

In the light of the data presented it may be tentatively suggested that the population of the world as a whole has been growing in the recent past at a rate of something of the order of one per cent per annum-perhaps a little more, perhaps a little less, but at about that figure. This would mean, if continued without change, a doubling of the present world population in about seventy years. There is, however, no reason to suppose that the total population of the world will ever, in its present cycle of growth, at least, be double what it is at the present time.

It seems reasonable to conclude from a great body of available data that the mean annual growth rate per cent for the world population is steadily decreasing at the present time, and has been during the recent past. In other words there is a general decline of fertility that appears not to be exclusively confined to highly "civilized" countries, where the populations are most sophisticated and eager and adept at birth-controlling. It seems rather to be a world embracing phenomenon-something affecting man as a species. But, as will appear clearly in a moment, it is a phenomenon of historically very recent appearance, in comparison with man's total span of existence on the earth as a distinct species. The world-wide decline in fertility is certainly a much more recent thing than the making of efforts at contraception. On the evidence it appears likely that the marked slowing up of the growth rate of world population per unit of time did not begin until about the beginning of the present century, or in the preceding decade. But nearly two centuries ago Short, in his entertaining treatise on the population of England-perhaps history's most venomous diatribe against the establishment of hospitals and homes for foundlings, usually considered an innocent form of altruistic behavior-has repeated references to the prevalence of contraceptive practices. As an example he deplores the fact that in "Cities and great Towns . . . the wicked Arts of preventing Conception are more generally known 
and used" than in rural habitats. These examples sufficiently indicate that long before the world population began to slow down in its growth rate, enough contraceptive effort was being made in the western world, at least, to worry some students of the matter.

\section{III}

In 1924 I published a logistic curve fitted to the data assembled by Knibbs to indicate the growth of population of the world, from the estimate of Riccioli in 1660 up to and including that of Knibbs himself as of 1914.

It became apparent some time ago that this original world logistic needed revision badly, because by 1930 the population of the world had already exceeded the upper limit set by the curve. Consequently we have recently brought the old curve up to date, adding five more estimates of world population since 1914, the latest being our own of mean date 1931.5. The new logistic curve is shown in Figure 16.

As might reasonably be expected, the estimates of world population have been strewn irregularly about a trend line that may perhaps be fairly regarded, taking all the circumstances into account, as reasonably represented by the logistic curve. The nature of figures that have to be used in lieu of "observations," which even at the present date represent only about 75 per cent of complete actual observation, precludes the possibility of ever getting anything like a really smooth fit with a four-constant curve. But taking the material for what it is, with all its inherent disabilities, a number of interesting points are presented for discussion.

In the first place the upper limit of the current cycle of growth is raised by about 31 per cent of the former figure, to a new value of 2645.5 millions. According to the curve this colossal total will be closely approached around 2100 A.D., provided nothing happens in the meantime to alter seriously the present trends of reproductivity. No formal prediction is made, however, that this will represent the ultimate size of the world's 
human population. It is only an extrapolation from the available evidence as to what the past history of world population growth has been up to the present time. No other interpretation than this should be put upon it. It is a figure that future events and trends now wholly unpredictable may alter, just as proved to be the case with the former extrapolation.

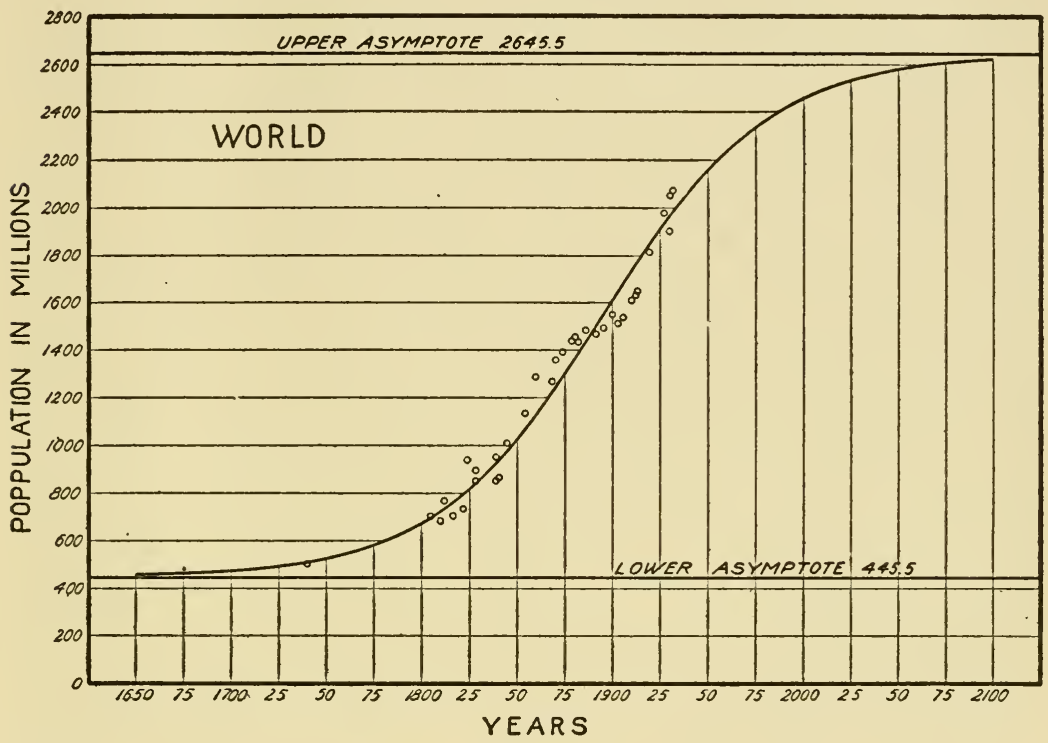

FIG. 16. The population growth of the world from the seventeenth century to 1931-32. The circles give the observations, and the smooth line gives the graph of the logistic equation

The present logistic cycle of world population growth got discernibly under way at about the middle of the seventeenth century-say three hundred years ago in round figures-and started from a lower asymptotic value of about 445 millions. This is, of course, only an estimate, but cannot be far away from what was the actual fact. Indeed all competent students of population agree on a value of about this general magnitude for the time stated. Since then the world's population has increased to about 2105 millions, again in round figures, as of an average date of about 1935. In other words there has been in 
roughly three hundred years a 4.7 -fold multiplication of human beings on the face of the earth, and this present cycle of growth appears to be only about two-thirds completed. A nearly fivefold net multiplication of the population of a species with such relatively poor reproductivity as man displays, in a time period of only about three hundred years, is certainly a noteworthy phenomenon demanding the most serious consideration.

But man, as a distinct and differentiated species, had been on the earth an extremely long time prior to the seventeenth century. Few, if any, anthropologists nowadays question that he had become differentiated and was making flint tools of the pre-Chellan type early in the Quaternary, certainly somewhere in the first inter-glacial period. Nor is it doubted that from at least that time he has continued on the earth in an unbroken succession of generations; through the long second and third inter-glacial periods and the glaciations that separated them. Geologists, anthropologists and archaeologists seem, however, not to have been able, up to very recent times, to agree as to the number of calendar years it took man to climb this long evolutionary ladder. Lately, however, Zeuner has synthesized all the evidence in a masterly way, with results that warrant and appear to be receiving general acceptance, so that it may be hoped that the timing of prehistory may be at last regarded as reasonably settled. He reaches the conclusion that Homo heidelbergensis from the Mauer sands (the oldest find in Central Europe) has a probable date on the absolute time scale of about 500,000 years before 1800 A.D.

So then the following situation is presented for our consideration. In the 500,000 odd years from the time that man got under way as a distinct zoological entity, up to about 1630-50 say, he had certainly increased in numbers in the normal biological way of things. He may be presumed to have multiplied during these years as rapidly, on the whole, as his inherent biological equipment and the circumstances of his natural environment would permit. Yet the total world population in 1630 was only 445 million, with a density of a little over eight persons per square mile as against the present forty-one. 
This being so at least three possible alternative inferences present themselves. The first of these is that the human population of this globe more or less steadily grew for 500,000 years, but at an extremely slow time rate as compared with the growth performance of any but a very few populations now existing. On this hypothesis it may be regarded as probable that growth of world population was not entirely steady and continuous along a smooth curve, logistic or other, but instead was irregular, fluctuating up and down about the ever rising time-trend line.

A second possible alternative is that for a long time-thousands of years-prior to the seventeenth century the population of the world stood stable at between roughly four and five hundred million, or oscillated in waves of relatively small amplitude about some such figure. On such a view this value would represent a relatively stable upper asymptotic level achieved in a cycle of population growth that was consummated long before, and at a relatively early stage of man's evolution.

Finally a third possible alternative is that during some period or periods in this vast span of 500,000 odd years of man's life on the earth the world population was much higher than 445 million, and subsequently lessened, for reasons wholly unknown, to reach that final figure at the time when reasonably reliable population history begins.

Which of these three alternatives is true? No one can say with any authority. But all the relevant evidence seems to indicate that there were as many (or more) human beings living on the face of the earth in 1630 as there ever had been at any prior time since man set up in business for himself. Most particularly. to be counted against the third alternative is the fact that until recent times man's culture was not of the sort to make possible the existence of large populations on the earth. As was pointed out in the preceding lecture hunting, pastoral, and primitive agricultural cultures are not compatible with large total populations, as we know them nowadays, because high densities cannot be supported at these cultural levels or stages.

Similarly the evidence seems definitely to be against the second hypothesis. 


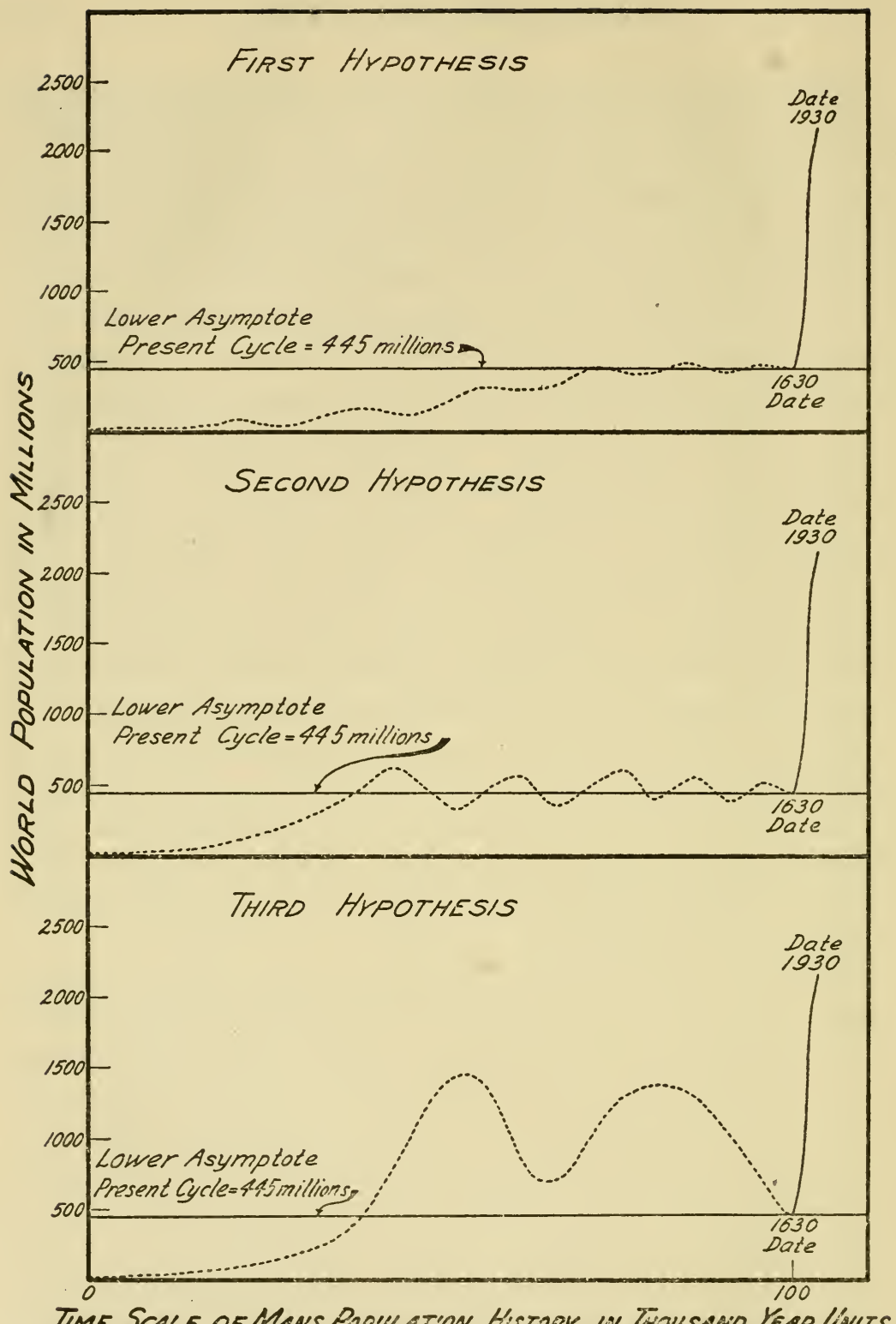

TIME SCALE OF MANS POPULATION HISTOAY IN THOUSAND KEAR linJTS

FIG. 17. Diagram to illustrate alternative hypotheses as to the history of the human population of the earth. The portions of the curve drawn in broken lines are purely hypothetical, except as to the total time scale. The portions of the curves depicted by a continuous solid line (1630-1930) represent the known facts as to world population growth, and are plotted to the same time scale as the earlier portion 
So then we are left with the first alternative, a very slow and irregular time rate of growth of world population over a very long time prior to the Middle Ages, let us say, followed by a relatively tremendous spurt of growth not yet ended.

The implications of the three alternative hypotheses will be made plainer by the diagram shown in Figure 17.

For reasons of practical convenience in drawing and reproduction this diagram is scaled as though the total period of man's life on the earth prior to the 17 th century was a span of 100,000 years instead of the 500,000 that seems undoubtedly much nearer the truth. The diagram understates the case by so much.

How is this sharp spurt of population growth after 1930 to be explained? The primary cause behind the new cycle of logistic growth of world population that started in the seventeenth century seems clearly to have been that mankind first became aware at about that time that its effective universe was expanding. The earth was not growing physically bigger to be sure; there were no new acres of land being really added to the planet. But many were being discovered, uncovered, and put to use, and, in general, man's effective universe for purposes of living certainly was expanding; and at an accelerating rate. This was being brought about by new discoveries and new ideas that made it possible for man to exploit far more effectively than he had known how to before, the natural resources for human living inherent in the earth on which he lived. One of the most important and obvious aspects of the expansive changes in man's effective universe that have appeared in the last three hundred years was the ever increasing facility of communication and transportation, with its consequent broadening of the base and acceleration of the tempo of trade. Indeed it was the development of railroads that had a large part in making the gloomy prophecies of Malthus about the future of mankind at the end of the 18th century seem comically absurd soon after he made them. Another change of similar sort was the development of relatively cheap and highly effective power, associated in the 
first instance with the discovery and rapid improvement of practical steam engines. In generalized terms what expanded man's effective universe, and made possible a great spurt of population growth was scientific discovery and the application of its results, in the broadest sense including exploration as well as technology, to man's basic problem of how best to cope with and exploit his natural environment.

To this day, peoples who because of geographical location, climatic conditions, general stupidity, and other causes, have been unable to participate in any real sense in the consequences of an expanding effective universe, are still growing in population verp slowly, if at all. The conditions of living, and particularly the difficulties of getting a living, in the more primitive stages of culture where the individual wrings his living out of a raw and untempered environment by his own direct efforts, do not permit rapid population growth any more now than they ever did.

\section{IV}

The most obvious direct and objective consequence of the great spurt of world population growth that has occurred in the last 300 odd years is the increase in average density of population that it has entailed. It will be well to examine the facts about this in some detail.

The population of the earth is distributed with great unevenness over its land surface. This is shown in Figure 18.

This table is arranged in order of ascending density classes (persons per square mile). It is based upon 906 separate political or administrative units for which separate data are available as to area and population. By "political unit" is meant either a country, or a state, or a department, or a canton, or a colony, protectorate, or territory, or in a few cases a city having separate administrative status equivalent legally and politically to that of a state. Each such separate political unit was put in its appropriate density class and the areas and populations summed 


\section{LAND AREA 1939 POPULATION}

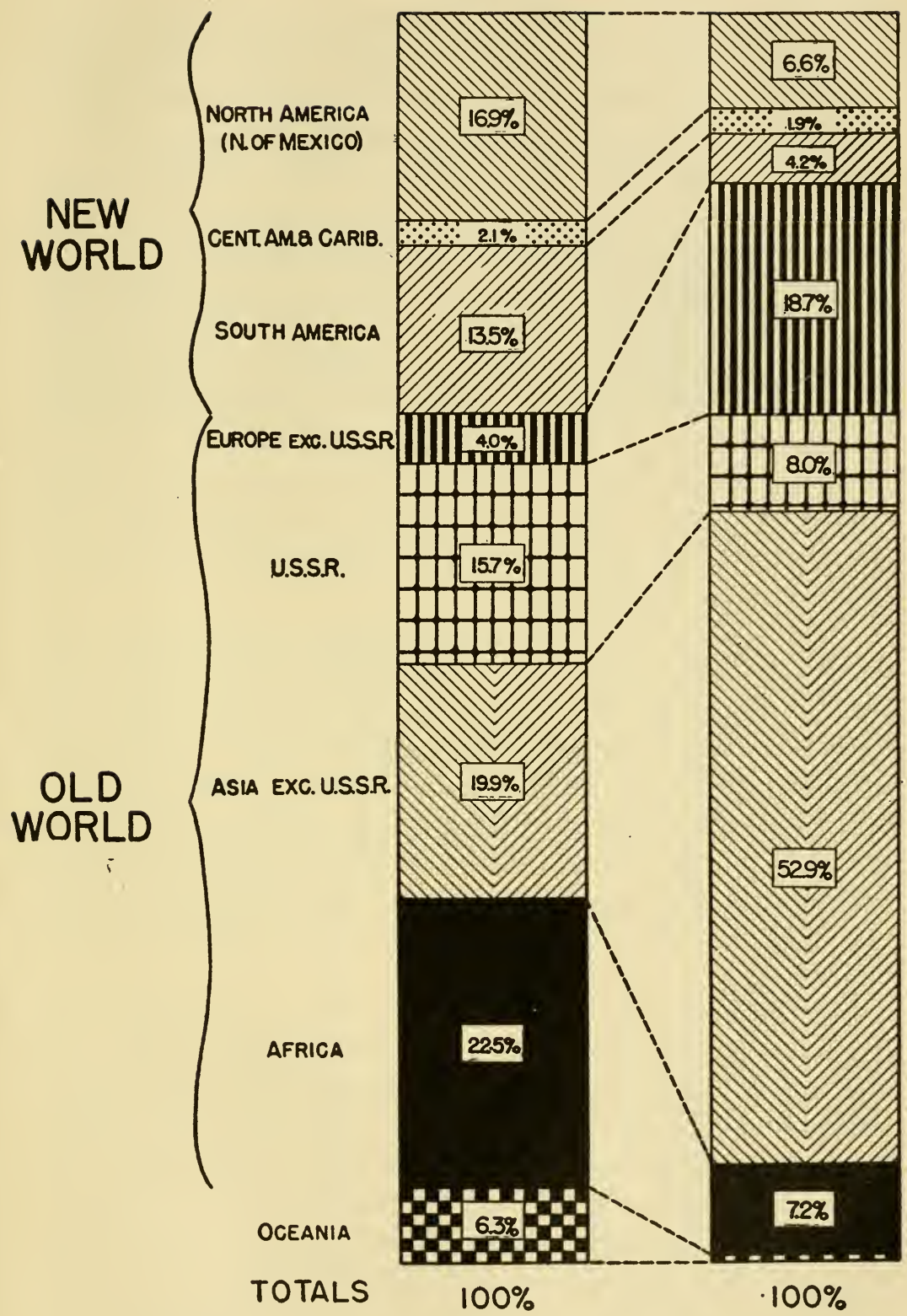

FIG. 18. Percentage distribution of land area and population for the main divisions of the earth, as of approximately the year 1939 
for the class. These absolute figures were then reduced to the percentages shown in the table. Thus the first density class, 0-9 persons per square mile, includes 147 "political units" whose aggregate area is over 29 million square miles. Even the highest density class ( 3100 and over persons per square mile) with only fourteen "political units" has an aggregate area of over 1200 square miles.

The first and most striking general fact that is evident from the table is the extreme skewness of the distribution of population density over the earth's surface. Taking the mean densities of the several classes as a conservative basis for estimating the range of intensity of human crowding upon the earth it is seen that about 36 per cent of the political units cover only 0.3 per cent of the whole range of population densities; and even 77 per cent of the political units cover less than 2 per cent of the total range of densities.

This skewness has come about initially through the selfinterested desire, and eventually the social and economic necessity for large numbers of people to live together in cities. This process of urbanization down through the ages has led to the formation of the great metropolitan centers, or "conurbations" as Fawcett calls them, in which so large a proportion of present day men live out their allotted spans. They represent one of the many quaint ways in which mankind is coming to resemble more and more clearly the termites in modes of life and social philosophy.

The matter may be looked at statistically in other ways that do not involve consideration of the separate political units. Well over a half ( 57 per cent) of the total land area of the earth is occupied by only four and a half per cent of the total population of the world. And about 81 per cent of the earth's total land area contains only $18 \mathrm{I} / 4$ per cent of the world's population. Only a little over 5 per cent of the land area of the earth (densities of 200 and above) contains nearly 53 per cent of its population.

Figure 19 emphasizes graphically certain broad facts of the 
distribution of world population over the land surface of the earth.

The area of the whole square is taken as that of the land area

\section{Total Iand Area of the Earth} AND

Inhabitants per Square Mile

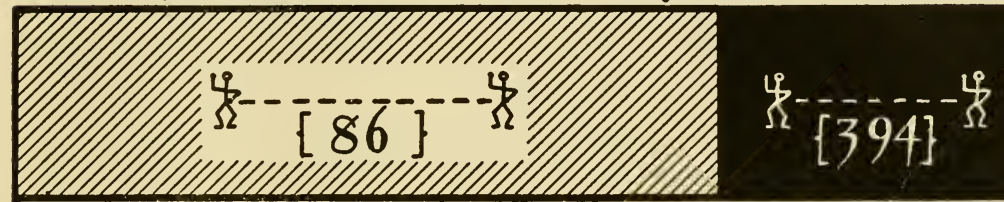

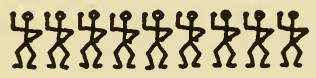 \\ [9]}

FIG. 19. Land area of the earth and population density. For further explanation see text.

of the globe. The lower unshaded rectangle-the "great open spaces" comprising roughly 81 per cent of the whole areahas an average density of population of only about 9 persons per square mile. The cross-hatched rectangle at the upper left 
corner comprises just over 13 per cent of the whole land area, and contains a little over a quarter of the total world population living at the not too unreasonable average degree of crowding of about 86 persons per square mile. Finally, the little black rectangle in the upper right corner comprises only just over 5 per cent of the total land area, but contains over one half of the whole world population. This moiety of poor humanity lives at an average density of 394 persons to the square mile. All told we have in this diagram a picture of the net biological result that human civilization had wrought by its efforts up to the year of grace 1930 .

The average density of world population as a whole is nearly 41 persons per square mile, as we have seen. Yet the populations on over 81 per cent of the total land area are living at densities under 40 . About 14 per cent of the population of the worldroughly one person in seven-is living at densities of 600 or above, that is with one acre or less per person, on an even personal distribution of area. Now as a rough and round figure it is estimated by Brown, a competent and conservative authority, that 2.5 acres are needed to support a human being. Obviously this implies good land, and all of it intensively cultivated. But neglect these latter points for a moment, so as to put the best case possible. If we take the 2.5 acre figure at its face value and with the obviously too optimistic assumption that all land functions at that scale, then in order to get the means of subsistence to something over a half of the world's population today will involve a significant problem of transportation and distribution. Here one of the principal villains of the socioeconomic melodrama enters the scene. It is one of the commonest of assertions that the faults and troubles connected with the "distribution" of goods are chiefly to blame for the world's woes, with the implication that if these faults could be eliminated the world's economic troubles would largely disappear.

But, faults or no faults, the present geographical arrangement of world population makes it plain that without substantial "distribution" of the means of subsistence from the places where 
they are produced to the places where they are used, something over a half of all human beings could not go on living at all. Somebody must haul to these city dwelling near-termites with only two legs, much too large heads, and no exoskeleton, all that they eat, all that they wear, and everything that protects their soft bodies from the rigors of the physical environment. Furthermore this transport must never cease. If it stops for even a short time Death stalks in and starts his reaping, dis-

TABLE 5

Twenty most densely populated countries

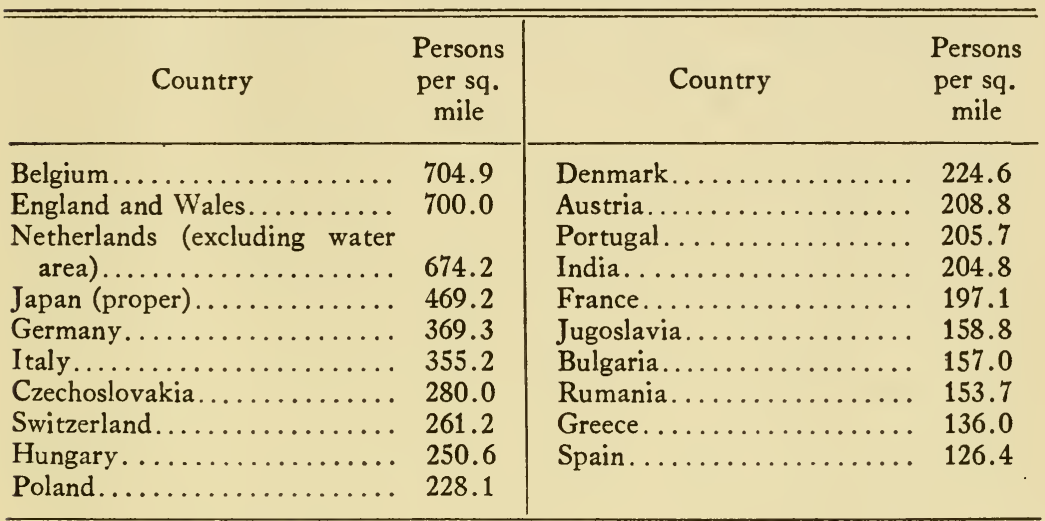

criminatingly mowing first the lush meadows where the lower castes grow, but very quickly getting on to the aristocratic uplands, where the growth is sparser but more choicely flavored.

The next table, Table 5, shows the number of persons per square mile in the twenty most densely populated countries of the world, according to the latest figures (our 1937 revision), leaving out China as doubtful.

This table plainly is about equivalent to a catalogue of the European nations. Only two non-European countries appear in it (Japan and India).

Taking a world view, it is evident that the increase of urbanization has by no means reached its end. On the contrary it is still going on, and, on the whole, at an ever accelerating pace. In a broad sense the most striking thing that has taken 
place in regard to agriculture during the last fifty years, not alone in the United States or Canada or Argentina but in some degree more or less all over the world, is that the progressive development of new knowledge, improved techniques and fuller application of power and machinery have made it possible for fewer human beings to produce more of everything than was formerly the case.

From the point of view of population density an odd sort of paradox results. Social and economic forces and modes of thought that are fundamentally identical-namely, applications of new discoveries, improved machinery, better transport, and communication, to the business of getting a better living-work in opposite directions when applied to agriculture and to the manufacturing type of industry so far as concerns the trend toward human crowding. On the one hand, the movement is toward a still lower density of population in agricultural regions, already the most sparsely peopled portions of the earth's surface capable of supporting any substantial population at all. On the other hand, there is the trend toward an ever higher densitystill greater crowding-in urban industrial centers, already most densely populated. What makes the paradox is that identically the same set of forces, at bottom, is producing these diverse results.

The same principle applies to a considerable extent as between mother countries and their colonies or other dependencies. Densely populated countries with small areas, like those of Europe, and Japan, are highly industrialized and commercialized. They cry for more land so that their people may spread out. But their nationals, by and large, refuse to leave the homeland in any considerable numbers to settle in the fair but sparsely populated regions available to them. Italy, for example, had succeeded up to the time of the World War in placing only about 8,000 of her people in all her African colonies together. Again, the colonial empire that was Germany's on July 1, 1914, had, all told, but a meager 24,000 or so German inhabitants. 
National as well as individual psychology is involved. $\mathrm{Na}$ tions have their pride as well as individuals. As they look about the world they perceive an unequal distribution of the richer lands.

\section{$\mathrm{V}$}

The greatest problem that confronts every single soul that makes one of the units that add up to these colossal human aggregates we have been considering is: "How shall I get a living?" For the science of biology is quite dogmatically sure about one thing. Every living organism must get its living or perish. Life is a dynamic process. It requires a constant flow of energy and matter to keep going.

The logical consequences of this purely natural law are obvious, in a broad sense. Each living organism, including each man, woman, and child, either must get its own living, or an arrangement must be made such that somebody else gets the living for it. We, and a good many other organisms, arrange to get the livings for our babies-embryos and still undeveloped young-until they are biologically able to fend for themselves. Mankind, to an enormously greater extent than any other species, makes similar arrangements for the continued living of other categories of individuals-notably the aged, infirm, defective, and degenerate-incapable on their own resources of keeping their vital fires alight. The fact that man does this is probably the chief reason why he regards his species as a noble one, a view in which it is doubtful whether the true termites would concur. But never mind about termitodoxic moral judgments for the moment. The important thing is that a very considerable number of persons now on this earth who are neither babies, nor aged, infirm, nor defective, find themselves, or think themselves, completely unable to get their livings by their own efforts.

What is going to be done about it? Some say one thing, some another. The view that, on the whole, seems to be most generally favored in the United States at the present time is that 
those who are getting a living for themselves shall support those who are not. This is a biologically possible temporary solution, there as elsewhere, chiefly because the extravagantly lush bounty of this good earth of ours, the true "unearned increment," has not yet been entirely exhausted. And until it is, there is plainly no reason why we should not average up the pleasures of human living, if it pleases us so to do-reducing them for some to the end that they may be increased for others. But this process will continue only so long as it causes the fit and industrious no serious discomfort, and does not threaten their survival.

The checks to bad behavior afforded by social organization are extremely feeble and ineffective things when groups of men are, or think they are, threatened with biological elimination, or even with the discomfort of a definitely lowered standard of living. Events of the last few years in Asia and Africa, and still more recently in Europe, leave no doubt on this point. "Live and let live" is a fine and noble maxim, but it works pragmatically only so long as there is enough "living"-that is, desired good things that make living pleasant-to go around. Men as individuals and as groups will beg, steal, fight, murder, and otherwise demean themselves to the level of other beasts not yet "civilized," in order, hopefully, to ensure the continued survival of themselves, their own flesh and blood, and their. kind, if they feel that survival is threatened.

Some persons find it difficult to understand or to admit such a view of the ultimate human behavior pattern. They see most people not only living peaceably, most of the time, but also at considerable expense of time and money keeping alive evergrowing numbers of biologically unfit persons. The physically and mentally defective and degenerate, as well as the very young and very old, are taken care of in a manner unparalleled in any other form of life except man's. In the course of history, this process has become largely socialized, first through religious organizations, then through private groups of laymen, until, finally, more and more of the burden has been spread 
over the whole fit population as a recognized function of government.

Each individual man, woman, and child now living has available for its living and all the activities associated with and derivative from human living, under sixteen acres of land counting all the land, good, bad, and indifferent together, and probably nearer half of this number of acres of land really good for anything, in the literal sense of the words. This is a meaningless and fantastic average if it is thought of in the sense of forcibly attaching each individual human being to a particular sixteen acres of the earth's surface. But it is an average fraught with the deepest meaning in a world view, when it is remembered that in last analysis all the means of human living, whether by the agricultural, industrial, commercial, or any other method, are derived, directly or indirectly, from the inexpansible earth and the energy from the sun's rays.

In the meantime the world's population keeps on growing, even if at a slowing rate, and the earth on and from which man must live is not an inexhaustible source of the means of living. Jacob G. Lipman, a recognized authority on the biology and chemistry of soils, has recently pointed out that whereas, on the average the four elements oxygen, silicon, aluminum, and iron make up about 87 percent of all known terrestrial matter (including lithosphere, hydrosphere, and atmosphere) these elements, with the exception of oxygen, constitute only an insignificant fraction of organic matter, the matter of living things. The solid matter of a man reduced to ash and analyzed, contains about 0.0001 per cent of aluminum, 0.03 per cent of iron, and 0.005 per cent of silicon. On the other hand 54 per cent of the dry matter of man-merely reduced to complete dryness but not burned to ashes-is carbon. This element all living organisms get, directly or indirectly, from the atmosphere or the lithosphere, or both, each in its own way; and by their vital processes all build it into their living structure, of which it is the keystone of the arch. But of the total known terrestrial matter, again including lithosphere, hydrosphere, and atmos- 
phere, carbon constitutes on the average only 0.08 per cent. And of this, only about one two-hundred-and-fiftieth part is in such form as to be directly usable by plants, animals, and men for the purpose of their living. The great bulk of it is in insoluble forms such as coal and oil, where it was laid down by the living beings of past geological eras after they had finished with it. For the carbon cycle is, in considerable part, a degradative one from the standpoint of living things. The total store of carbon that is directly usable by and absolutely necessary to organisms for their growth and living tends constantly to diminish by being transferred to insoluble forms.

The position regarding carbon will be clarified by the following quotation from Lipman:

"Under the head of debits, we may note the assimilation annually of more than 16 billion tons of carbon by vegetation. There is the fixing of large amounts of carbon in the weathering of rocks and in the formation of insoluble carbonates. An equivalent of 5 billion tons of carbon is fixed annually through the life processes of sea organisms. Altogether, it appears that the carbon dioxide withdrawn from the atmosphere by plants is balanced by that added to the air by microorganic and other processes in the soil. By way of further clarification, we should note that the carbon given off by the soil comes partly from the destruction of organic matter and partly from root respiration. According to the investigations of $\mathrm{J}$. W. Shive, the root respiration of a corn crop amounts to about 35 per cent of the quantity of carbon fixed as organic matter by this same corn crop. If this ratio is extended to the entire plant world, it would mean that about 7,000 of the 19,000 million tons of the carbon addition diffusing from soils can be credited to root respiration, leaving 12,000 million tons due to the destruction of organic matter. If we add the 7,000 million tons of carbon transpired by roots to the 16,300 million tons of the carbon assimilated by plants, we obtain a total of 23,300 million tons of carbon utilized annually by vegetation. The release through soil respiration is but 19,000 million tons." 
While carbon is the keystone it is not the whole organic arch. The story of annual net loss of the stuffs of life is similar for other essential chemical elements. Lipman estimates that the soils of the United States suffer the following annual net losses: of nitrogen 2.7 million tons; of phosphorus 1.2 million tons; of potassium 30.7 million tons; of calcium 43.2 million tons; of magnesium 14.2 million tons; of sulphur 1.1 million tons; and of organic matter generally 222 million tons.

Let it not be supposed that the problem concerns food alone, or that mankind is scheduled to perish miserably by starvation in the next fortnight. The problem of adequate food production for the present or an even larger world population is not the most serious aspect of the matter. The industrial and commercial modes of life that are in an obligate way essential to the maintenance of our dense urban populations are using up their basic resources at an even faster rate than that of soil exhaustion. To support a world increase of population of about two and a half times between 1800 and 1918, coal, and pig iron production had to be increased about a hundred-fold.

There seems to the biologist some reason to believe that mankind is at the present time engaged in the process of biologically adjusting or adapting itself to the situation that has developed as the combined result of the growth of scientific knowledge and the tremendously accelerated growth of population that that increase in knowledge has fostered in the last three hundred years. This adaptation appears to be going on in what must be regarded as the normal biological way, namely by processes that are not, for the most part, the resultants of conscious group effort or planning, and may therefore be designated as natural, insofar at least. Birth rates over a large part of the world are generally falling, and have been falling for a considerable time past. This decline in human reproduction is nowhere a consequence as yet of a type of behavior deliberately planned by the state for the whole mass of its people and deliberately forced upon them; nor, on the best evidence, is it anywhere wholly due to individual planning to reduce reproduction by birth 
control. It has occurred and is now occurring among peoples where effective birth control is but very little practised if at all. Rather what is going on appears to be a much more complex biological adjustment or adaptation involving many factors, both immediate and evident as well as remote and obscure.

Full comprehension of the implications of the present situation of the world's population, makes it seem to the biologist that the adaptive regulatory processes demanded will probably be the greatest and most far-reaching that the human species has ever so far had to undertake in its evolutionary history. Those required during the glaciation of the greater portion of the northern hemisphere seem insignificant by comparison. For, in truth, as was so ably shown by Prof. H. L. Hawkins two years ago in his brilliant address as Chairman of the Section on Geology of the British Association for the Advancement of Science, the position of man as a species presents today an extraordinary similarity to that displayed by many others in the paleontological record just prior to their disappearance from the cosmic scheme of things. The case cannot be better presented than in his own words, though the quotation must necessarily be too brief to do justice to the original exposition:

"All of those brave civilisations and empires of which we have records seem to have shown a succession of similar histories. They have risen from obscurity through possession of successful attributes, and have reached the peak of their power only to pass it.

"Until comparatively recently, there has been a persistent proportion of 'backward' types, unaffected by the civilising influence of the progressive powers. These have remained to provide a new upstart when the current one had crashed. To-day there are few races of this kind left; almost all of mankind has encountered civilisation and either perished or been transmuted. The fatal complexity of civilisation grips the whole species, crushing it into unity.

"The specific causes of the collapse of once dominant races are doubtless varied; but there is general agreement that one 
universal factor in disintegration is complexity, an aspect of over-specialisation.

"The correspondence between this state of affairs and the morphogenetic trends in other races of animals is so close that it needs no elaboration. Those who deny that human institutions are subject to the laws of organic evolution know either no history or no Palaeontology.

"There is no doubt of man's ability to become the most successful type of animal that has ever existed; but the reward of success in that direction is death."

This cogent statement of the case by a paleontologist distils to three essentials, in the view of the human biologist: (a) excessive specialization, to the end of (b) altering enormously the balance of nature in directions and ways thought by man to be to his immediate advantage, which in turn (c) has permitted and encouraged an enormous growth of population, entirely disproportionate in magnitude and rapidity. On the existing record, as Hawkins points out, no species has ever yet been able, in the long history of life on the earth, to adapt itself swiftly and skilfully enough to survive this combination of circumstances. Whether mankind will or not lies in the lap of the future. The problem presented is of a sort that statesmen, for the most part, are by their own natures and aptitudes, by their training, and in truth by the very nature of their business, quite unable to envisage or understand, and still less able to do anything effective about. Some philosophers and men of science understand the problem well enough, but lack the power of a Caesar or the persuasiveness of a Pied Piper to lead mankind to a solution, even if they knew just the road to take to a practical way out. So, on the whole, man's only chance of coming successfully through the ghastly mess he is plainly in for, would seem to lie, for what it may prove to be worth when put to the supreme test, in the fact that he has shown himself on occasions to possess somewhat greater innate powers of adaptability than any other organism ever known. 


\section{PATTERNS FOR LIVING TOGETHER}

\section{I}

IN THE preceding lectures in this series it has repeatedly appeared that a set of problems of great insistence and of major intrinsic difficulty and complexity has confronted man in his attempts to bring order into the business of his collective living. These problems exist, and get steadily more difficult, because there are so many people trying to live together and to get their livings in a spatially limited universe. Man is definitely and considerably handicapped in his struggles with these problems by the fact that he is a mammal and heavily loaded down with a lot of baggage entailed by that zoological affinity. It is essential baggage, but troublesome rather than helpful in working out techniques for living together. For mammals as a class are not naturally strong on sociality. Their innate tendencies are much more towards the side of rugged individualism. In consequence such degrees of sociality as they have developed, including even the human, have always been in the nature of a compromise between their natural instincts individually to mind their own business and fend for themselves, and the necessity to work together imposed by numbers in relation to territory.

This conflict of interests is an inherent element of all sociality, as the biologist sees the matter. The organism living in social relations finds itself always struggling to play a double roleto be at once both a soloist expressing its own personal individuality and at the same time the humble member of a chorus constrained to blend his tune harmoniously with those of the 
others composing the social group. This is not an easy thing to do. But it is essentially what sociality demands. The group may, as a group, do things that are distasteful to every single individual in it, and against his individual interest considered per se. For example, it is easily conceivable that a nation may decide by popular vote to engage in war, even though each person in that nation has, as an individual, no appetite whatever for either killing or being killed. So it is that at the mammalianhuman level there always has to be a compromise-a balancing between individual and communal interests, strivings, and goods -rather than the sort of whole-hearted and self-eliminating espousal of communal group interests to the exclusion of all other considerations that would be ideal from a purely social point of view. This kind of complete 100-percent sociality has never been achieved by mammals. Their social structures always have in them considerable gaps left open for individual selfdetermination-for minding one's own business as well as the communal affairs. Even such extreme social organizations as those of Soviet Russia and Nazi Germany have a niche or two carefully left in them that will permit the possibility for the individual to rise and shine as Führer or Chief Commissar. Reflection on the matter leads to the conclusion that one of the most fundamentally distinctive characteristics of mammalian sociality, whether it be of rodents, ruminants, carnivores, or men, is its unfailingly included concept of leadership by somebody. That somebody may be an individual or a group. It does not matter which in the underlying philosophy. But, as anyone will perceive who makes the attempt, it is extremely difficult for us to think of a form of social organization of which we could conceivably be a part which did not involve somewhere, in some form or other, this concept of leadership.

It is in this respect perhaps more than in any other single one that mammalian forms of social organization differ from those that have been evolved by other kinds of living things, and particularly the social insects, ant, bees, wasps, and termites. In the sociality of those forms there is literally nothing truly 
corresponding to our concept of leadership. There the social group itself as a whole constitutes a biological unit. Each individual in the group lives its life and makes its contribution to the communal welfare and interests, not because it is told to do so by a leader, or by the community as a whole in town-meeting assembled, but because, and only because, it is its innate, entailed biological nature so to do. The community is made up of castes that are differentiated structurally, functionally, and behavioristically to do certain things in the common interest. Being so differentiated they do these things automatically, skilfully, and unfailingly; without yearnings to alter their station in life, without strikes or picketing, and without troublesome political ambitions. Power and influence reside in, and appertain only to the community as a whole, because the physical and physiological elements that constitute power are so evenly and minutely divided between the several individuals composing the community that the very concept itself of power as we understand it disappears. In such a form of social organization there is no vestige of what we understand as individual opportunity, incentive, or orginality. The community is socially organized in such a way as to promote and ensure so far as possible the continued survival of the group as such and as a biological unit. Whether the individual survives or not is a matter of no community concern or importance, save in the case of individuals differentiated for the task of reproduction. The insect plan of social organization, perhaps wisely, segregates this function to a few individuals in preference to distributing it uniformly over the whole community, and then develops a lot of group adaptations to protect and ensure the survival of these few breeders.

All sociality or social organization is biologically an adaptive response to stimuli arising out of the difficulties of living together in a spatially limited universe, as was pointed out in an earlier lecture. But the primary objective of this adaptation is fundamentally different in mammalian sociality from what it is in insect sociality. The basic objective of the former is the sur- 
vival of the individual, that of the latter the survival of the community. "Mutual aid" in the mammalian and human scheme, wherever and insofar as it occurs, is a communal effort to help individuals as such to survive, not an attempt to keep the community or the social system going. When the citizens of Baltimore, somewhat reluctantly and after long delay, decided to tax themselves to build a city-wide sewer system instead of individually disposing of their bodily wastes, they were moved to do this not because they wanted to preserve Baltimore, but because they finally came to believe that the probability of their dying of typhoid fever and of their children dying of dysentery would be lessened as a result of this course of action. Politicians are well aware of the individualistic element in mammalian sociality. The ward boss knows that his clients favor the Tammany type of socio-political organization for no other important reason than because it sees that they are shod and fed. Hence Tammany Hall survives as a social institution. If the Republicans, or the Communists, or anarchists, or Beelzebub himself shod and fed the customers better than Tammany, their contributions of votes to the "mutual aid" system would be pretty promptly transferred to helping the continuance of whatever social instrument did the better shoeing and victualling. It is as Byron said in Childe Harold, "Mammon wins his way where seraphs might despair." On the national scale it will have been noted that the impassioned pleas for more and more social legislation that are currently dinning in our ears are based on and aimed at the survival of "underprivileged" individuals, not at the survival of the American form of government, which is to say the American pattern of social organization. Nobody calls the American social system "my friend," or ever will. Nobody could. It would be completely foreign to the mammalian way of thought. Those in control of affairs in Russia delude themselves into believing they are accomplishing the equivalent of this. But at the same time they are permitting and encouraging individuals to have savings bank accounts. The truly and exclusively 
communistic termite society behaves differently. The termite savings banks have only one customer per bank, the colony. No individual has an account.

\section{II}

Now while the insect patterns of sociality have certain evident points of superiority over the mammalian patterns, notably in respect to their much greater stability and efficiency, after all they are intrinsically different and not well suited to man as he is constituted at present. Perhaps in the slow passage of time he may evolve further towards these insect patterns. There are signs that this may turn out to be his trend. But before going into that question it will be profitable to examine in some detail the patterns of existing human society.

The technique that man evolved as an adaptive process to meet the difficulties that arose out of the necessity for living together in restricted quarters is essentially comprised within the frame of the system called government by law. This system had its dim beginnings in evolutionary history at the very inception of mammalian sociality itself with the biological family-parents and children constituting a group that must be socially organized for at least the rather prolonged period of infancy during which offspring cannot get their own livings. Let us consider for a moment what the terms law and government really mean. When individual mammals have to live together friction inevitably arises. One annoys another, or interferes with it, or damages it. Whether the individuals are kin to each other makes no difference; nor does the age distribution of the group, or any other of its biological characteristics. At bottom the difficulties arise out of too close and too persistent contiguity. This leads to what we have called the "collision effect"-mere bumping into each other, as it were. In the case of the fruitfly Drosophila, where there appears to be no trace of true sociality at all, it has been possible to show experimentally that as density of population increases, and by consequence there is an increase in the frequency of interference of individuals with each other, such 
purely physiological matters as individual fecundity and life duration are adversely affected in quantitatively predictable proportion to the intensity of the collision effect. Wherever there is even the beginning of social organization, as in the mammalian family group, the group, as well as its component individuals, has an interest and concern in the nuisances that particular individuals may make of themselves. So there begin to arise restrictions or taboos that set limits to the permissible behavior of the individuals. These restrictions in the group interest do not have to be written down and codified to be real. They exist in entirely effective form in mammals far below man. Many examples could be given if there were time. But a simple one will suffice. Watch a cat playing with a litter of kittens. When a kitten gets too rough or bites too hard mama promptly punishes him. The rule that kittens must not bite a member of the group too hard is quickly learned.

Human laws began in the evolutionary sense as rules of individual conduct or behavior, to protect the group from the nuisances and torts that might be perpetrated by individuals. Government followed as a group invention having for its purpose to see that the rules were observed. Since no one ever has been able to think up any practical mechanism to ensure the observance of the rules except to punish their infraction, punishment became a group function relegated to government. The social group in which law and government began was the primitive family. The history of Roman law, that corpus juris upon which the existing jurisprudence of all civilized peoples is based and modeled, in a foreshortened and epitomized way throws light on the essentials of the evolutionary history of all law and government. The stages are clearly evident in the following passage quoted from Greenridge's Historical Introduction to the fourth edition of Edward Poste's classic Gai Institutiones or Institutes of Roman Law by Galus (Oxford, Clarendon Press, 1904): "The fact that the primitive Roman State was in many ways conditioned by its clan organization seems to be certain. As the State grew stronger, it substituted the Family for the 
Clan. Between the two there is only a difference of degree. The Family (Familia) is the aggregate of the members of a household under a common head, the Paterfamilias; whereas the Gens is the aggregate of all individuals who bear a common name and who, therefore, if their ancestory could be traced in the male line through all its stages, would be found to be the descendants of some ultimate common ancestor. But the Familia is a far smaller, and therefore a far less powerful, unit than the Gens. It cannot so effectively dominate the State or impede its activities. Again, the heads of families are many in number; the heads of the Gentes (who must have existed at the time when the Gens was the important unit) were necessarily few. The State which deals with families deals with a multitude of individuals, not with an oligarchy representing the interests of a number of corporations. The conception of individual rights, in their modern sense, was, it is true, never fully recognized in Roman Private Law. It was impeded by the Patria Potestasthe life-long power of the father over the son. But much was ultimately done to lessen the rigour of this patriarchal rule; and the principles of Roman Law were finally extended to races which knew nothing of the Patria Potestas. This law ultimately gave the most perfect expression hitherto witnessed by the world of rights which were both universal and individual. The existence of the Empire gave Rome the power, possessed in as high a degree by no other State, of dealing with the individual on universal lines, because she was not hampered by the barriers between man and man thrown up by separate national institutions."

We see from this how the laws of nations grew out of the rules for family conduct administered by the head of the family acting as governor.

It has already been pointed out that the rules for behavior that later developed into laws as we understand them originated as group adaptations, which is to say derived their sanctions from the group attitudes that represent the beginnings of sociality. This fact cannot be too strongly emphasized, because it is of the 
utmost importance to a clear and critical analysis and understanding of theories of government. Another, and fundamentally different view of the essential origin of law rather widely prevailed in the early part of the nineteenth century. It is historically associated with the name of John Austin, the English jurist, who first propounded it in his famous Province of Jurisprudence Determined (1832). He was one of the founders of University College, London, and its first professor of jurisprudence. In his first class was John Stuart Mill, who disagreed in toto with Austin's views on political subjects, but said of him after his death that he had been the man "to whom he (Mill) had been intellectually and morally most indebted." Austin's view, in essence, was that all laws properly so-called are commands addressed by a human superior to a human inferior, and that the system or institution of government by law evolved from this basis.

Naturally and obviously this is a position with which no student of animal behavior could be expected wholly to agree. He would quite willingly admit that many laws were, and are, stated verbally in the form of commands, but that fact seems to him to be of only rhetorical importance. What the student of behavior dislikes is the implication of Austin's argument, of which he was fully aware and accepted, that the whole system of government by law came into being because a few individuals were created superior, and a great many inferior, and that the former governed the latter by commanding them to do, or not to do, certain things. Such a view is repugnant to the biologist because it so completely neglects the evolutionary background and basis of human behavior. Mammalian social behavior is not of the pattern implicit in Austin's formulation. Proof of this is abundant, for example, in Fraser Darling's important study $A$ Herd of Red Deer, already quoted in these lectures. Herd leaders are not commanders. They function much more as special sense organs for the group, that is the herd. They watch and listen for the group, while the other members tend to the other businesses of life. The group reactions of the herd are 
not responses to commands, but rather group reflexes set off by stimuli transmitted through the leader acting as sensory receptor for the group.

Austin's theory no longer enjoys quite the prestige it once did, either in or out of the legal profession. The development of sociology, and particularly the points of view growing out of what may perhaps be fairly called the natural history type of approach to the problem of sociality exemplified at its highest level in the work of William Graham Sumner, have been major factors in diminishing general esteem for Austin's closely reasoned, but heavily a priori, logical treatment of what is, after all, a biological problem at bottom. There clings to it an odor of scholasticism that is not in the present mode. At the same time it must be said that in overt or concealed form Austin's main thesis constantly bobs up in theoretical discussions of government, politics, and social progress, and particularly in connection with "isms" of one sort or another.

Austin's analysis of jurisprudence was thoroughly and penetratingly criticised about a half century after its publication by Sir Henry Maine, in his Early History of Institutions (1875). Only one small portion of Maine's interesting discussion can be quoted here, but that little must be, because of the important implications for human biology embodied in its last sentence. The whole quotation is an example or illustration brought forward by Sir Henry to show that the most despotic sort of government conceivable need contain none of the "command" element postulated by Austin. "My instance," he said, "is the Indian province called the Punjaub, the country of the Five Rivers, in the state in which it was for about a quarter of a century before its annexation to the British Indian Empire. After passing through every conceivable phase of anarchy and dormant anarchy, it fell under the tolerably consolidated dominion of a half-military half-religious oligarchy known as the Sikhs. The Sikhs themselves were afterwards reduced to subjection by a single chieftain belonging to their order, Runjeet Singh. At first sight there could be no more perfect embodiment than Runjeet 
Singh of sovereignty as conceived by Austin. He was absolutely despotic. Except occasionally on his wild frontier he kept the most perfect order. He could have commanded anything; the smallest disobedience to his commands would have been followed by death or mutilation; and this was perfectly well known to the enormous majority of his subjects. Yet I doubt whether once in all his life he issued a command which Austin would call a law. He took as his revenue a prodigious share of the produce of the soil. He harried villages which recalcitrated at his exactions, and he executed great numbers of men. He levied great armies; he had all material of power, and he exercised it in various ways. But he never made a law. The rules which regulated the lives of his subjects were derived from their immemorial usages, and those rules were administered by domestic tribunals in families or village communities-that is, in groups no larger or little larger than those to which the application of Austin's principles cannot be effected on his own admission without absurdity."

It is just such "rules derived from immemorial usage" that constitute the primitive pattern and foundation of all social organization, and also of enduring government. But obviously as the numbers of men increased, and the average distance apart of human beings from each other got steadily smaller, the whole business of living became more complicated. There had to be more and more rules. The rules got steadily more complicated and difficult to administer, until now we have reached a situation in which not only such avowed dictators as Mussolini and Hitler, but even our own Thurman W. Arnold, professor of law in Yale University - an institution steeped in the authentic juices of liberty if ever there was one-advocate as the ideal government one by men instead of one by principles. There could be no franker return to the position of John Austin, nor more convincing evidence that old patterns of human sociality solidly grounded in mammalian biology have gone sadly awry as the difficulties and complexities of living together have grown along with the stupendous increases in population density that have 
occurred. Under such circumstances an individual in temporary possession of political power always wants to "command," and to be freed from the restraints imposed on his will and fancy by laws based upon the "immemorial usages" of the group. To get rid of these irksome hindrances he endeavors to take over completely, and as a purely personal prerogative and appanage, the legislative and judicial functions of the social organization. If the attempt succeeds what appears on the surface to be great efficiency of government temporarily results. But the situation is ephemeral. It is just as true now as it was a century and a half ago, when the Great Pontificator told his friend General Oglethorpe about it, that "The more contracted power is, the more easily it is destroyed. A country governed by a despot is an inverted cone."

\section{III}

When we have seen that rules and then laws came into the primitive picture of free mammalian behavior from the necessity imposed by sociality, it must always be remembered that it was necessity rather than desire that brought them in. The natural state of living things is the most complete freedom and liberty attainable within the frame of the physical environment. Any and all restrictions on this natural freedom are inherently irksome. This fact has always constituted a real and serious difficulty in the making of workable and acceptable rules and laws. Jeremy Bentham was profoundly right when he said (The Theory of Legislation, Chap. X): "It is with government as with medicine; its only business is the choice of evils. Every law is an evil, for every law is an infraction of liberty. Government, I repeat it, has but the choice of evils. In making that choice, what ought to be the object of the legislator? He ought to be certain of two things: 1st, that in every case the acts which he undertakes to prevent are really evils; and, 2 nd, that these evils are greater than those which he employs to prevent them. "He has then two things to note-the evil of the offence, and the evil of the law; the evil of the malady, and the evil of the remedy. 
"An evil seldom comes alone. A portion of evil can hardly fall upon an individual, without spreading on every side, as from a centre. As it spreads, it takes different forms. We see an evil of one kind coming out of an evil of another kind; we even see evil coming out of good, and good out of evil. It is important to know and to distinguish all these kinds of evil, for in this the very essence of legislation consists."

It is a major tragedy of the world today that this distinction so wisely urged by Bentham has been so completely forgotten. The souls and bodies of millions of innocent and harmless human beings are being tortured because self-righteous and selfseeking men in temporary possession of power ruthlessly and contemptuously disregard the fact that all regimentation, whether it be by law or not, is an evil in itself. And this fact is in no smallest degree altered by asseverations of nobility of purpose.

The practical difficulty in framing a working pattern of human sociality has always been, and probably will continue to be for a long time in the future, the achievement of a satisfactory steady state of equilibrium between what is good from the standpoint of the group on the one hand, and what is evil from the standpoint of the individual on the other hand. Compromise is the only possible way of dealing with such an issue. Because it is gives the reasons why law and government have always been compromises in their essential nature. If the pattern is formed solely in the interest of either the group or the individual it has little stability or power to survive.

The actual machinery of operation of government and rulemaking, the basic social organization, has exhibited in all human history only two really different patterns. One of these is the autocratic, oligarchic pattern, the other the democratic. The difference between them in theory and in fact-whenever it has seemed worth while to translate the theory into fact-is that in the one case the laws and government are made and administered by a few individuals in the group without let, hindrance, or advice from the rest of the group; while in the other case all the individuals in the group have a direct first-hand share in the 
fashioning of the pattern of their sociality. The autocratic pattern stems evolutionary from the patriarchal or matriarchal family sociality. The democratic pattern was a slower growth that came to full flower in human society as men progressed in intelligence and power to reason, and in consequence developed the desire to affirm the full essence of their being. The individualistic way of life is a basic characteristic of the mammalian stem. To mould it into practical consilience with the necessity for social organization was a long, slow, and painful process. Actually the concept that all men should have an equal share in making the group pattern of law and government remained, with some exceptions, largely a negative one so far as action was concerned until the seventeenth century, though the abstract idea was much older. Aristotle was perfectly familiar with it, and rightly held that its denial was the most potent cause of revolutions.

Actually the setting up and maintenance of an autocratic or oligarchic form of government, as well as of any other form, can happen only with the "consent of the governed," as the old cliché has it. But there are two ways in which this consent can be got. These are either through intimidation maintained by force, or by voluntary agreement of the demos. Historically and statistically the former technique has been by far the more usual one, frequently camouflaged and sugar-coated, but not less real underneath. The present autocratic dictatorships in Europe, as everyone knows, insist loudly that they rest on the voluntary consent of the people, but a lot of purging with castor oil, gunpowder, and other even less pleasant pharmaceuticals seems to be required to maintain such semblance of sweetness and light as exists in the business. And the techniques of the elections by which the popular will is supposed to be expressed in the dictated countries have their comic aspects, which we can perhaps the better appreciate because they have such marked resemblances to the modes open to the Negroes in our deeper South to manifest their political and social ideas. In short Germany, and Italy, and Russia do not appear to offer any real 
exception to the general rule that intimidation is a usual, and indeed necessary, element in the maintenance of autocratic or oligarchic patterns of sociality wherever found. But intimidation by force majeure has two fundamental defects as a social agent. In the first place, with human beings constituted as they are, it is a lot of trouble to keep up. The despot and his gang get careless and inattentive, and lax about cracking the whip. The strain involved in being a pompous bogey-man gets wearisome. In the second place, fear is a curable and largely self-limited disease. The steady advance of man's knowledge through science about how to control and alter to his use and benefit his environment and the inherently awesome forces of nature, have been the great curative agents for the fear disease in all its varied manifestations. Organized religion has learned this lesson well. The "wrath of God" scares few folks these days. The "might of rulers" scares them only temporarily. Even that quintessentially timid fellow, the American businessman, seems now slightly less afraid of Tommy the Cork than he was a while back.

The struggle of man to make his general pattern of socialitygovernment by law-a stable, enduring, and satisfactory one has been long and arduous. It has encountered many difficulties. But there can be no question, I think, that its spiritual goal all along the way has been that ideal of democracy well stated by Harold J. Laski as one that is based on the "notion that the only way to respond to the wants of the individual is to associate him with the process of authority. It accepts therefore the old claim that exclusion from a share in power is also exclusion from a share in benefit. It regards the rights of man to share in the results of social life as broadly equal; and it regards differences of treatment as justifiable only in so far as they can be shown to be directly relevant to the common good." This goal has never yet been wholly achieved and stabilized anywhere. But with many waverings and setbacks mankind has moved forward toward it. And there are still those who like to think that Nicholas Murray Butler was right when he said thirty 
years ago: "The future of this nation, as the future of the world, is bound up with the hope of a true democracy that builds itself on liberty."

\section{IV}

But is this going to be the path of the future evolution of human sociality? Or is it going always to be merely the silly sort of abstract ideal symbolizing what does not really exist, that cynical pseudo-Machiavellians say it is and always has been? Being acutely conscious that "the coasts of history are strewn with the wrecks of predictions launched by historians and philosophers," as Lord Bryce once said, I have no present intention of cracking a bottle of champagne on the prow of a prophecy. But I should like to discuss briefly some of the difficulties and possibilities of the case. Let the discussion start with a question: Why is it that the adoption and practical operation of the idea of democracy has encountered so many difficulties, when it has all along enjoyed the esteem and approval not alone of philosophers, but of sensible men almost universally? The answer to this question seems to me to be bound up with certain fundamental biological considerations that have already been discussed in these lectures but without specific application to the present problem. The first and most important of these is that men vary, and widely, in their capacities and talents to get a living as well as in their opportunities. A primary function of all social organization is to expand and so far as possible equalize the opportunities for all individuals in the group to get their livings. In particular it is a basic tenet of the philosophy of democracy to do this. But no conceivable amount or kind of organization is ever going to equalize the innate differences between men in capacity, ability, or talent. Social theories and patterns of organization may categorically deny the existence of such differences, or may seek to smother and overwhelm them by systems that give equal rewards for extremely unequal services or performance of whatever sort. But this is mass self-delusion, unworthy of grown men. The real biological fact is that some men 
are both better animals and better men than others. And in any form of social organization, or in any way of life that does not by force prevent it, the better men will tend on the average to get the greater and better rewards for their efforts. This was just as true in the hunting stage of culture as it is today in industrial Detroit. An inevitable consequence is the development of economic inequalities. The innately abler individuals do better than just get their livings. They accumulate wealth. There is nothing in this inherently baneful or anti-social. It is not more sinister for men so to behave than it is for squirrels. In fact it is just a normal biological process for both, an effort to make continued survival more certain.

But in the course of its development there has gradually, and as to its successive stages almost imperceptibly, been added to the political philosophy of democracy a new element that demands "a close economic equality on the ground that the benefits a man can obtain from the social process are, at least approximately and in general, a function of his power of effective demand, which in turn depends on the property he owns," to use Laski's phraseology. It is held that the theory of democracy must necessarily be hostile to everything in the nature of privilege growing out of economic differences between individuals, and that liberty must be contingent upon, and constrained within, a framework of economic equality. The logical mischief inherent in this doctrine is evident as soon as it is stated. Any sort of constraint is essentially repugnant to the concepts of liberty and freedom. Procrustes building uniform beds to fit only the economically short or medium-statured, and sawing off the feet of the economically long-legged to make them conform to the beds, is still engaged in an inhumane as well as unbiological pursuit. If biology and history have any validity at all it is certain that this technique will never achieve an enduring solution of the problem of living together. Whether the scheme be labelled communism or democracy, or whether it be operated by dictatorship or through a majority of popular votes, it inherently lacks survival value, simply because all men are not 
equal in natural endowments. The attempts to extend the principle of democracy beyond group rule-making, which in the mammalian pattern of sociality is in biological fact a group function, so that it shall also include, and operate in respect of getting a living has not added to the acceptability or the stability of democracy as a social pattern. In the basic mammalian sociality getting a living is an individual function, and not a group function as it is in the termite pattern.

There would seem to be two possible alternative trends of man's further bio-social evolution that might conceivably be followed, provided he succeeds in surviving as a species. In this apparently elliptical statement is intended to be implicit the truism that man himself plays an important and conscious part in determining the course of his own social evolution, and that there are discernible now only two suggestions of possible future trends that seem to have a sufficient element of probability in them to be worth discussing. One of these that is at least theoretically possible, even if necessarily slow in practical accomplishment, would be by breeding out the innate differences that now exist between men and making them into a uniform lot except for such caste differentiations as might seem desirable to perpetuate, or might naturally evolve, in the interest of group efficiency solely. Such a process would eradicate all significant individual differences within each caste. Individual incentives and strivings would disappear, and also the social troubles they always produce. The process might conceivably be hastened, in the manner suggested in Brave New World, by conditioning the young from the moment of fertilization on for group conformity in the long period while genetic differences were being eliminated by breeding. In the end getting rid of differences would result in the human equivalent of the termite pattern of sociality. All men then would be truly equal, within the caste, and economically and socially equal within the total group, the colony, or state, or world. In cold fact this may be precisely the present trend of human evolution. We are here and now breeding out the innate differences between men, and at an accelerating rate. 
The genes that condition human characteristics are being more uniformly and evenly distributed over the whole of mankind. Perhaps we may all be something like happy little termites yet. But on the whole it seems unlikely that the process will ever continue to an end point involving such colossal biological alterations as would be necessary to change our pattern of sociality completely over to the termite pattern.

The other evolutionary trend that may be envisaged demands no such fundamental biological reconstruction. It contemplates instead only the continued and more intelligent development and application of the social process itself. We have seen in an earlier lecture that ever since his emergence as a distinct form man has steadily progressed in devising new and always easier ways of getting his living. This has come about through ever increasing control and utilization of natural resources, dependent in turn upon the steady advance of scientific knowledge. It seems probable that if scientific knowledge and discovery continue to advance, and there is no presently discernible reason why they should not, the consequences in increased aggregate ease of getting mankind's collective living that have followed in the past will continue to follow in the future. In other words there would appear to be no indication now of even a beginning of the operation of the principle of diminishing returns in the sphere of the application to useful ends of scientific discovery and developments. If science does continue to advance and extend man's power to utilize natural resources and forces, the inevitable consequence will be a general condition of progressive plenty. Many thoughtful persons are of the opinion that we are at this moment definitely and measurably already in that condition, and certainly a rather convincing case can be made that this is at least partially so. But granting for the sake of the argument that we are in fact already in an age of plenty, it is evident that there is the widest diversity of opinion as to how the maximum of social benefit is to be derived from that situation. Scientific men, who themselves constitute the group responsible for the condition of plenty in so far as it exists, are no more homo- 
geneous or helpful than any other group in their opinions about how social advantage is to be taken of easier methods of getting the collective living. Generally opinion regarding the problem is saturated with emotion and sentiment, and that in great part accounts for its wide diversity. Propaganda is substituted for rational analysis, and only tiresome confusion results.

Certain objective realities that exist now, however, have bearing on the alterations of the social pattern that may occur. The first and most important of these is the high average density of world population. Maximum social benefit will never accrue from a condition of plenty, if population is always maintained at a level where in actual practice it presses close upon the then existing possibilities of bare subsistence. The average individual enjoyment of plenty will be greater and keener if there are fewer individuals to divide it among. There is at the present moment an almost universal tendency to reduce the total population of the world through the reduction of human fertility. This tendency is being accelerated by the ever wider spread of the practice of more and more effective techniques of contraception. There is good reason to suppose that within a century or less knowledge of such techniques will be nearly or quite universally disseminated. Probably within that time such techniques will be taught universally in the schools in all civilized countries, as they now are or very shortly will be in Sweden. The prevalent idea that this will result in extinction by depopulation does not seem likely to the student of mammalian biology. What appears infinitely more probable is that mankind will use contraception as one agent of self-regulation of the total population to a level where the maximum of social benefits accruing from a condition of plenty may be enjoyed.

Secondly, there is a definitely increasing aggregate consciousness that the social burden of the biologically unfit, degenerate and worthless portions of humanity is becoming intolerable, and that their further breeding will have to be stopped. Sensible men are not likely indefinitely to permit a great part of the plenty that might be enjoyed by the fit wasted on a growing 
horde of sorry specimens that any intelligent breeder, or nature itself if permitted, would promptly eliminate as of no biological worth. The eugenists are grappling with the problem of devising adequate and practical ways of accomplishing this result. They have not solved it yet. But there is every reason to suppose that in another century or so great and real progress will have been made in this direction.

Suppose we now let our imaginations jump ahead that century and envisage a world population of an average density of perhaps 30 per square mile of land area instead of the present 41 , and a population rid of a substantial part of the burden of the unfit, living in a world of a vastly greater plenty than anything we now know or can intelligently imagine, as a result of the intervening progress of science. What pattern of government by law would, in such a state of affairs, conduce to the maximum of social benefit practically achievable? This question can be answered only with an opinion; and by me, if I am to be sensible and honest, only with my opinion. I present it, not because it has any particular intrinsic importance, but because it is a convenient way to make one final point that I regard as significant.

The pattern of government by law that I think would be adequate to meet the postulated premises would be one in which all ultimate governmental power rested in and was equally distributed among all the people composing the group. As one of its two main objectives it would preserve, so far as possible, the innate biological differences between men. I mean this in the broadest sense of the word biological, to include abilities, talents, and opinions as well as purely anatomical and physiological traits. But it would not merely strive to preserve innate differences. It would also actively and zealously encourage and promote the freest possible expression of those differences in every aspect of life, insofar as such expression was consilient with the equal distribution of the privilege to all. Specifically it would encourage individual incentive and striving in the economic and every other field of activity, and both permit and encourage 
different rewards proportioned to differences in abilities and skills. In conformity with the basic mammalian pattern of sociality it would give opportunity and encouragement to the superior individual to rise to leadership. Its second main objective would be to make such rules as would strictly limit as to amount and degree and as to duration the power that any man or sub-group of men could have over the souls or bodies or lives of their fellows, whether political power, economic, social, or any other kind. It would do this at whatever cost of group efficiency, either alleged or real, that might be entailed. It would do this on the ground that freedom to exercise concentrated power is the one kind of liberty that no man or no limited group of men can be entrusted with; there is still too much of the beast left in his-make-up. Concentration of power to control and coerce men is bad in itself, always and everywhere, and without the slightest relation to whether it is used to accomplish ends which either you or I or anybody else regard as good or beautiful or wise. Because there would be no concentration of power in this social pattern there would be no economic monopolies, no great trusts, no holding companies. Some men would be richer than others, but no man would be either inordinately rich or terribly poor. With all ancillary aids to the acquisition and retention of power outlawed, no man could exercise more influence over the lives of his fellows than what could temporarily be derived from his true innate superiority as a man. In guarantees of liberty, opportunity, and strictly limited concentration of power, coupled with a general condition of plenty, there is reason to hope and to believe that real social security would reside. 



